INFORMATION CLEARANCE FORM

\begin{tabular}{|c|c|}
\hline \multicolumn{2}{|c|}{ A. Information Category } \\
\hline$\square$ Abstract & $\square$ Journal Article \\
\hline$\square$ Summary & $\square$ Internet \\
\hline$\square$ Visual Aid & $\square$ Software \\
\hline$\square$ Full Paper & 叉 Report \\
\hline $70^{\text {th }}$ & \\
\hline
\end{tabular}

\begin{tabular}{l} 
B. Document Number DOE/ORP-99-01 \\
\hline C. Title \\
Review Guidance for the TWRS FSAR Amendment for Waste Retrieval \\
and Waste Feed Delivery \\
\hline D. Internet Address
\end{tabular}

E. Required information

1. Is document potentially Classified? ONo OYes (MANDATORY)

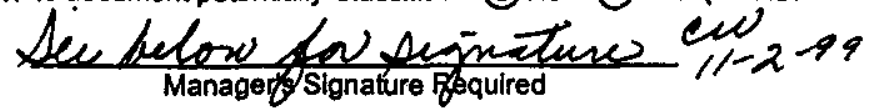

If Yes Ono OYes Classified ADC Signature Required

4. Does Information Contain the Following: (MANDATORY)
a. New or Novel (Patentable) Subject Matter?
Ono OYes
If "Yes", Disclosure No.:

b. Information Received in Confidence, Such as Proprietary and/or Inventions?

ONo OYes if "Yes", Affix Appropriate Legends/Notices.
c. Copyrights?
No
OYes
If "Yes", Attach Permission.
d. Trademarks?
Ono OYes
If "Yes", Identify in Document.

2. Internal Review Required?
If Yes, Document Signatures Below

Ono Ores

Counsel

5. Is Information requiring submission to OSTI? $O$ No $\bigcirc$ Yes

If Yes UCand $B \& R-$

Program

6. Release Level? $\bigcirc$ Public $\bigcirc$ Limited

3. References in the Information are Applied Technology ONo OYes Export Controlled Information Ono Ores

7. Charge Code 09000

F. Complete for a Journal Article

1. Title of Journal

G. Complete for a Presentation

1. Title for Conference or Meeting

2. Group Sponsoring

3. Date of Conference

5. Will Information be Published in Proceedings? $\bigcirc$ No $\bigcirc$ Yes

4. City/State

H. Author/Requestor

Robert $w$. Griffith et affocece $\mathrm{Pr}$ (Print and Sign)

6. Will Material be Handed Out? $\bigcirc$ No $\bigcirc$ Yes

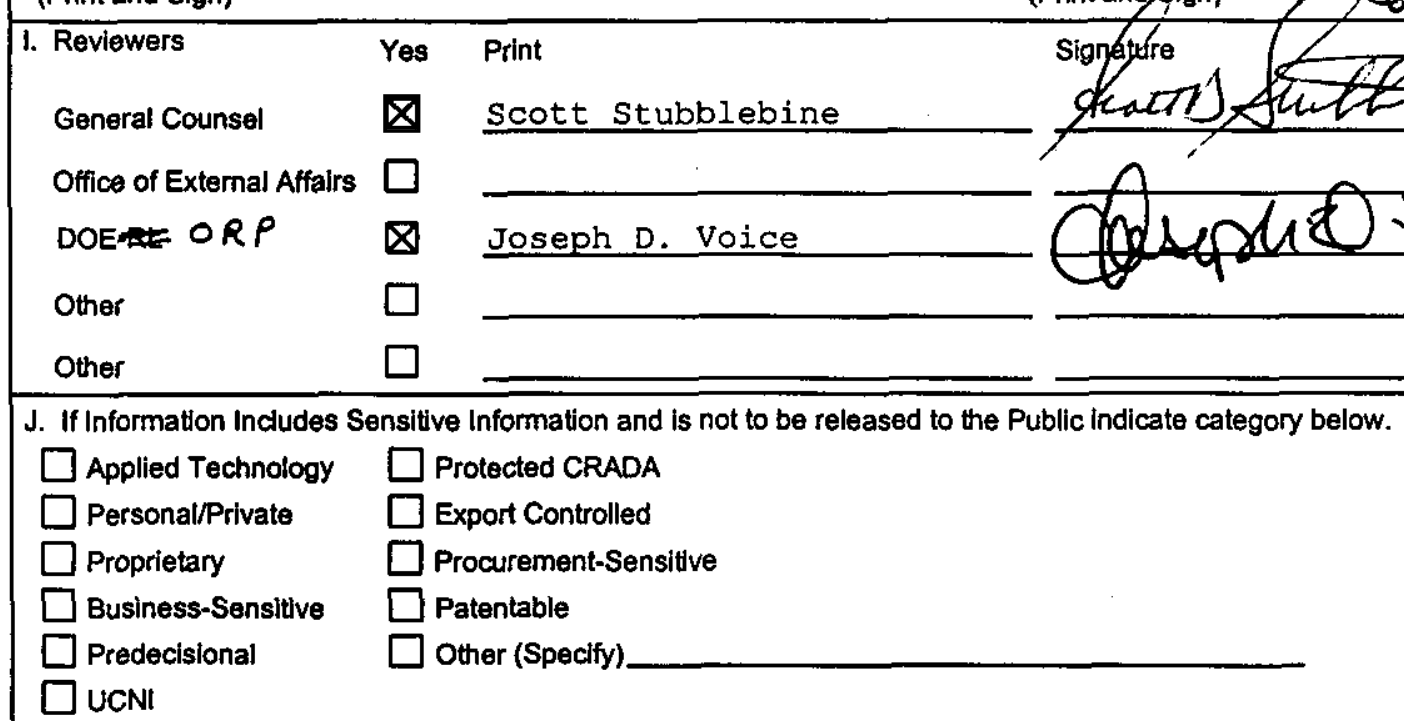

K. If Additional Comments, Please Attach Separate Sheet 
DATE: OCT 61999

REPLY TO

ATTN OF:

SUBJECT:
99-RU-0569

\begin{abstract}
REVIEW GUIDANCE FOR THE TWRS FSAR AMENDMENT FOR WASTE RETRIEVAL AND WASTE FEED DELIVERY (DOE/ORP-99-01)
\end{abstract}

TO: $\quad$ R. T. French, Manager

Office of River Protection

This transmittal provides the Office of River Protection (ORP) with review guidance for the Tank Waste Remediation System (TWRS) Final Safety Analysis Report (FSAR) amendment for waste retrieval and waste feed delivery. The review guidance was prepared in accordance with the RNPS/ORP agreement signed on March 18, 1999, and was revised to incorporate comments provided by the ORP staff.

The review guidance was prepared by the Regulatory Unit (RU) using the same approach used to prepare review guidance for the Construction Authorization Request to be submitted by BNFL for the TWRS-P Waste Treatment Plant. The guidance is based upon, and consistent with, the guidance of DOE Standard DOE-STD-3009-94, "Preparation Guide for U.S. Department of Energy Nonreactor Nuclear Facility Safety Analysis Reports."

As noted in the RNPS/ORP agreement, a subsequent agreement between RNPS and ORP could accommodate incorporation of Project Hanford Management Contractors'comments into the guidance, or support ORP in the review of the FSAR amendment. The RU would certainly consider any request to provide this or related support to ORP.

If you have questions on the review guidance, please call me or Bob Griffith of my staff on (509) $372-2821$

RNP:RWG

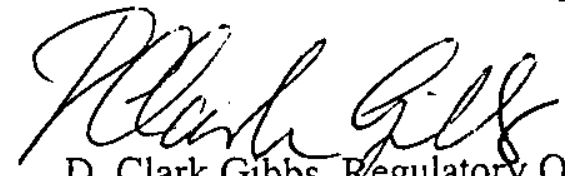

D. Clark Gibbs, Regulatory Official Office of Radiological, Nuclear and Process Safety Regulation

Attachment

cc w/attach:

K. Klein, RL

S. Wiegman, ORP

J. Voice, TSD

RECEIVED

D. Irby, TSD

J. Noorani, TSD

OCT 121999 


\section{REVIEW GUIDANCE FOR THE TWRS FSAR AMENDMENT FOR WASTE RETRIEVAL AND WASTE FEED DELIVERY}

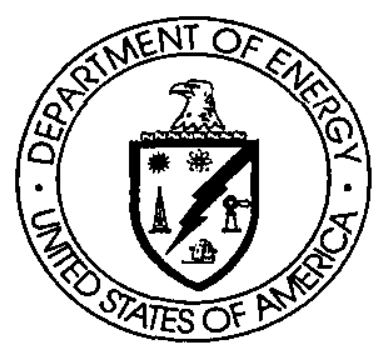

October 1999

Office of River Protection

Richland Operations Office P.O. Box 550

Richland, Washington 99352 


\section{RELEASE AUTHORIZATION}

Document Number:

\section{Document} Title:
DOE/ORP-99-01, Rev. 0

Review Guidance for the TWRS Amendment for Waste Retrieval and Waste Feed Delivery

\section{This document, reviewed in accordance with DOE Order 241.1, "Scientific and Technical Information Management," and DOE G 241.1-1, \\ "Guide to the Management of Scientific and Technical Information," does not contain classified or sensitive unclassified information and is:}

\section{APPROVED FOR PUBLIC RELEASE}

\section{$\frac{\text { Chistime Srieleigham }}{\text { C. Willingham }}$}

$11 / 3 / 99$

Date

Lockheed Martin Services, Inc.

Document Control / Information Clearance

Reviewed for Applied Technology, Business Sensitive, Classified, Copyrighted, Export Controlled, Patent, Personal/Private, Proprietary, Protected CRADA, Trademark, Unclassified Controlled Nuclear Information.

LEGAL DISCLAIMER. This report was prepared as an account of work sponsored by an agency of the United States Government. Netther the United States Government nor any agency thereof, not any of their employees, nor any of their contractors subcontractors or their employees, makes any warranty, express or implied, or assumes any legal liability or responalbility for the accuracy, completeness, or any third party's use or the reauls of such ues of any information, apparatus, product, or procese discloced, or represents that th use would not infringe privately owned riohts. Refierence herein to any

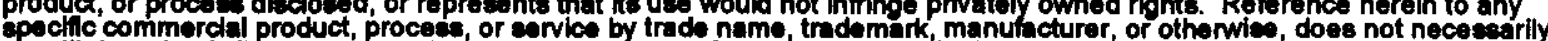
coneffecommercal product, procese, or enrvice by trade name, trademark, manufacturer, or othenwiee, does not necesearily contractors or aubcontractors. The views and opinions of authors expresesed herein do not necessarily state or remect those of the United States Government or any agency thereof. This report has been reproduced from the best available copy. Printed in the United States of America. 


\section{REVIEW GUIDANCE FOR THE TWRS FSAR AMENDMENT FOR WASTE RETRIEVAL AND WASTE FEED DELIVERY}

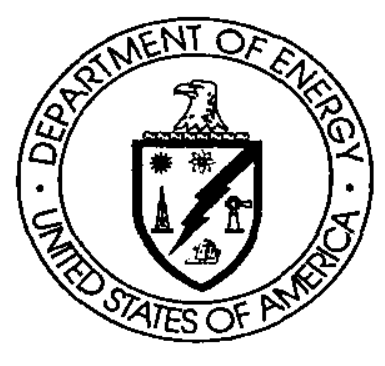

October 1999

Office of River Protection

Richland Operations Office

P.O. Box 550

Richland, Washington 99352

Approved:

Date: 


\section{PREFACE}

The Department of Energy's (DOE) Richland Operations Office (RL) issued a request for proposal in February 1996 for privatized processing of waste as part of the Hanford Tank Waste Remediation System (TWRS) program which in 1999 came under the cognizance of the Office of River Protection (ORP). Offerors were requested to submit proposals for the initial processing of the tank waste at the Hanford Site. Some of this radioactive waste has been stored in large underground storage tanks at the Site since 1944. Currently, approximately 54 million gallons of waste containing approximately 250,000 metric tons of processed chemicals and 215 million curies of radionuclides are being stored in 177 tanks. These caustic wastes are in the form of liquids, slurries, saltcakes, and sludges. The wastes stored in the tanks are defined as high-level radioactive waste (10 CFR Part 50, Appendix F) and hazardous waste (Resource Conservation and Recovery Act).

Under the privatization concept, DOE intends to purchase waste processing services from a contractor-owned, contractor-operated facility through a fixed-price contract. DOE will provide the waste feedstock for processing but maintain ownership of the waste. The contractor must: (a) provide private financing; (b) design the equipment and facility; (c) apply for and receive required permits and licenses; (d) construct the facility and commission its operation; (e) operate the facility to process tank waste according to DOE specifications; and (f) deactivate the facility.

The TWRS Privatization (TWRS-P) Project is divided into two phases, Phase I and Phase II. Phase $I$ is a proof-ofconcept/commercial demonstration-scale effort. The objectives of Phase I are to (a) demonstrate the technical and business viability of using privatized contractors to process Hanford tank waste; (b) define and maintain adequate levels of radiological, nuclear, process, and occupational safety; (c) maintain environmental protection and compliance; and (d) substantially reduce life-cycle costs and time required to process the tank waste. The Phase 1 effort consists of three parts: Part A, Part B-1, and Part B-2.

Part A, which concluded in August 1998, was a twenty-month period to establish technical, operational, regulatory, and financial elements necessary for privatized waste processing services at fixed-unit prices. This included identification by the TWRS.P Contractors and approval by DOE of appropriate safety standards, formulation by the Contractors and approval by DOE of integrated safety management plans, and preparation by the Contractors and evaluation by DOE of initial safety assessments. Of the twenty-month period, sixteen months was for the Contractors to develop the Part A deliverables and four months was for DOE to evaluate the deliverables and determine whether to authorize Contractors to perform Part B. Part A culminated in DOE's authorization on August 24, 1998, of BNFL Inc. to perform Part B-1.

Part B-1 is a twenty-four month period to (a) further the waste processing system design introduced in Part $A$, (b) revise the technical, operational, regulatory, and financial elements established in Part A, (c) provide firm fixed-unit prices for the waste processing services, and (d) achieve financial closure.
Part B-2 is a sixteen-year period to complete design, construction, and permitting of the privatized facilities; provide waste processing services for representative tank wastes at firm fixed-unit prices; and deactivate the facilities. During Part B-2, approximately $10 \%$ by volume ( $25 \%$ by activity) of the total Hanford tank wastes will be processed.

Phase II will be a full-scale production effort. The objectives of Phase Il are to implement the lessons learned from Phase I and to process all remaining tank waste into forms suitable for final disposal.

An essential clement of the TWRS-P Project is DOE's approach to safety regulation. DOE has specifically defined a regulatory approach and chartered a dedicated Office of Radiological, Nuclear and Process Safety Regulation of the TWRS-P Contractor (Regulatory Unit). The DOE aim in proceeding with the safety regulation of the TWRS-P contractor is to establish a regulatory environment that will permit privatization to occur on a timely, predictable, and stable basis. In addition, attention to safety must be consistent with that which would accrue from regulation by external agencies. DOE is patterning its radiological and nuclear safety regulation of the TWRS-P contractor to be consistent with that of the U.S. Nuclear Regulatory Commission (NRC). For industrial hygiene and safety (IH\&S), regulation is consistent with that of the Occupational Safety and Health Administration (OSHA).

The RL Manager has responsibility and authority for safety regulation and has assigned this authority to the RL Director of the TWRS-P Regulatory Unit (the Regulatory Official). This regulatory authority is exclusive to the regulation of the TWRS-P contractor. The Regulatory Official is the formal point of execution for safety regulation of the TWRS-P contractor.

The DOE requires the contractor to integrate safety into all facets of work planning and execution. This Integrated Safety Management (ISM) process emphasizes that it is the contractor's direct responsibility for ensuring that safety is an integral part of mission accomplishment. Like the approach taken by the NRC and OSHA, the privatized contractor has primary responsibility for safety. The DOE, through its program, is responsible for ensuring that the contractor establishes and complies with approved safety limits.

The relationship between DOE and the privatized contractor performing work under a fixed-price contract is different than the relationship under traditional Management and Operations (M\&O) contracts. For fixed-price contracting to be successful, this different safety relationship with the contractor is accompanied by modified relationships among DOE's internal organizations. For example, the arrangement by which the RL Manager applies regulation to the TWRS-P contractor should be a surrogate for an external regulator (such as the NRC or OSHA) with strong emphasis on independence, reliability, and openness.

Regulation by the RU in no way replaces any legally established external regulatory authority to regulate in accordance with their duly promulgated regulations nor relieves the Contractor from any obligations to comply with such regulations or to be subject to the enforcement practices contained therein. 


\begin{tabular}{|c|c|c|}
\hline \multicolumn{3}{|c|}{ RECORD OF REVISION } \\
\hline \multicolumn{3}{|c|}{$\begin{array}{l}\text { Document Title: Review Guidance for the TWRS FSAR Amendment for Waste Retrieval and Waste } \\
\text { Feed Delivery }\end{array}$} \\
\hline \multicolumn{3}{|c|}{ Document Number: DOE/ORP-99-01, Rev. 0} \\
\hline Revision Date & Revision Number & Reason for Revision \\
\hline October 1999 & Rev. 0 & New Issue \\
\hline & & \\
\hline & & \\
\hline & & \\
\hline & & \\
\hline & & \\
\hline & & \\
\hline & & \\
\hline & & \\
\hline & & \\
\hline & & \\
\hline & & \\
\hline & & \\
\hline & & \\
\hline & & \\
\hline & & \\
\hline & & \\
\hline & & \\
\hline & & \\
\hline & & \\
\hline & & \\
\hline & & \\
\hline
\end{tabular}




\section{Contents}

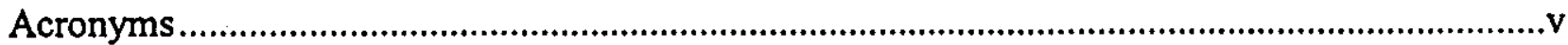

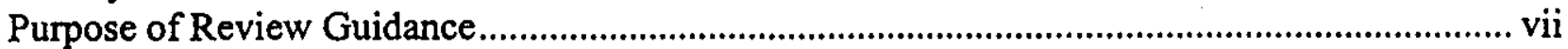

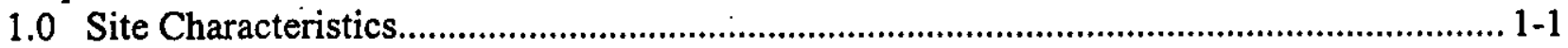

1.1 Purpose of Review ....................................................................................................

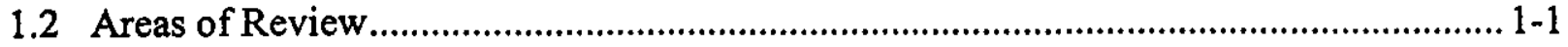

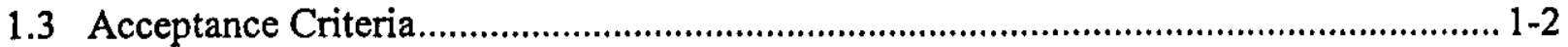

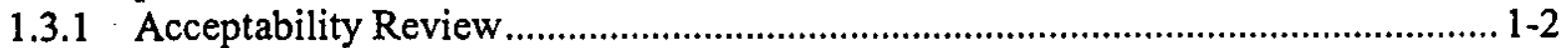

1.3.2 Regulatory Requirements..................................................................................... 1-3

1.3.3 Regulatory Acceptance Criteria .......................................................................... 1-3

1.4 Evaluation Findings ........................................................................................... 1-4

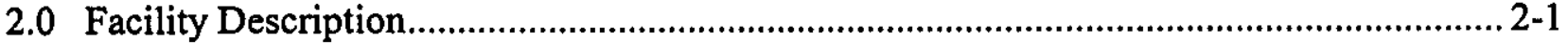

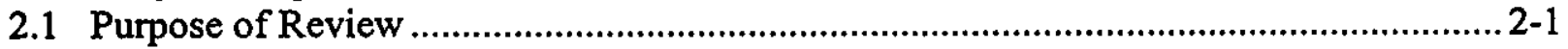

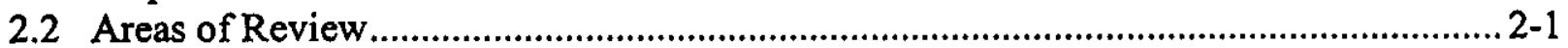

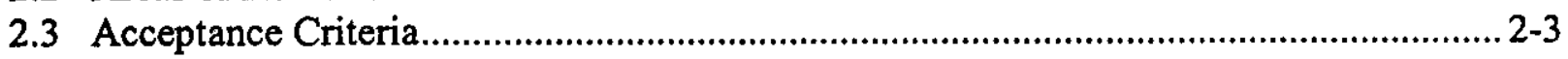

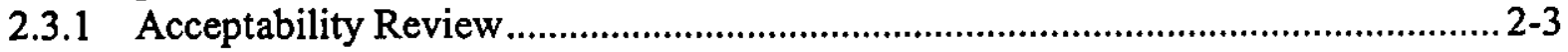

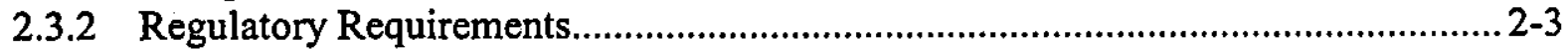

2.3.3 Regulatory Acceptance Criteria ......................................................................... 2-4

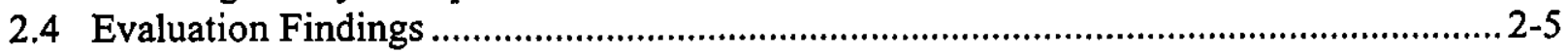

3.0 Hazard and Accident Analysis................................................................................... 3-1

3.1 Purpose of Review ....................................................................................................

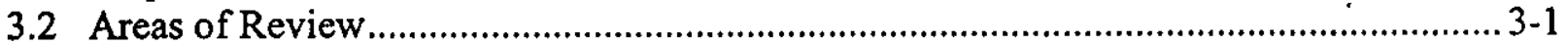

3.2.1 Hazard Analysis ..............................................................................................

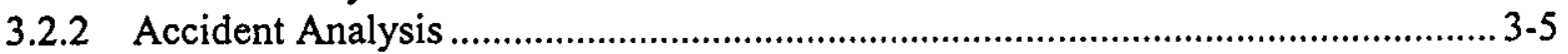

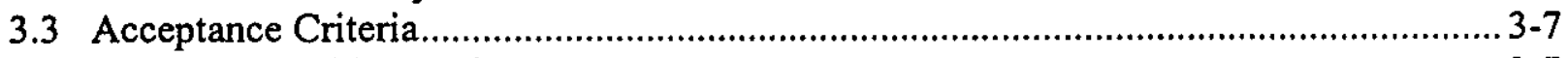

3.3.1 Acceptability Review...................................................................................... 3-7

3.3.2 Regulatory Requirements...................................................................................

3.3.3 Regulatory Acceptance Criteria ......................................................................... 3-7

3.3.3.1 Hazard Analysis ........................................................................................ 3-8

3.3.3.2 Accident Analysis ................................................................................... 3-11

3.4 Evaluation Findings ................................................................................................. 3-17

4.0 Safety Structures, Systems, and Components................................................................ 4-1

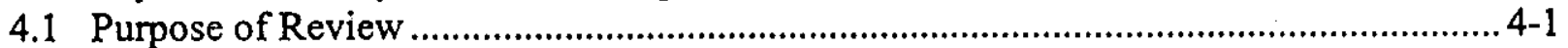

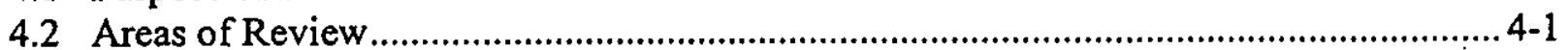

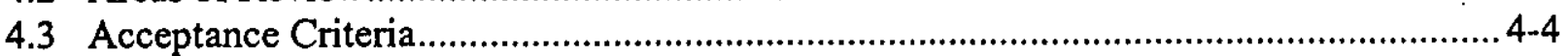

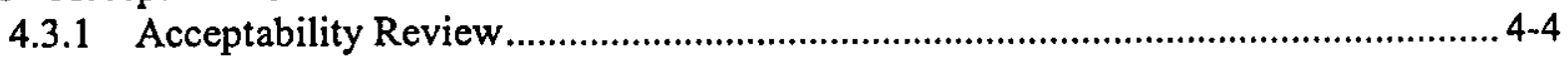

4.3.2 Regulatory Requirements................................................................................ 4-4

4.3.3 Regulatory Acceptance Criteria .......................................................................... 4-5

4.4 Evaluation Findings ...................................................................................................

5.0 Derivation of Technical Safety Requirements ................................................................ 5-1

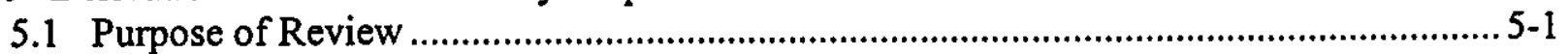

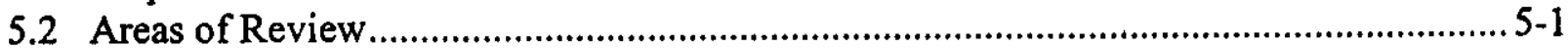

5.3 Acceptance Criteria......................................................................................................

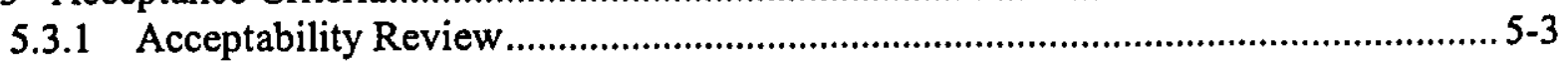




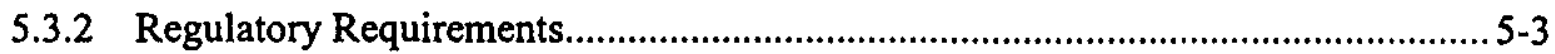

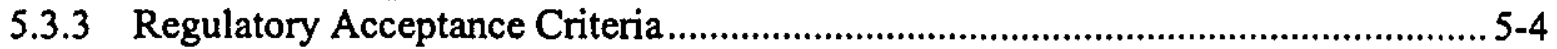

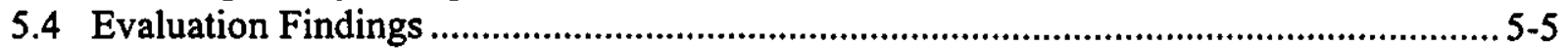

6.0 Prevention of Inadvertent Criticality ..................................................................................

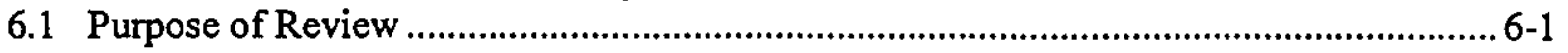

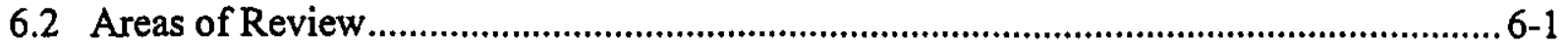

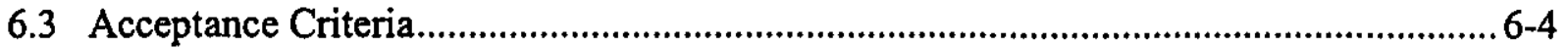

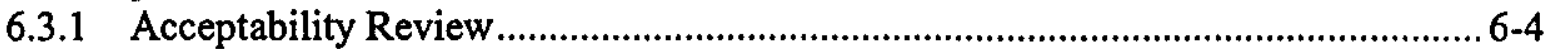

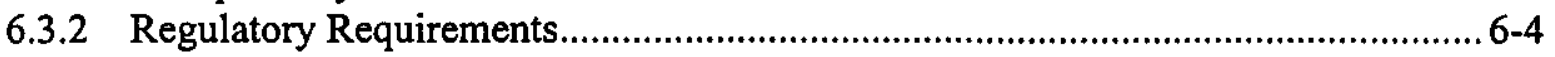

6.3.3 Regulatory Acceptance Criteria ............................................................................... 6-5

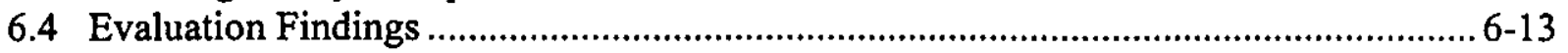

7.0 Radiation Protection.................................................................................................

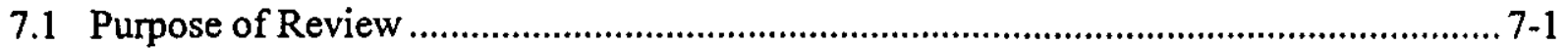

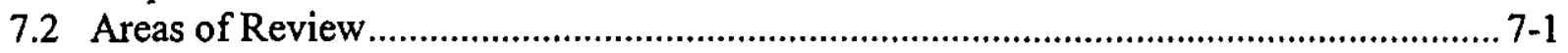

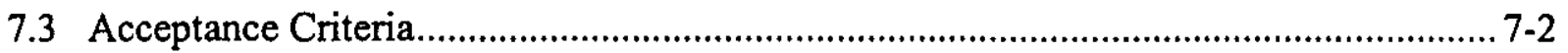

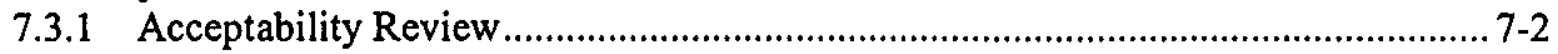

7.3.2 Regulatory Requirements.................................................................................

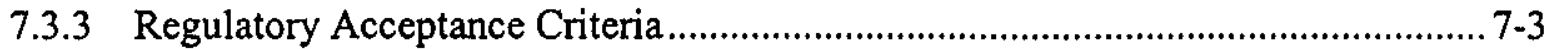

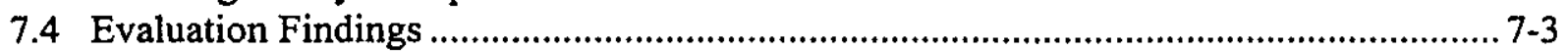

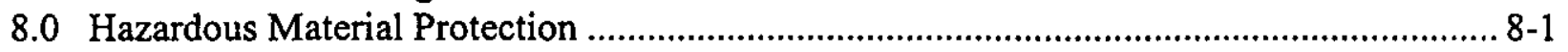

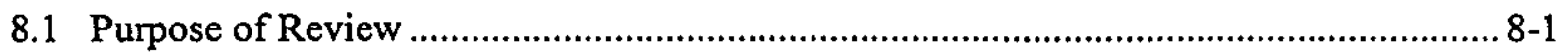

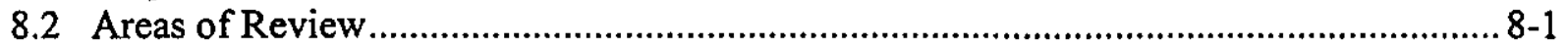

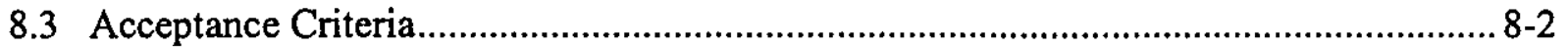

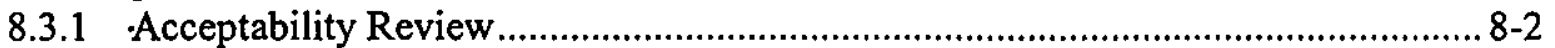

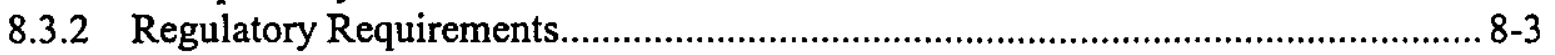

8.3.3 Regulatory Acceptance Criteria ............................................................................ 8-3

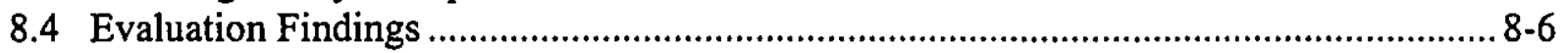

9.0 Radioactive and Hazardous Waste Management............................................................... 9-1

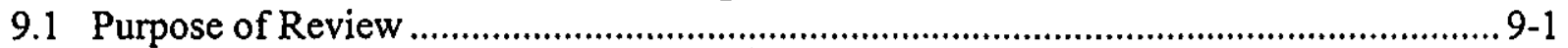

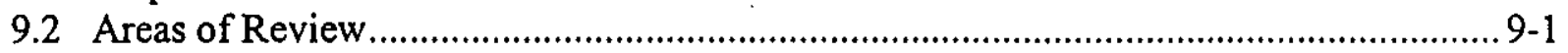

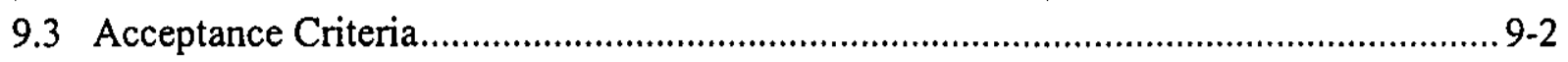

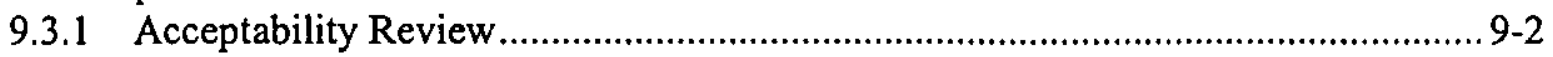

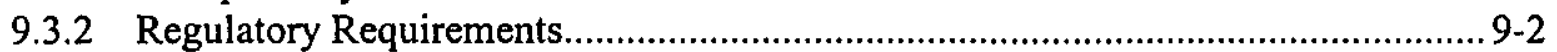

9.3.3 Regulatory Acceptance Criteria ......................................................................

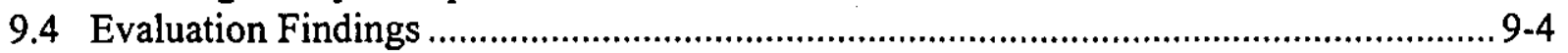

10.0 Initial Testing, In-Service Surveillance, and Maintenance ......................................... 10-1

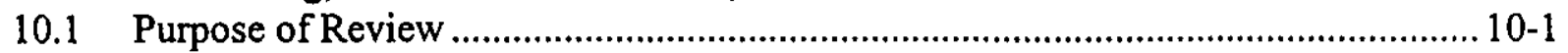

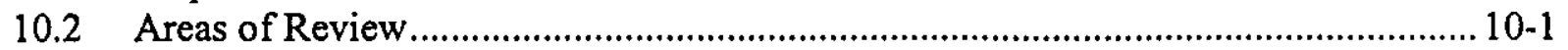

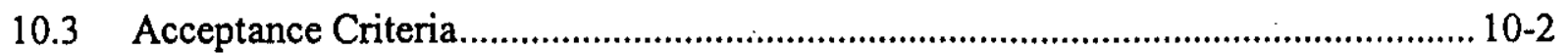

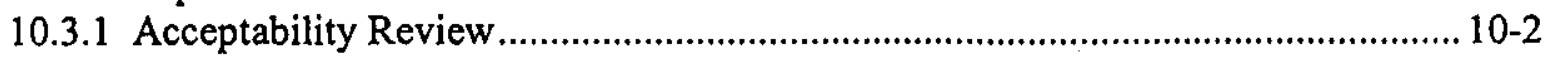

10.3.2 Regulatory Requirements............................................................................. 10-2

10.3.3 Regulatory Acceptance Criteria ........................................................................... 10-3

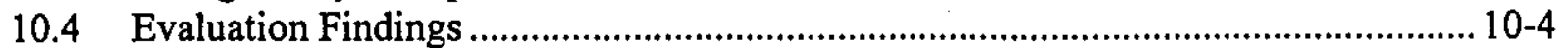

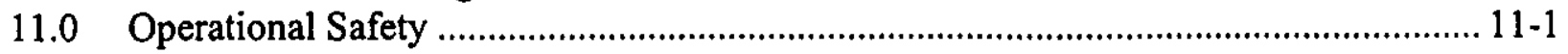

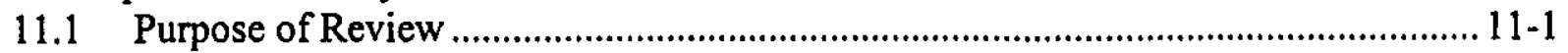

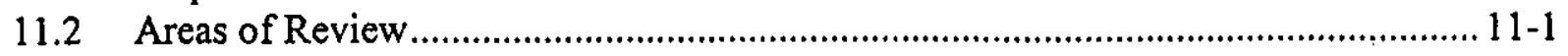




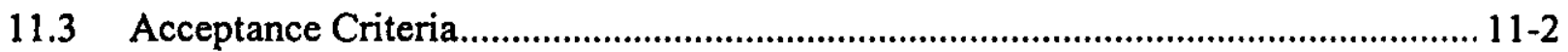

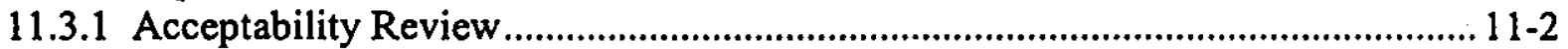

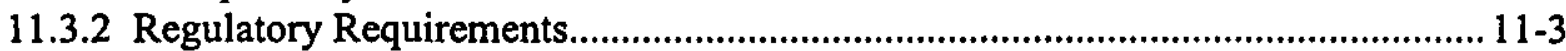

11.3.3 Regulatory Acceptance Criteria ...................................................................11-3

11.4 Evaluation Findings ..........................................................................................11-5

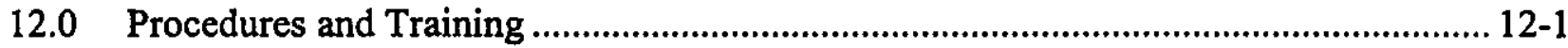

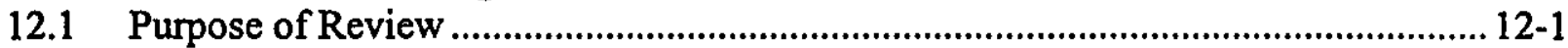

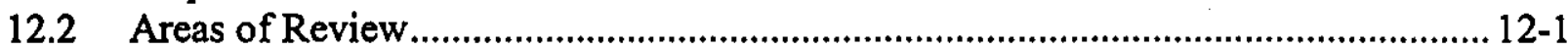

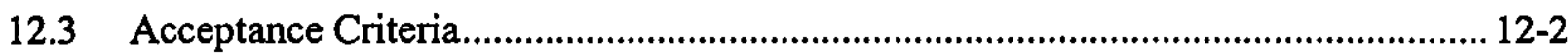

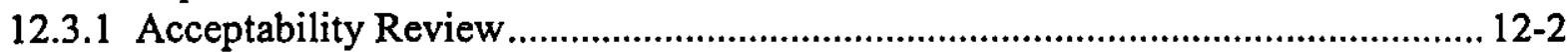

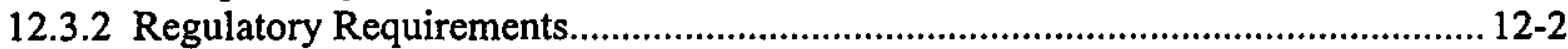

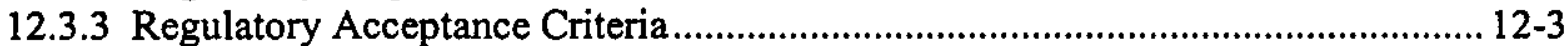

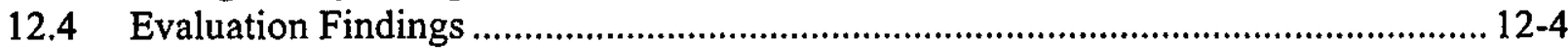

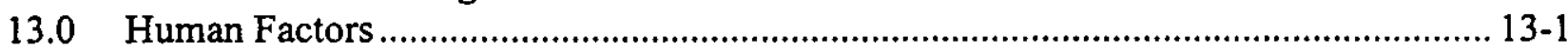

13.1 Purpose of Review .......................................................................................13-1

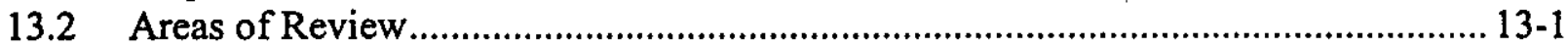

13.3 Acceptance Criteria ........................................................................................... 13-3

13.3.1 Acceptability Review...................................................................................... 13-3

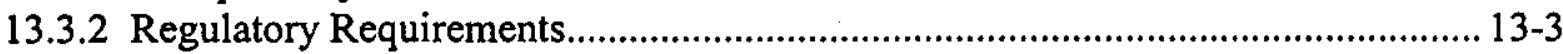

13.3.3 Regulatory Acceptance Criteria .......................................................................... 13-3

13.4 Evaluation Findings .........................................................................................13-7

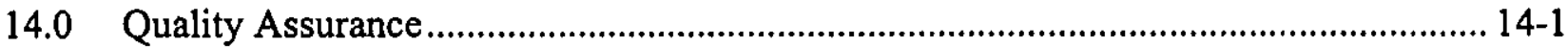

14.1 Purpose of Review .............................................................................................. 14-1

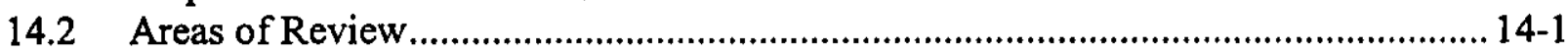

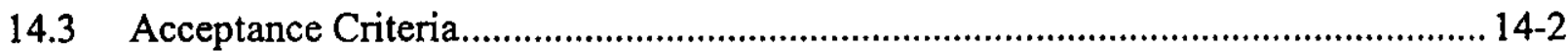

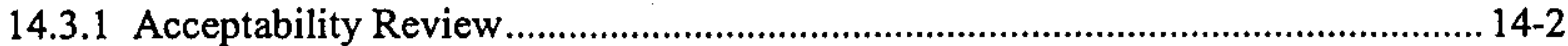

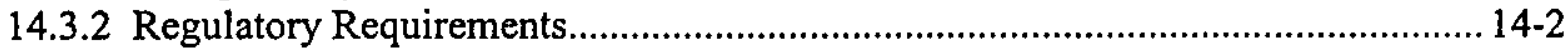

14.3.3 Regulatory Acceptance Criteria ....................................................................... 14-2

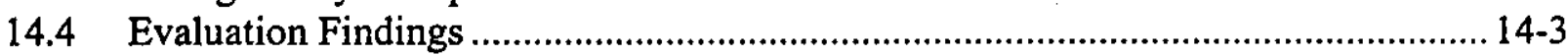

15.0 Emergency Preparedness Program ………........................................................... 15-1

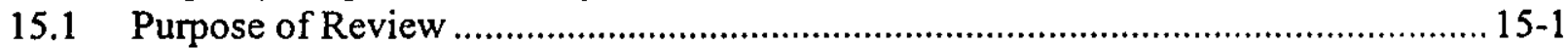

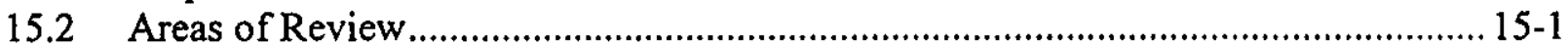

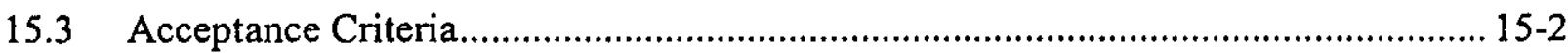

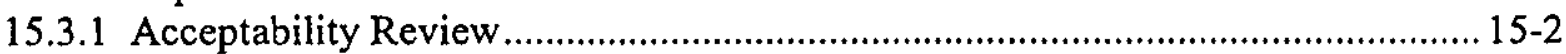

15.3.2 Regulatory Requirements........................................................................... 15-2

15.3.3 Regulatory Acceptance Criteria ....................................................................... 15-3

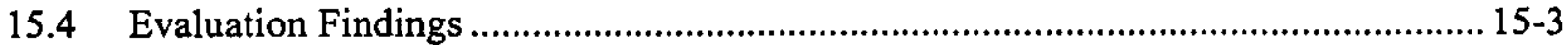

16.0 Provisions for Decontamination and Decommissioning................................................. 16-1

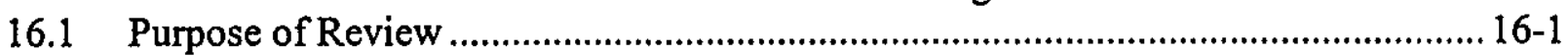

16.2 Areas of Review................................................................................................... 16-1

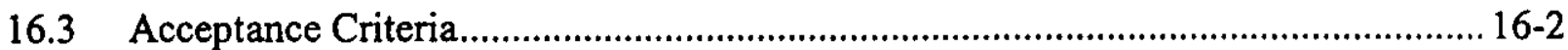

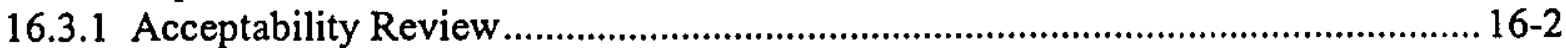

16.3.2 Regulatory Requirements................................................................................. 16-2

16.3.3 Regulatory Acceptance Criteria ....................................................................... 16-2

16.4 Evaluation Findings ............................................................................................. 16-3

17.0 Management, Organization, and Institutional Safety Provisions.................................. 17-1

17.1 Purpose of Review .................................................................................................. 17-1

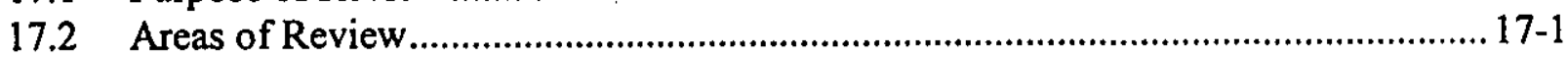




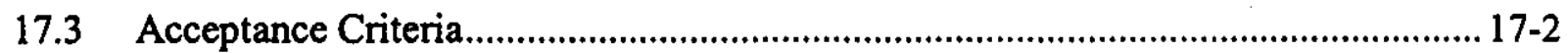

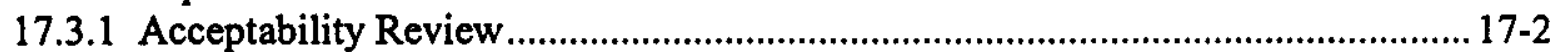

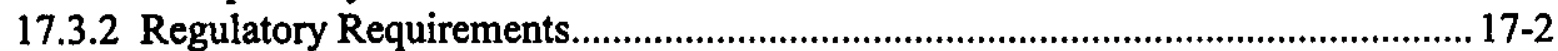

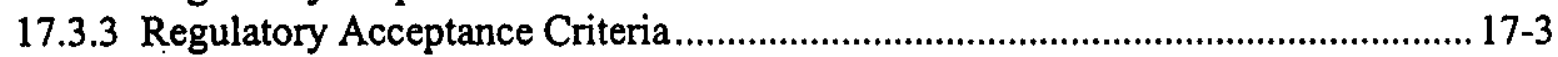

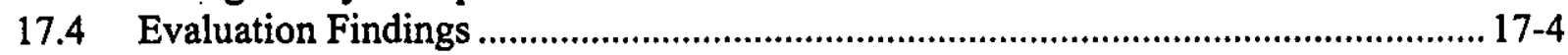




\section{ACRONYMS}

$\begin{array}{ll}\text { ALARA } & \text { as low as reasonably achievable } \\ \text { CWM } & \text { conservative waste model } \\ \text { D\&D } & \text { decontamination and decommissioning } \\ \text { DBA } & \text { design basis accident } \\ \text { DOE } & \text { Department of Energy } \\ \text { EIS } & \text { environmental impact statement } \\ \text { EPP } & \text { emergency preparedness program } \\ \text { ERPG } & \text { Emergency Response Planning Guidelines } \\ \text { FHA } & \text { Fire Hazard Analysis } \\ \text { FSAR } & \text { Final Safety Analysis Report } \\ \text { HEGA } & \text { high efficiency gas adsorbers } \\ \text { HEPA } & \text { high efficiency particulate air } \\ \text { LCO } & \text { Limiting Conditions for Operation } \\ \text { OSHA } & \text { Occupational Safety and Health Administration } \\ \text { ORP } & \text { Office of River Protection } \\ \text { ORR } & \text { operational readiness review } \\ \text { PEL } & \text { permissible exposure limit } \\ \text { PHMC } & \text { Project Hanford Management Contract } \\ \text { RPP } & \text { River Protection Project } \\ \text { SAR } & \text { Safety Analysis Report } \\ \text { SER } & \text { Safety Evaluation Report } \\ \text { SSC } & \text { structures, systems, and component } \\ \text { SR } & \text { Surveillance Requirement } \\ \text { TSR } & \text { Technical Safety Requirement } \\ \text { TWA } & \text { time-weighted average } \\ \text { USQ } & \text { Unreviewed Safety Question }\end{array}$




\section{PURPOSE OF REVIEW GUTDANCE}

This review guidance (Guide) was developed for Office of River Protection (ORP) reviewers to use in reviewing the amendment to the Tank Waste Remediation System (TWRS) Final Safety Analysis Report (FSAR) covering waste retrieval and waste feed delivery. Waste retrieval and waste feed delivery are necessary to supply nuclear waste from TWRS storage tanks to the TWRS Privatization (TWRS-P) Contractor's vitrification facility and to receive intermediate waste from the vitrification facility back into the TWRS tank farms for interim storage. An amendment to the approved TWRS FSAR (HNF-SD-WM-SAR-067, Rev. 0) is necessary to change the authorization basis to accommodate waste retrieval and waste feed delivery.

The ORP's safety responsibility in reviewing the FSAR amendment is to determine that reasonable assurance exists that waste retrieval and waste feed delivery operations can be accomplished with adequate safety for the workers, the public, and the environment. To carry out this responsibility, the ORP will evaluate the Contractor's amendment to the TWRS FSAR for waste retrieval and waste feed delivery to determine whether the submittal provides adequate safety and complies with applicable regulatory requirements.

The guidance in this document does not, in itself, constitute requirements except as noted in Sections X.3.2 of each chapter. The Contractor may propose other means to demonstrate safe waste retrieval and waste feed delivery design, operation, and compliance of the facilities with applicable regulatory requirements. However, the topics in this Guide are expected to be addressed by the FSAR amendment submittal because the Guide follows DOE Order 5480.23' and the standard Department of Energy (DOE) format and content for preparing Safety Analysis Reports (SARs). ${ }^{2}$

While the Guide follows the standard DOE format and content, not all sections of the standard must be specifically included in the FSAR amendment for waste retrieval and waste feed delivery. Rather, this Guide focuses on areas that have the potential to change as a result of waste retrieval and waste feed delivery. For example, in Section 1, "Site Characteristics," the site demography, meteorology, hydrology, geology, and natural phenomena threats are not expected to change from the current descriptions in the TWRS FSAR due to waste retrieval and waste feed delivery. Therefore, informational expectations for these subsections of site characteristics are not included in the Guide, and the Contractor's submittal is only expected to provide a brief justification of the applicability of the existing sections from the approved TWRS FSAR to waste retrieval and waste feed delivery.

The scope of the FSAR amendment should include activities associated with, and the modifications required for, retrieval of double-shell tank waste and delivery of the waste (as feed material) to the TWRS-P vitrification facility. The task also includes activities associated with and modifications required for the secondary wastes generated within the vitrification process that are returned to the Project Hanford Management Contract (PHMC) for storage and/or further processing, if any. The amendment will not address retrieval of waste from single-shell tanks,

\footnotetext{
${ }^{\prime}$ Nuclear Safety Analysis Reports, DOE Order 5480.23, Change 1, March 1994.

${ }^{2}$ Preparation Guide for U.S. Department of Energy Nonreactor Nuclear Facility Safety Analysis Reports, DOESTD-3009-94, July 1994.
} 
nor the storage of immobilized low-activity waste or immobilized high-level waste returned from the TWRS-P Contractor.

The approved FSAR amendment describes the portions of the TWRS tank farms that are authorized to be operated. Changes from what is described in the approved FSAR are subject to the change process currently approved for the Contractor. ${ }^{3}$

TWRS has initiated several projects that, taken together, are expected to comprise the waste retrieval and waste feed delivery modification. These projects are listed below for completeness and information only and not to establish the scope of waste retrieval and waste feed delivery:

- Project W-211 - Initial Double-Shell Tank Retrieval Systems - Provides new pumps (mixer pumps, decant pumps, slurry pumps, and supernate pumps), electrical system upgrades, instrumentation and control system upgrades, chemical addition system, and valving upgrades for the first eight double-shell tanks (1997-2004).

- Project W-521 - Waste Feed Delivery Systems - Provides nine, double-shell tank retrieval systems similar to those in Project W-211 (1999-2010).

- Project W-522 - Double-Shell Tank Waste Retrieval Systems - Provides five double-shell tank retrieval systems similar to those in Project W-211 (2005-2015).

When the amendment to the TWRS FSAR is approved, it is expected that waste retrieval and waste feed delivery operations can be performed while providing adequate safety to the workers, the public, and the environment.

${ }^{3}$ Authorization Basis Document Process, Lockheed Martin Hanford Company procedure, HNF-IP-0842, Volume IV, Section 5.10, Rev. 1, July 27, 1999. 


\subsection{SITE CHARACTERISTICS}

\subsection{PURPOSE OF REVIEW}

The purpose of this review is to determine whether the Contractor's TWRS FSAR amendment submittal adequately describes the site characteristics that must be evaluated as a result of waste retrieval and waste feed delivery. The site characteristics must also be consistent with the site information contained in the environmental impact statement (EIS) for the TWRS. ${ }^{1}$

\subsection{AREAS OF REVIEW}

This chapter of the FSAR describes the site characteristics necessary for understanding the waste retrieval and waste feed delivery environs. Information is provided to support and clarify assumptions used in the hazard and accident analyses (Chapter 3 in this Guide) and to identify and analyze external and natural phenomena accident initiators and accident consequences potentially impacting waste retrieval and waste feed delivery operations.

As identified in DOE Order $5480.23^{2}$ and DOE-STD-3009-94, ${ }^{3}$ the site characteristics for waste retrieval and waste feed delivery should include the following review areas: ${ }^{4}$

1. Codes and Standards - The design codes, standards, regulations, and DOE Orders required to establish the safety basis of the waste retrieval and waste feed delivery activities should be identified. (Only site characteristics requirements that are pertinent to the safety analysis for waste retrieval and waste feed delivery should be listed.)

2. Site Geography - This area of review should include the following:

a. A general location map should be provided, showing the distance of significant waste retrieval and waste feed delivery structures, systems, and components (SSCs) from the site boundary.

b. The point where the radiological and toxicological risk guidelines are applied should be identified.

c. Additional maps or drawings, as needed, should be provided to present details on the orientation of waste retrieval and waste feed delivery SSCs relative to nearby buildings, traffic routes, transmission lines, and neighboring structures needed to perform the hazard and accident analyses.

3. Demography - No changes to the existing TWRS FSAR are expected.

\footnotetext{
' Tank Waste Remediation System, Hanford Site, Richland, Washington Environmental Impact Statement, August 1996.

${ }^{2}$ Nuclear Safety Analysis Reports, DOE Order 5480.23, Change 1, March 1994.

${ }^{3}$ Preparation Guide for U.S. Department of Energy Nonreactor Nuclear Facility Safety Analysis Reports, Chapter 1, "Site Characteristics," DOE-STD-3009-94, July 1994.

${ }^{4}$ Only areas expected to change as a result of waste retrieval and waste feed delivery need to be addressed.
} 
4. Meteorology - No changes to the existing TWRS FSAR are expected.

5. Hydrology - No changes to the existing TWRS FSAR are expected.

6. Geology - No changes to the existing TWRS FSAR are expected.

7. Natural Phenomena Threats - No changes to the existing TWRS FSAR are expected.

8. External Man-Made Threats - External man-made phenomena (e.g., explosions and accidents from nearby transportation activities) that could be potential accident initiators for waste retrieval and waste feed delivery operations should be identified and described, including the assumptions supporting the accident analyses (Chapter 3 in this Guide) relative to man-made threats.

9. Nearby Facilities - Nearby facilities should be identified that could be affected by waste retrieval or waste feed delivery accidents or that could adversely impact the waste retrieval or waste feed delivery SSCs. In addition, the facilities' location relative to the waste retrieval and waste feed delivery facilities should be described.

10. Validity of Existing Environmental Analyses - The validity of site characteristic assumptions for existing environmental analyses and impact statements (e.g., the RPP EIS) relative to the safety analysis to be performed for waste retrieval and waste feed delivery should be discussed.

Existing supporting documentation should be referenced. Brief references of documentation should be included with enough salient facts to provide an understanding of the referenced documentation and its relation to this chapter. On request, complete references can be provided to the regulatory entity.

\subsection{ACCEPTANCE CRITERIA}

\subsubsection{Acceptability Review}

A one-week acceptability review will be performed to determine whether the submittal on site characteristics contains sufficient information to evaluate it against the regulatory acceptance criteria in Section 1.3.3 below. Where applicable, the Contractor may demonstrate that information in the TWRS FSAR pertaining to site characteristics is adequate to support the hazard and accident analyses for waste retrieval and waste feed delivery.

The information in this section forms the basis for the evaluations performed in the hazard and accident analysis section of the submittal (Chapter 3 in this Guide). The information must also be consistent with the site information contained in the RPP EIS. If significant deficiencies are identified in the submittal, the Contractor will be requested to submit additional information before the start of the detailed review of the FSAR amendment. 


\subsubsection{Regulatory Requirements}

The review will confirm that the FSAR satisfies the requirements of DOE Order 5480.23, paragraph 8.b.(3)(c), as amplified in Attachment 1, paragraph 4.f.(3)(d)3, of the Order (Topic 3) related to site characteristics. The submittal should also include information, if applicable, that will partially satisfy the requirements of DOE Order 5480.23, paragraphs 8.b.(3)(b), (f), and (u), as they relate to the site characteristics.

To facilitate the review, the submittal's format should follow DOE-STD-3009-94, Preparation Guide for U.S. Department of Energy Nonreactor Nuclear Facility Safety Analysis Reports.

Specific regulations and DOE Orders that apply to site characteristics in support of safety analysis and design include DOE-STD-1022-94, Natural Phenomena Hazards Site Characterization Criteria, Change 1, 1994.

\subsubsection{Regulatory Acceptance Criteria}

The site characteristics submittal is acceptable if it is presented at a level of detail appropriate to support the hazard and accident analyses (Chapter 3 in this Guide) and if the following criteria are met:

1. The Contractor identifies the design codes, standards, regulations, and DOE Orders required to establish the safety basis of the waste retrieval and waste feed delivery activities as they relate to site characteristics.

2. The Contractor describes or shows the location of major waste retrieval and waste feed delivery SSCs relative to the site boundary.

3. The Contractor identifies the point at which the radiological and toxicological risk guidelines are applied. This point should be the same relative point as is identified in the current TWRS FSAR, unless the Contractor justifies a revised location based on waste retrieval and waste feed delivery operations.

4. The Contractor provides maps or drawings that present details on the orientation of waste retrieval and waste feed delivery SSCs relative to nearby buildings, traffic routes, transmission lines, and neighboring structures that have potential significance to the hazard and accident analyses (Chapter 3 in this Guide).

5. The Contractor addresses external man-made phenomena (e.g., explosions and accidents from nearby transportation activities) that could be potential accident initiators for waste retrieval and waste feed delivery operations. The discussion should clearly state any assumptions regarding external man-made phenomena that support the hazard and accident analyses (Chapter 3 in this Guide). In the current TWRS FSAR, discussions regarding tank waste remediation system accidents and external man-made threats should provide the basis

\footnotetext{
${ }^{5}$ Where applicable, the Contractor may demonstrate that the information on site characteristics, as provided in the approved TWRS FSAR, is essentially unchanged with respect to impacting the hazard and accident analyses for waste retrieval and waste feed delivery and, therefore, no changes are required.
} 
for identifying external man-made threats to waste retrieval and waste feed delivery operations.

6. The Contractor discusses nearby facilities that could be adversely affected by waste retrieval or waste feed delivery accidents such that the adequacy of the safety analyses for those facilities can be verified. The Contractor describes accidents in nearby facilities that could potentially affect waste retrieval or waste feed delivery SSCs or operations. These accidents are properly reflected in the hazard and accident analyses (Chapter 3 in this Guide) performed for waste retrieval and waste feed delivery.

7. The Contractor discusses and verifies the continued validity of site characteristic assumptions in existing environmental analyses and impact statements. If applicable, the Contractor discusses significant discrepancies, including the need to revise and update assumptions used in the existing environmental documents.

If the Contractor chooses to use existing TWRS FSAR information on site characteristics for waste retrieval and waste feed delivery activities, the Contractor should ensure that the information satisfies the relevant acceptance criteria listed above and should justify the applicability of the existing information to waste retrieval and waste feed delivery.

\subsection{EVALUATION FINDINGS}

The reviewer will prepare material for a Safety Evaluation Report (SER), stating whether the Contractor has provided information describing changes to the characteristics of the site and the surrounding area as they relate to waste retrieval and waste feed delivery. The reviewer will indicate whether the information is sufficiently detailed to support the hazard and accident analyses. The report should include a summary of what was reviewed and why the reviewer finds the material acceptable. For example, the reviewer can document the review as follows:

The site characteristics chapter has been reviewed against the acceptance criteria in Section 1.3 in this Guide and has been found to be acceptable. The Contractor has updated and summarized the site characteristics information or has justified the adequacy of the existing TWRS FSAR information. The information will support complete hazard and accident analyses as they relate to waste retrieval and waste feed delivery. The information, as updated, is consistent with the site information in the present EIS for RPP.

Any exceptions should be noted and stated in a way to provide the Contractor with a clear understanding of the revisions necessary for approval. The reviewer may recommend that the submittal be conditionally approved with provisions for the Contractor to submit additional information within a specified timeframe. 


\subsection{FACILITY DESCRIPTION}

\subsection{PURPOSE OF REVIEW}

The purpose of this review is to determine whether the Contractor's TWRS FSAR amendment submittal adequately describes the SSCs and process features for waste retrieval and waste feed delivery that are significant to the hazard and accident analyses.

\subsection{AREAS OF REVIEW}

This chapter of the FSAR describes the waste retrieval and waste feed delivery SSCs and processes in sufficient detail to support assumptions made in the hazard and accident analyses (Chapter 3 in this Guide). The descriptions should focus on all major waste retrieval and waste feed delivery features necessary to understand the hazard and accident analyses, not just safety SSCs.

As identified in DOE Order 5480.23 ${ }^{1}$ and DOE-STD-3009-94, ${ }^{2}$ the SSC and process descriptions for waste retrieval and waste feed delivery should include the following review areas: ${ }^{3}$

1. Codes and Standards - The design codes, standards, regulations, and DOE Orders required to establish the safety basis of the waste retrieval and waste feed delivery activities should be identified. (Only facility and process description requirements that are pertinent to the safety analysis for waste retrieval and waste feed delivery should be listed.)

2. Facility' Overview - This area of review should describe the following:
a. The waste retrieval and waste feed delivery system.
b. The basic waste retrieval and waste feed delivery processes.

3. Facility Structure - The buildings and structures (e.g., transfer pits, valve pits, and double wall piping) proposed for waste retrieval and waste feed delivery should be described, including construction details such as layout drawings, construction materials, and dimensions that are significant to the hazard and accident analyses.

4. Process Description - This area of review should describe the following:

a. The individual processes (e.g., waste transfer using mixer/slurry pumps, sluicers, and transfer pumps) within waste retrieval and waste feed delivery, including normal process parameters (e.g., pressure, temperature, and flow rates).

\footnotetext{
${ }^{1}$ Nuclear Safety Analysis Reports, DOE Order 5480.23, Change 1, March 1994.

${ }^{2}$ Preparation Guide for U.S. Department of Energy Nonreactor Nuclear Facility Safety Analysis Reports, Chapter 2, "Facility Description," DOE-STD-3009-94, July 1994.

${ }^{3}$ Only areas expected to change as a result of waste retrieval and waste feed delivery need to be addressed.

"As used here, "facility" can refer to either a physical structure or to the tank farms in general. 
b. The parameters for each process, including a summary of the types and quantities of hazardous materials, process equipment, instrumentation and control systems and equipment, process flow diagrams, and operational considerations associated with the individual processes.

c. The interfaces and relationships between existing and proposed SSCs for waste retrieval and waste feed delivery.

5. Confinement Systems - This area of review should describe the following:

a. The SSCs used to provide confinement functions for the waste retrieval and waste feed delivery (e.g., process vessels, glove boxes, ventilation systems and associated high efficiency particulate air [HEPA] filters, double-contained receiver tanks, valve and pump pits, and transfer pits).

b. The interface between new and existing Tank Farm confinement equipment.

c. The adequacy of confinement systems to function under normal and anticipated offnormal conditions.

6. Safety Support Systems - The individual safety support systems for the waste retrieval and waste feed delivery should be described (e.g., fire protection, criticality monitoring, radiological monitoring, chemical monitoring, and effluent monitoring), including each system's purpose and an overview of its principal components, operations, and control function.

7. Utility Distribution Systems - The electrical distribution system for waste retrieval and waste feed delivery, including the offsite power supplies and onsite components of the system, should be described.

8. Auxiliary Systems and Support Facilities - In the facility, any remaining portions that are required for waste retrieval and waste feed delivery and are necessary to perform the hazard and accident analyses but were not included in the preceding sections should be described.

In addition to describing facilities and equipment installed for waste retrieval and waste feed delivery, the above discussions should clearly identify any existing facilities and equipment that will be used for waste retrieval and waste feed delivery activities and should fully describe their role in such activities.

Existing supporting documentation should be referenced. Brief abstracts of referenced documentation should be included with enough salient facts to provide an understanding of the referenced documentation and its relation to this chapter. On request, complete references can be provided to the regulatory entity. 


\subsection{ACCEPTANCE CRITERIA}

\subsubsection{Acceptability Review}

A one-week acceptability review will be performed to determine whether the facility description contains sufficient information to evaluate the SSCs and process descriptions against the regulatory acceptance criteria in Section 2.3.3 below. Where applicable, the Contractor may demonstrate that information in the TWRS FSAR pertaining to the facility description is adequate to support the hazard and accident analyses for waste retrieval and waste feed delivery. If significant deficiencies are identified in the submittal, the Contractor will be requested to submit additional information before the start of the detailed review of the FSAR amendment.

\subsubsection{Regulatory Requirements}

The review will confirm that the FSAR satisfies the requirements of DOE Order 5480.23, paragraph 8.b.(3)(d), as amplified in Attachment 1, paragraph 4.f.(3)(d)4a, of the Order (Topic 4). The submittal should also include information, if applicable, that will partially satisfy the requirements of DOE Order 5480.23, paragraphs 8.b.(3)(b), (f), and (u), as they relate to the facility description.

To facilitate the review, the submittal's format should follow DOE-STD-3009-94, Preparation Guide for U.S. Department of Energy Nonreactor Nuclear Facility Safety Analysis Reports.

Specific regulations and DOE Orders that apply to the waste retrieval and waste feed delivery SSC and process descriptions in support of the hazard and accident analysis include the following:

- 10 CFR 830.120, "Quality Assurance Requirements," April 5, 1999.

- DOE Order 5400.5, Radiation Protection of the Public and the Environment, Change 2, 1993.

- DOE Order 5480.7A, Fire Protection, Change 0, 1993.

- DOE Order 6430.1A, General Design Criteria, April 6, 1989.

- DOE-STD-1020-94, Natural Phenomena Hazards Design and Evaluation Criteria for Department of Energy Facilities, Change 1, 1994.

- DOE-STD-1021-93, Natural Phenomena Hazards Performance Categorization Guidelines for Structures, Systems, and Components, Change 1, 1993.

- DOE-STD-1022-94, Natural Phenomena Hazards Site Characterization Criteria, Change 1, 1994.

- DOE-STD-1023-95, Natural Phenomena Hazards Assessment Criteria, Change 1, 1995. 


\subsubsection{Regulatory Acceptance Criteria}

The facility and process description submittal is acceptable if it is presented at a level of detail appropriate to support the hazard and accident analyses (Chapter 3 in this Guide) and if the following criteria are met: ${ }^{5}$

1. The Contractor identifies the design codes, standards, regulations, and DOE Orders required to establish the safety basis of the waste retrieval and waste feed delivery activities as they relate to the facility description.

2. The Contractor describes the system configuration, projected uses, and basic processes for waste retrieval and waste feed delivery in sufficient detail to support the hazard and accident analyses.

3. The Contractor describes the buildings and structures (e.g., transfer pits, valve pits, and double-wall piping) to be used for waste retrieval and waste feed delivery, including construction details (e.g., layout drawings, construction materials, and dimensions that are significant to the hazard and accident analyses). The information provides an overall understanding of the structure and general arrangement of waste retrieval and waste feed delivery equipment as it pertains to the hazard and accident analyses.

4. The Contractor describes the individual processes within waste retrieval and waste feed delivery (e.g., waste mixing and transfers using mixer/slurry pumps, sluicers, and transfer pumps), including normal process parameters (e.g., pressure, temperature, and flow rates). The descriptions summarize the types and quantities of hazardous materials, process equipment, instrumentation and control systems and equipment (e.g., master pump shutdown system, continuous air monitoring systems, leak detection systems, and waste tank thermocouple trees), process flow diagrams, and operational considerations of individual processes or the entirety of waste retrieval and waste feed delivery. The descriptions also identify the major interfaces and relationships between SSCs for waste retrieval and waste feed delivery and the existing Tank Farm SSCs and the planned TWRS-P facilities. The information provides an understanding of the FSAR assessment of normal operations, the safety analysis and its conclusions, and insight into the types of operations that should be addressed as part of the RPP safety management program.

5. The Contractor describes waste retrieval and waste feed delivery SSCs that perform confinement functions. This description includes waste tanks, double-walled piping, doublecontained receiver tanks, ventilation systems and associated HEPA filters, valve pits, and transfer pits used for confinement. The Contractor also describes interfaces between confinement systems installed for waste retrieval and waste feed delivery and the existing Tank Farm operations as well as any interfaces with the TWRS-P facilities' confinement systems.

6. The Contractor describes the principal waste retrieval and waste feed delivery SSCs that

\footnotetext{
${ }^{5}$ Where applicable, the Contractor may demonstrate that the information on facility and process descriptions, as provided in the approved TWRS FSAR, is complete, encompasses waste retrieval and waste feed delivery, and supports the hazard and accident analyses and, therefore, no changes are required.
} 
perform safety support functions (e.g., fire protection, criticality monitoring, radiological monitoring, chemical and effluent monitoring, shutdown interlocks, standard hydrogen monitoring system, as characterization system, and Food Instrumentation Corp. gauges). The descriptions include the purpose for each system and the principal components, operations, and control functions. The Contractor describes the interfaces between existing and new waste retrieval and waste feed delivery equipment/systems in sufficient detail to determine compatibility.

7. The Contractor provides a schematic outline of the basic electrical distribution system, including a description of the offsite power supplies and onsite components of the system. System details are at a level necessary to understand the electrical distribution philosophy and system operation. The description focuses on any additional electrical distribution or requirements needed for waste retrieval and waste feed delivery operations.

8. The Contractor describes any auxiliary systems and support facilities that are necessary for waste retrieval and waste feed delivery and that were not discussed in the previous sections. This description could include auxiliary systems such as service air, steam, and chemical addition/dilution.

If the Contractor chooses to use existing TWRS FSAR information on facility and process descriptions for waste retrieval and waste feed delivery activities, the Contractor ensures that the information satisfies the relevant acceptance criteria listed above and justifies the applicability of the existing information to waste retrieval and waste feed delivery.

\subsection{EVALUATION FINDINGS}

The reviewer will prepare material for an SER, stating whether the Contractor has provided sufficient information describing the SSCs and processes associated with waste retrieval and waste feed delivery and whether the information is sufficiently detailed to support the hazard and accident analyses. The report should include a summary of what was reviewed and why the reviewer finds the material acceptable. For example, the reviewer can document the review as follows:

The facility description chapter has been reviewed against the acceptance criteria in Section 2.3 in this Guide and has been found to be acceptable. The Contractor has updated and summarized the SSCs and process descriptions associated with waste retrieval and waste feed delivery or has justified the adequacy of existing TWRS FSAR information, and the information will support complete hazard and accident analyses.

Any exceptions should be noted and stated in a way to provide the Contractor with a clear understanding of the revisions necessary for approval. The reviewer may recommend that the submittal be conditionally approved with provisions for the Contractor to submit additional information within a specified timeframe. 


\subsection{HAZARD AND ACCIDENT ANALYSIS}

\subsection{PURPOSE OF REVIEW}

The purpose of this review is to determine whether the Contractor's TWRS FSAR amendment submittal adequately 1) describes the methods used to systematically identify and assess the hazards associated with waste retrieval and waste feed delivery operations; 2) identifies the hazards and potential accidents associated with the hazards; and 3) evaluates the potential internal, external, and natural phenomena events that can result in loss of control of energy and/or hazardous materials (i.e., accidents), with subsequent potential harm to workers, collocated workers, and the public.

Because accidents may occur during normal waste retrieval and waste feed delivery operations, may result from process upsets (i.e., unplanned conditions or abnormal operations), and may occur during startup, standby, or shutdown of waste retrieval and waste feed delivery, all modes of operation should be recognized and evaluated in the hazard and accident analysis section of the FSAR amendment.

\subsection{AREAS OF REVIEW}

This chapter of the FSAR describes the hazard and accident analyses performed to define the safety basis, document the logic of its derivation, demonstrate adherence to the safety basis, and justify its adequacy for waste retrieval and waste feed delivery. The safety basis to be analyzed includes management, design, construction, operation, and engineering characteristics necessary to protect the public, the workers, and the environment from the safety and health hazards posed by waste retrieval and waste feed delivery operations.

This chapter of the submittal should describe the process used to systematically identify and assess hazards to evaluate the potential internal, external, and natural phenomena events that can cause the identified hazards to develop into accidents. This chapter also presents the results of this hazard identification and assessment process. The dominant contributors to exposure from waste retrieval and waste feed delivery operations should be identified and analyzed.

The hazard analyses should consider the complete spectrum of accidents that may occur from waste retrieval and waste feed delivery operations, ranging from normal events to those identified as low probability/high consequence. The hazard analyses should qualitatively analyze potential accident consequences to the public and workers; estimate likelihood of occurrence; identify and assess associated preventive and mitigative features; identify safetysignificant' SSCs; and identify a selected subset of accidents, designated design basis accidents (DBAs), to be formally defined in accident analyses. Accident analyses subsequent to the hazard

\footnotetext{
1 The nomenclature used in this Guide (e.g., safety-significant, safety-class, defense-in-depth, and design basis accidents) is identical to that used in DOE Order 5480.23 and in DOE-STD-3009-94.
} 
analyses should evaluate these DBAs for comparison with Evaluation Guidelines ${ }^{2}$ to identify and assess the adequacy of safety-class SSCs. The Evaluation Guidelines applicable to the RPP are the radiological dose and toxicological exposure guidelines shown in Table 3.1.

Table 3.1. Radiological Dose and Toxicological Exposure Guidelines ${ }^{(a, b)}$

\begin{tabular}{|c|c|c|c|}
\hline \multicolumn{4}{|c|}{ Radiological Dose Guidelines } \\
\hline \multirow[b]{2}{*}{$\begin{array}{c}\text { Frequency } \\
\text { Category }\end{array}$} & \multirow[b]{2}{*}{$\begin{array}{l}\text { Frequency } \\
\text { Range }\left(\mathrm{yr}^{-1}\right)\end{array}$} & \multicolumn{2}{|c|}{ Effective Dose Equivalent: Sv (rem) } \\
\hline & & Onsite & Offsite \\
\hline Anticipated & $>10^{-2}$ to $\leq 10^{\circ}$ & $5.0 \mathrm{E}-03(5.0 \mathrm{E}-01)$ & $1.0 \mathrm{E}-03(1.0 \mathrm{E}-01)$ \\
\hline Unlikely & $>10^{-4}$ to $\leq 10^{-2}$ & $5.0 \mathrm{E}-02(5.0 \mathrm{E}+00)$ & $5.0 \bar{E}-03(5.0 \mathrm{E}-01)$ \\
\hline Extremely Unlikely & $>10^{-6}$ to $\leq 10^{-4}$ & $1.0 \mathrm{E}-01(1.0 \mathrm{E}+01)$ & $4.0 \mathrm{E}-02(4.0 \mathrm{E}+00)$ \\
\hline \multicolumn{4}{|c|}{ Toxicological Exposure Guidelines } \\
\hline \multirow[b]{2}{*}{$\begin{array}{c}\text { Frequency } \\
\text { Category }\end{array}$} & \multirow[b]{2}{*}{$\begin{array}{c}\text { Frequency } \\
\text { Range }\left(\mathrm{yr}^{-1}\right)\end{array}$} & \multicolumn{2}{|c|}{ Primary Concentration Guidelines } \\
\hline & & Onsite & Offsite \\
\hline Anticipated & $>10^{-2}$ to $\leq 10^{0}$ & $\leq \mathrm{ERPG}-1$ & $\leq$ PEL-TWA \\
\hline Unlikely & $>10^{-4}$ to $\leq 10^{-2}$ & $\leq$ ERPG-2 & $\leq E R P G-1$ \\
\hline Extremely Unlikely & $>10^{-6}$ to $\leq 10^{-4}$ & $\leq \mathrm{ERPG}-3$ & $\leq$ ERPG-2 \\
\hline
\end{tabular}

(a) ERPG - Emergency Response Planning Guideline; PEL - permissible exposure limit; and TWA - timeweighted average.

(b) These Evaluation Guidelines are from the TWRS FSAR (WHC-SD-WM-SAR-067, Rev. 0), February 1999.

The radiological dose and toxicological exposure guidelines shown in Table 3.1 are from the existing TWRS FSAR. The ORP currently is preparing an Implementing Directive to provide updated and likely, less conservative (i.e., evaluation guidelines more consistent with values used elsewhere in the DOE complex), radiological dose, and toxicological exposure guidelines. The reviewer of this Guide should confirm that the radiological risk and toxicological exposure guidelines used in the accident analysis and the safety-class and safety-significant SSCs identified for waste retrieval and waste feed delivery are up to date and DOE-approved.

\subsubsection{Hazard Analysis}

Process-related, natural phenomena, and external hazards associated with waste retrieval and waste feed delivery should be comprehensively identified and evaluated as the first step in the submittal's hazard analysis. The inventory of hazardous materials (type, amount, and location of radioactive materials and hazardous chemicals) and energy sources associated with waste retrieval and waste feed delivery processes and operations should be identified. Inventories to be

\footnotetext{
${ }^{2}$ Evaluation Guidelines refer to hazardous material dose/exposure values against which the accident scenario is evaluated. The intention is that theoretical individual doses/exposures exceeding the Evaluation Guidelines should not occur at a given point, unlike other values such as emergency planning thresholds. Offsite Evaluation Guidelines are established for identifying and evaluating safety-class SSCs. Onsite Evaluation Guidelines are established for identifying and evaluating safety-significant SSCs for protecting onsite workers. Evaluation Guidelines are not required for identifying and evaluating safety-significant SSCs for protecting facility workers.
} 
encountered in waste retrieval and waste feed delivery operations should be adequately enveloped (i.e., the hazard analysis should be based on an inventory enveloping all radioactive and non-radioactive hazardous materials that are stored, used, or may be formed in waste retrieval and waste feed delivery).

The hazard analysis should 1) consider the complete spectrum of potential accidents due to waste retrieval and waste feed delivery operations, ranging from normal events through those identified as low probability/high consequence (i.e., events with a probability of occurrence per year ranging from 1 to $10^{-6}$ ); 2) qualitatively estimate the potential accident consequences to the public and the workers; 3) estimate the likelihood of occurrence; 4) identify and assess the associated preventive and mitigative features; 5) identify safety-significant SSCs; and 6) identify a selected subset of accidents, designated DBAs, to be formally defined and quantitatively evaluated in the accident analysis portion of the FSAR amendment.

Because the hazard analysis is also used to provide the final facility hazard classification, the hazard analysis should identify and incorporate into programmatic requirements the measures necessary to protect workers, the public, and the environment from potential accidents. Defensein-depth features should be identified, including safety-significant SSCs and other items needing technical safety requirement (TSR) coverage according to DOE Order 5480.22. ${ }^{3}$ Any relevant programs to be covered under TSR administrative controls (that are major contributors to worker safety and defense-in-depth) should be identified in the hazard analysis.

As identified in DOE Order $5480.23^{4}$ and DOE-STD-3009-94, ${ }^{5}$ the hazard analysis topics for waste retrieval and waste feed delivery should include the following review areas: ${ }^{6}$

1. Codes and Standards - The design codes, standards, regulations, and DOE Orders required to establish the safety basis of the waste retrieval and waste feed delivery activities should be identified. (Only hazard analysis requirements that are pertinent to the hazard analysis for waste retrieval and waste feed delivery should be listed.)

2. Methodology - This review area should include the following descriptions:

a. The hazard analysis methods to be used.

b. The approach and methods used to identify all potential accidents.

c. The approach and methods used for assessing the consequences of postulated accidents, with and without mitigation.

3. Hazard Identification - The types, amounts, and locations of the hazards and hazardous materials, including energy sources associated with waste retrieval and waste feed delivery operations, should be identified.

\footnotetext{
${ }^{3}$ Technical Safety Requirements, DOE Order 5480.22, March 1992.

${ }^{4}$ Nuclear Safety Analysis Reports, DOE Order 5480.23, Change 1, March 1994.

${ }^{5}$ Preparation Guide for U.S. Department of Energy Nonreactor Nuclear Facility Safety Analysis Reports, Chapter 3, "Hazard and Accident Analysis," DOE-STD-3009-94, July 1994.

${ }^{6}$ Only areas expected to change as a result of waste retrieval and waste feed delivery need to be addressed.
} 
4. Hazard Classification - The preliminary and final hazard categories selected for waste retrieval and waste feed delivery or segments thereof should be provided.

5. Hazard Evaluation - This review area should include the following:

a. Internal and external accident frequencies should be estimated.

b. The consideration of common-cause events such as natural phenomena events, external man-made events, loss of electrical power, fire, and internal missiles should be discussed.

c. The spectrum of accident sequences or scenarios that could release hazardous materials, ranging from normal events through those identified as low probability/high consequences, should be discussed. (For example, the potential for igniting pumped organic liquids is included. If a leak occurs during the pumping of organic liquids, the liquid spray could be atomized and ignited by a spark or other ignition source.)

d. The basis for the binning of accidents in the hazard analysis should be documented.

e. The potential hazard control strategies and protective features to manage the risk for each potential accident should be identified.

f. The results of the hazard identification and assessment process should be documented.

6. Planned Design and Operational Safety Improvements - No changes to the existing TWRS FSAR are expected.

7. Defense-in-Depth - The application of defense-in-depth should be described for identifying safety-significant SSCs and TSRs.

8. Safety-Significant SSCs - This review area should include the following:

a. Safety-significant SSCs based on onsite worker safety should be identified.

b. Hazardous conditions associated with waste retrieval and waste feed delivery activities should be examined to determine if they present a potential for serious injury or death to an onsite worker. If such hazardous conditions are identified, controls beyond those identified for the analyzed accidents should be considered.

9. Technical Safety Requirements - Safety-significant TSRs based on defense-in-depth and worker safety should be identified.

10. Environmental Protection - Environmental protection provisions (i.e., design and operational features) should be identified.

11. Accident Selection - A limited subset of unique accidents and representative accidents (i.e., DBAs) related to waste retrieval and waste feed delivery should be selected for comparison with the radiological dose and toxicological exposure guidelines (Table 3.1). 
Existing supporting documentation should be referenced. Brief references of documentation should be included with enough salient facts to provide an understanding of the referenced documentation and its relation to this chapter. On request, complete references can be provided to the regulatory entity.

\subsubsection{Accident Analysis}

The term "accident analysis" refers to bounding analyses selected for inclusion in the FSAR amendment to properly implement DOE Order 5480.21. ' Accident analysis should be used to formally quantify the limited subset of potential accidents (i.e., DBAs) arising from waste retrieval and waste feed delivery for comparison with the radiological dose and toxicological exposure guidelines (Table 3.1) to identify and assess the adequacy of safety-class and safetysignificant SSCs. DBAs are a class of accidents that provide the design parameters for release barriers and mitigating systems. They also help identify requirements, operating procedures, etc., which would prevent the DBA.

All assumptions made in the accident analysis (i.e., the defining points in scenario progression) should be validated as part of the accident analysis activity. However, this does not imply that the FSAR amendment must contain detailed validations for all accident analysis assumptions. The accident analysis provided in the FSAR amendment should present information at a sufficient level for review and approval of the FSAR amendment. Referencing an auditable trail of information as part of the controlled supporting documentation is acceptable.

As identified in DOE Order $5480.23^{8}$ and DOE-STD-3009-94, ${ }^{9}$ the accident analysis topics for waste retrieval and waste feed delivery should include the following review areas: ${ }^{10}$

1. Codes and Standards - The design codes, standards, regulations, and DOE Orders required to establish the safety basis of the waste retrieval and waste feed delivery activities should be identified. (Only accident analysis requirements that are pertinent to the accident analysis for waste retrieval and waste feed delivery should be listed.)

2. Methodology - The methods (including any computer models and codes) used to determine the accident progression sequence or to quantify the consequences of operational accidents, natural phenomena events, and external events selected as representative accidents for waste retrieval and waste feed delivery should be discussed.

3. Design Basis Accidents - This review area should include the following:

a. The DBA scenarios, including the rationale for their selection, should be described.

b. All major assumptions used in the accident scenarios should be identified, validated, and documented.

\footnotetext{
${ }^{7}$ Unreviewed Safety Question, DOE Order 5480.21, March 1992

${ }^{8}$ Nuclear Safety Analysis Reports, DOE Order 5480.23, Change 1, March 1994.

${ }^{9}$ Preparation Guide for U.S. Department of Energy Nonreactor Nuclear Facility Safety Analysis Reports, Chapter 3, "Hazard and Accident Analysis," DOE-STD-3009-94, July 1994.

${ }^{10}$ Only areas expected to change as a result of waste retrieval and waste feed delivery need to be addressed.
} 
c. The source term for the material at risk, the leak path factors, and the release fractions and respirable fractions appropriate to the accident phenomenology and any decontamination factors assigned to the facility should be identified.

d. The accident analyses for defining a clear safety basis in support of the process for determining the Unreviewed Safety Question (USQ) should be documented. (A USQ is a change or as-found condition that could result in a facility being outside its authorization basis. A facility's authorization basis consists of aspects of the facility's design, including procedures, that DOE relied on to authorize operation. Lack of a clear definition of the safety basis in the FSAR impedes the application of the USQ process set forth in DOE Order 5480.21 for identifying USQs.)

e. Key references and calculation notes used in the DBA analyses for waste retrieval and waste feed delivery should be provided.

f. The determination of accident consequences and the comparison to the radiological dose and toxicological exposure guidelines (Table 3.1) should be documented.

g. The safety SSCs and accident analysis assumptions judged to require TSR coverage to meet the radiological dose and toxicological exposure guidelines (Table 3.1) should be identified.

h. The set of bounding operating conditions for waste retrieval and waste feed delivery for which safety SSCs must function should be identified.

4. Beyond Design Basis Accidents ${ }^{t \prime}$ - This review area should include the following:

a. The beyond DBA analysis should be summarized.

b. The likelihood and consequences of accidents beyond the design basis should be evaluated and documented.

c. Key references and calculation notes used in the beyond DBA analyses for waste retrieval and waste feed delivery should be provided.

Existing supporting documentation should be referenced. Brief references of documentation should be included with enough salient facts to provide an understanding of the referenced documentation and its relation to this chapter. On request, complete references can be provided to the regulatory entity.

\footnotetext{
"Beyond DBAs are accidents with a frequency of less than $10^{-6}$. An evaluation is performed to assess risk reduction as a means to protect against beyond DBAs, as opposed to protecting at the level of the DBAs as a method for evaluating the adequacy of the DBA.
} 


\subsection{ACCEPTANCE CRITERIA}

\subsubsection{Acceptability Review}

A one-week acceptability review will be performed to determine whether the hazard and accident analysis in the FSAR amendment submittal contains sufficient information to evaluate it against the regulatory acceptance criteria in Section 3.3.3 below. Alternatively, the Contractor may show that information in the approved TWRS FSAR pertaining to the hazard and accident analysis encompasses waste retrieval and waste feed delivery. The Contractor should provide key references and calculation notes for the accident analyses. If significant deficiencies are identified in the submittal, the Contractor will be requested to submit additional information before the start of the detailed review of the FSAR amendment.

\subsubsection{Regulatory Requirements}

The review will confirm that the FSAR satisfies the requirements of DOE Order 5480.23, paragraphs 8.b.(3)(e) and 8.b.(3)(k), as amplified in Attachment 1, paragraphs 4.f.(3)(d) 5 and 4.f.(3)(d)11, of the Order (Topics 5 and 11). The FSAR amendment submittal should also include information, if applicable, that will partially satisfy the requirements of DOE 5480.23, paragraphs 8.b.(3)(b),(f), and (u), as they relate to hazard and accident analyses.

To facilitate the review, the submittal's format should follow DOE-STD-3009-94, Preparation Guide for the U.S. Department of Energy Nonreactor Nuclear Facility Safety Analysis Reports.

DOE requirements on defining the Hanford Site boundary for safety analyses are contained in Scott ${ }^{12}$ and Kruger. ${ }^{13}$ DOE requirements on risk guidelines to be used in the TWRS FSAR amendment are contained in Kinzer, ${ }^{14}$ with clarifications documented in Bacon. ${ }^{15}$

Specific regulations and DOE Orders that provide requirements and guidance for performing hazard and accident analyses and establishing the safety basis for waste retrieval and waste feed delivery include DOE-STD-1027-92, Hazard Categorization and Accident Analysis Techniques for Compliance with DOE Order 5480.23, Nuclear Safety Analysis Reports, 1992.

\subsubsection{Regulatory Acceptance Criteria}

Planned activities associated with waste retrieval and waste feed delivery interface with activities already documented and evaluated in the approved TWRS FSAR. In this light, the reviewer

\footnotetext{
${ }^{12}$ W.B. Scott, "Clarification of Hanford Site Boundaries for Current and Future Use in Safety Analyses" (letter 9504327 to Director, Pacific Northwest Laboratory, and President, Westinghouse Hanford Company), U.S.

Department of Energy, Richland Operations Office, Richland, Washington, September 26, 1995.

${ }^{13}$ P.W. Kruger, "Further Discussion on Previous Site Boundary Memorandum" (letter 9600588 to Director, Pacific Northwest National Laboratory, and President, Westinghouse Hanford Company), U.S. Department of Energy, Richland Operations Office, Richland, Washington, March 9, 1996.

${ }_{14}$ J.E. Kinzer, "Interim Radiological Dose Acceptance Criteria for the Hanford Tank Farms Safety Analysis" (letter 96-MSD-069 to A. L. Trego, Westinghouse Hanford Company), U.S. Department of Energy, Richland Operations Office, Richland, Washington, April 8, 1996.

${ }^{15}$ R.F. Bacon, "Tank Waste Remediation System Accident Analysis Risk Evaluation Guidelines" (letter 9651709 to J. E. Kinzer, U.S. Department of Energy, Richland Operations Office), Westinghouse Hanford Company, Richland, Washington, April 22, 1996.
} 
should compare the hazard and accident analyses of waste retrieval and waste feed delivery with analogous sections of the approved FSAR. If significant inconsistencies in the hazard and accident analyses are found, the reviewer should note the variances and determine whether the Contractor's submittal satisfactorily explains the differences.

Because certain planned activities (and corresponding hazard and accident analyses) associated with waste retrieval and waste feed delivery may be similar to activities currently authorized, the Contractor may determine that certain sections of Chapter 3 of the approved FSAR are applicable to the amendment without modification and provide arguments supporting this position. In that case, the reviewer should determine whether the Contractor's arguments are acceptable considering the criteria below.

The reviewer should determine whether the Contractor's submittal systematically and adequately evaluates the set of DBAs associated with waste retrieval and waste feed delivery arising from the hazard analyses. The reviewer should confirm that the Contractor's hazard and accident analyses, as recorded in the FSAR amendment and other supporting documents, provide sufficient evidence that the design, modification, construction, operation, maintenance, and decommissioning of waste retrieval and waste feed delivery SSCs can be done while protecting health and safety of the workers, the public, and the environment.

\subsubsection{Hazard Analysis}

The hazard analysis portion of the submittal's hazard and accident analysis chapter is acceptable if it adequately and systematically evaluates the hazards and potential accidents associated with waste retrieval and waste feed delivery operations and if the following criteria are met: ${ }^{16}$

1. The Contractor identifies the design codes, standards, regulations, and DOE Orders required to establish the safety basis of the waste retrieval and waste feed delivery activities as they relate to hazard analysis.

2. The Contractor adequately describes the hazard analysis methods used for waste retrieval and waste feed delivery, including the methods for identifying assumptions that are part of the hazard analysis. The description includes the following:

a. If the hazard identification methods include reviews of design documentation, waste analyses, TWRS safety documents and analyses, or operating experience at TWRS and other DOE facilities, these sources are referenced to provide an auditable trail.

b. The potential accidents are identified using a structured, systematic approach (e.g., Hazard and Operability Study, Preliminary Hazards Analysis, and/or "What-if" Analysis methodologies) for the activities associated with waste retrieval and waste feed delivery, including the following:

\footnotetext{
${ }^{16}$ Alternately, the Contractor may demonstrate that information on hazard and accident analysis provided in the approved TWRS FSAR is adequate and encompasses the processes and operations for waste retrieval and waste feed delivery and, therefore, no changes are required.
} 
- Failures in implementing institutional safety programs and accidents initiated or compounded by human error.

- Scenarios initiated by system interactions (including common-cause/common-mode failures) and by accidents at neighboring and interfacing facilities.

c. The method for determining unmitigated accident frequencies is documented.

3. The Contractor systematically identifies and summarizes in a table the hazard topography (i.e., the amount, type, and location of hazards and hazardous materials, including radioactive materials and chemical materials that could lead to an accident) for waste retrieval and waste feed delivery. The scope of hazard topography includes the following:

a. The chemistry of tank waste and its physical properties (e.g., mass, specific gravity, volume, pressure, kinetic energy, thermal energy [including heat loads], shear strength, and viscosity) that, with failure of an SSC, could lead to a substantial release of energy.

b. Accident initiators, including natural phenomena (e.g., wind, lightning, and seismic activity) and human activities (e.g., excavation, vehicular accidents, and personnel errors).

4. The Contractor identifies the preliminary and final hazard categories for waste retrieval and waste feed delivery according to DOE-STD-1027-92. ${ }^{17}$ The identification includes the following:

a. The waste retrieval and waste feed delivery segment boundaries and individual segment classifications are identified.

b. Segmentation is justified in terms of independence.

c. If segmentation is used, the summary table of hazards (see criterion 3 above) is broken down by segment.

5. The Contractor performs and documents a comprehensive hazard evaluation for waste retrieval and waste feed delivery. The hazard evaluation includes the following elements:

a. The internal and external accident frequencies are estimated in a consistent manner and the assumptions are identified. Any active or passive SSCs or administrative controls that could reduce the frequency of the accident are not credited.

b. Historical experience is credited where applicable in determining expected accident frequencies.

c. Common-cause events, such as natural phenomena events, external man-made events, loss of electrical power, fire, and internal missiles, are considered and treated as discrete

${ }^{17}$ Hazard Categorization and Accident Analysis Techniques for Compliance with DOE Order 5480.23, Nuclear Safety Analysis Reports, DOE-STD-1027-92, 1992. 
events in the hazard analysis.

d. Secondary events directly caused by external events, such as hazards from other facilities, pipeline ruptures, and truck crashes, are evaluated.

e. The spectrum of accident sequences or scenarios that release hazardous materials, ranging from normal events to those identified as low probability-high consequences, is evaluated.

f. The basis for binning accidents in the hazard analysis is identified.

g. Potential hazard control strategies and protective features are identified to manage the risk for each potential accident.

h. The results of the hazard identification and assessment process are documented.

6. The Contractor identifies, justifies, and describes safety-significant SSCs and TSRs based on defense-in-depth and onsite worker safety.

7. The Contractor makes evident worker safety features as an integral part of waste retrieval and waste feed delivery design and operation, including the following:

a. Worker safety in terms of SSCs and administrative features is summarized.

b. Safety-significant SSCs for protecting workers are summarized.

c. Any safety management programs (e.g., criticality protection, radiation protection, hazardous materials protection, industrial safety provisions, procedures and training, operational safety, and emergency preparedness) that will be assigned TSR coverage in the form of administrative controls for adequate worker safety are identified.

d. Worker protection is provided by a number of means and briefly described, including programs described elsewhere in the FSAR amendment.

e. Waste retrieval and waste feed delivery operations are demonstrated to be adequate for worker safety.

The submittal should provide documented evidence that worker safety features are an integral part of waste retrieval and waste feed delivery design and operation; that basic waste retrieval and waste feed delivery operations for worker safety are adequate; and that workers are protected by a number of means, including programs described elsewhere in the FSAR or its amendments.

8. The Contractor identifies, describes, and justifies environmental protection provisions (i.e., design and operational features) that reduce the potential for large material releases to the environment, including the following:

a. Pathways for the uncontrolled release of large amounts of hazardous materials to the 
environment are documented.

b. Potential consequences and preventive and mitigative features associated with specific release pathways are evaluated and documented.

9. The Contractor identifies the accidents selected for comparison with the radiological dose and toxicological exposure guidelines (Table 3.1). A complete set of bounding conditions is provided against which the operations involving waste retrieval and waste feed delivery can be evaluated. The following is provided:

a. The determination that certain events are incredible (and therefore not subject to analysis) is justified. ${ }^{18}$

b. Potential higher frequency events are not inadvertently overlooked due to splitting of the event frequency. Accidents with similar mechanisms and consequences are rolled up into one accident scenario.

c. The set of internal and external DBAs clearly defines a set of bounding performance requirements for the SSCs relied on to control the hazards.

If the Contractor chooses to use existing TWRS FSAR information on hazard analyses for waste retrieval and waste feed delivery activities, the Contractor should ensure that the information satisfies the relevant acceptance criteria listed above and should justify the applicability of the existing program to waste retrieval and waste feed delivery.

\subsubsection{Accident Analysis}

The accident analysis portion of the hazard and accident analysis chapter of the submittal is acceptable if it demonstrates a thorough and formal quantification of the consequences associated with DBAs for waste retrieval and waste feed delivery operations, including a comparison with the radiological dose and toxicological exposure guidelines (Table 3.1) and an assessment of the adequacy of safety-class and safety-significant SSCs. In addition, this portion of the submittal is acceptable if the following criteria are met: ${ }^{19}$

1. The Contractor identifies the design codes, standards, regulations, and DOE Orders required to establish the safety basis of the waste retrieval and waste feed delivery activities as they relate to accident analysis.

2. The Contractor uses a graded approach for accident analysis involving a more thorough, documented assessment of complex, higher hazard operations than for simple, lower hazard activities. In this case, the level of analysis and documentation is commensurate with 1) the magnitude of the hazards being addressed, 2) the complexity of the waste retrieval and waste

\footnotetext{
${ }^{18}$ DOE Order 5480.23, Attachment 1, "Interim Guidance for DOE Order 5480.23," paragraph 4.f.(2)(d)1, Change 1, 1994: "...SARs should document the determination that the set really is representative and that there are no important omissions associated with the use of scenarios taken to be representative."

${ }^{19}$ Alternately, the Contractor may demonstrate that information on hazard and accident analysis in the approved TWRS FSAR is adequate and encompasses the processes and operations for waste retrieval and waste feed delivery and, therefore, no changes are required.
} 
feed delivery systems being relied on to maintain an acceptable level of risk, and 3) the early stage of the life cycle of waste retrieval and waste feed delivery.

3. The Contractor adequately describes the methods (including any computer models) used to determine and assess the event sequences or to quantify the consequences of operational accidents, natural phenomena events, and external events selected as representative accidents (i.e., the DBAs). Reliance is placed on data rather than expert opinions.

4. The Contractor adequately describes DBA scenarios for waste retrieval and waste feed delivery, including initiating (i.e., contributory and causal) events, mechanisms, and phenomena and the rationale for their selection. The description of the DBA scenarios includes the following:

a. Event trees are provided for complex potential accident scenarios where various outcomes are possible.

b. Event trees, if provided, are sufficiently detailed to provide a basis for estimating the consequences and frequency for each accident.

- Release durations and the release quantities and rates are modeled realistically.

- Realistic release rates account for available pressures, fluid properties, and the physical nature of potential escape paths.

5. The Contractor identifies all major assumptions made in the accident analysis, validates them as part of the accident analysis activity, and adequately documents them. Examples of the documentation include the following:

a. If an operator is supposed to push "Button Z" to stop an accident, the accident analysis clearly indicates that the operator can do so. Making it clear may simply involve noting that no physical phenomena associated with the accident would prevent the operator from doing so. Likewise, basic assurance must be provided that equipment relied on in unusual or severe environments will function.

b. According to the "graded approach" to hazard and accident analysis, the FSAR amendment need not contain detailed validation for all assumptions.

c. The frequencies of the DBAs are estimated and the assumptions on which they are based are documented. A probabilistic analysis of the range of accidents and range of potential consequences within an accident type is preferred over a simplistic frequency development.

6. The Contractor identifies the set of bounding operating conditions (i.e., operating environment and performance requirements) in which safety SSCs must function for normal operations and for off-normal and accident conditions. Examples of bounding operating conditions include the following: 
a. The environmental qualification requirements for safety SSCs are derived and documented.

b. The operating conditions consider temperature, pressure, humidity, radiation levels, and corrosive chemicals.

7. The Contractor adequately explains, justifies, and documents the source term for the material at risk, leak path factors, release fractions appropriate to the accident phenomenology, and any decontamination factors assigned to the facility. This includes the following:

a. Specific data on the material at risk are used and release rates for hazardous materials are modeled realistically. Examples of the modeling include the following:

- If a leak of a dense, highly viscous, hazardous fluid is postulated, airborne release fractions and respirable fractions appropriate to a fluid with that density and viscosity are used in the source term estimate.

- Bounding values of empirical airborne release and respirable fractions, e.g., those in DOE-HDBK-3010-94, ${ }^{20}$ may be used as appropriate.

- The postulated accident conditions and parameters are compared with the experimental conditions under which the empirical data were obtained to ensure that the data are appropriate to the postulated scenario.

b. Plume rise and depletion that would occur in an actual accident event resulting in an airborne release are appropriately factored into the consequence analysis, including the following:

- Particle size distributions in any postulated plumes are accounted for, and credible magnitudes and particle sizes for aerosols are assumed.

- Weathering and depletion of toxicological species as they migrate from the release point to the receptor are accounted for. Weathering accounts for the fact that, because many of the toxicological species are hygroscopic, the final chemical form will not be the same as the form released, and the particle size and weight will also increase.

- Plume dispersion calculations for a fire scenario involving release of hot combustion products do not assume that the plume would be neutrally buoyant. The hygroscopic nature of certain chemical species may result in absorption of atmospheric moisture and significant fallout during plume transit, which will result in lower estimated doses to hypothetical receptors downwind.

8. The Contractor estimates accident consequences, both unmitigated and mitigated, deterministically using appropriate methods (e.g., by atmospheric dispersion analyses and probabilistically, if necessary) to obtain a realistic estimate of the risk presented by waste

${ }^{20}$ Airborne Release Fractions/Rates and Respirable Fractions for Nonreactor Nuclear Facilities, DOE-HDBK3010-94, 1994. 
retrieval and waste feed delivery. These estimates ensure the following:

a. Unwarranted (excessive) conservatism is avoided.

b. The higher consequences of the explicitly defined, bounding accidents are not the consequences of the expected or anticipated events.

c. A probabilistic analysis of the range of accidents and range of potential consequences within an accident type is preferred over a simplistic analysis.

d. Unmitigated accident consequences do not take credit for active or passive SSCs or administrative controls that could reduce the consequences of the accident.

e. Dose conversion factors used to calculate the total effective dose equivalent for internal doses of radioactive materials are selected appropriately. ${ }^{21}$

f. Assumptions of exposure times are justified and documented.

g. The accident analysis substantiates the findings of the hazard analysis for a set of postulated events and confirms the consequences in a conservative manner. The calculated unmitigated accident consequences and frequencies confirm the qualitative estimates of consequence and frequency in the hazard analysis. If confirmation is lacking, the representative DBAs selected for quantitative evaluation in the accident analysis may need to be re-evaluated.

h. The consequences of postulated accidents are examined consistently. For accidents involving airborne dispersions of hazardous materials, fallout from aerosols is accounted for and the respirable fractions of airborne particulates are appropriate to the postulated accidents. For accidents involving leaks of pumped organic liquids, the concentration of organic solvents in the waste is accounted for.

9. The Contractor's analysis of postulated events that potentially exceed the radiological dose and toxicological exposure guidelines (Table 3.1) identifies associated safety SSCs and contains sufficient bases for deriving associated TSRs. This includes the following:

a. Additional levels of assurance, diversity, or redundancy (defense-in-depth) are used to avoid unduly relying on a single safety device or personnel action.

b. Controls, including defense-in-depth controls, are preferentially selected according to a structured methodology. For example, to satisfy the goal of enhanced reliability of hazard controls, passive controls are normally preferred over active controls, and engineered controls are preferred over administrative controls. However, practical considerations of implementation and cost-effectiveness prevent a pre-determined

\footnotetext{
${ }^{21}$ External Dose-Rate Conversion Factors for Calculation of Dose to the Public, DOE/EH-0070, July 1988; Internal Dose Conversion Factors for Calculation of Dose to the Public, DOE/EH-0071, July 1988; Limiting Values of Radionuclide Intake And Air Concentration and Dose Conversion Factors For Inhalation, Submersion, and Ingestion, EPA-520/1-88-020, Federal Guidance Report No. 11, September, 1988; External Exposure To Radionuclides In Air, Water, and Soil, EPA-402-R-93-081, Federal Guidance Report No. 12, September 1993.
} 
hierarchy of preferences from being automatically imposed. Controls are described in sufficient detail to permit their performance and adequacy to be evaluated.

c. The ability of the controls to prevent or mitigate the postulated accident(s) is determined. Equipment and personnel actions that are particularly important to the safety of the system are identified and their failure modes examined to determine whether the safety of waste retrieval and waste feed delivery operations unduly depends on such components or personnel actions.

d. The analyses include the application of risk assessment, reliability engineering, commoncause/common-mode failure analysis, human reliability analysis, and human factors safety analysis, as appropriate, to identifying, investigating, eliminating, mitigating, or controlling the vulnerabilities of the waste retrieval and waste feed delivery SSCs to accidents and accidental releases.

e. Controls are derived from bounding events but are verified against all potential hazardous conditions.

f. Control strategies and methods incorporate additional conservatism to ensure that safety criteria will be met with high confidence for potential accidents where quantitative uncertainty data are not available.

g. The total set of controls chosen to protect the workers and the public is reviewed to determine whether any significant worker hazards remain uncontrolled. Additional controls are identified for worker protection, as necessary.

h. Controls for environmental protection are determined on the basis of safety SSCs, TSR controls, other controls providing defense-in-depth, and other RPP information, including the following:

- Pathways for the uncontrolled release of large amounts of hazardous materials to the environment are identified.

- Large releases to the environment are not accepted if they can be easily prevented. For example, Chapter 3 of the TWRS FSAR concludes that no large release exists with the potential to cause significant environmental harm that an obvious and easily implemented change could alleviate or prevent. Accepting the risk of widespread river or groundwater contamination due to spills from a tank, for example, would be inappropriate if a simple dike around the tank would alleviate the problem but had not been installed.

i. Controls identified for protecting the public, onsite worker, and waste retrieval and waste feed delivery worker are examined to determine hazardous conditions for which the environment is also protected. Gloveboxes, ventilation zones of confinement, and HEPA filters may be provided to protect workers maintaining or repairing waste retrieval equipment. These measures would be adequate for closure of environmental contamination concerns arising from, for example, potential accidents during maintenance. 
j. Results of the controls selection and evaluation process are incorporated into the hazard analysis. The appropriateness of selected controls for each identified hazard and corresponding potential accidents is evaluated and, if necessary, additional controls are selected to manage the residual risk.

10. The Contractor identifies accident analysis assumptions judged to require TSR coverage (to meet the radiological dose and toxicological exposure guidelines [Table 3.1] and to protect the assumptions).

11. The Contractor's safety analysis results identify the dominant contributors to the residual risk of waste retrieval and waste feed delivery operations. The residual risk considers the unreliability of selected hazard controls in preventing or mitigating potential accidents.

12. The Contractor's discussion and results of the safety analysis demonstrate that waste retrieval and waste feed delivery operations anywhere within the envelope of permitted facility conditions will satisfy the constraints imposed by applicable design codes, standards, regulations, and DOE Orders (per acceptance criterion 1 above).

13. The Contractor's accident analyses define a clear safety basis (i.e., a framework or set of evaluation models) that is adequate to 1) determine whether new information or proposed changes in facility design or operation constitute USQs, 2) provide a basis for reviewing and evaluating such information, and 3) determine whether new information or proposed changes warrant changes in principal safety design criteria. A facility's authorization basis consists of aspects of the facility's design (including procedures) that DOE relies on to authorize operation. Lack of a clear definition of the safety basis in the FSAR impedes the application of the process set forth in DOE Order 5480.21 for identifying USQs.

14. The Contractor evaluates and documents the likelihood and consequences of accidents beyond the $\mathrm{DBA},{ }^{22}$ including the following:

a. The rationale is provided for recommending acceptance of waste retrieval and waste feed delivery operations, given the likelihood and consequences of beyond DBAs.

b. The residual risk from beyond DBAs associated with waste retrieval and waste feed delivery operations is estimated (including consideration of the potential effects to the public health and safety and protection for the workers).

c. The evaluation includes assessing the risk reduction resulting from protecting against beyond DBAs (as opposed to the method for evaluating the adequacy of the DBAs).

d. The evaluation of beyond DBAs provides a perspective of the potential vulnerabilities resulting from waste retrieval and waste feed delivery operations. Additional waste retrieval and waste feed delivery features are identified, if necessary, to prevent or reduce the severity of beyond DBA consequences.

${ }^{22}$ Nuclear Safety Analysis Reports, DOE Order 5480.23, Attachment 1, paragraph 4f(3)(d)11c, Change 1, March 1994. 
If the Contractor chooses to use existing TWRS FSAR information on accident analyses for waste retrieval and waste feed delivery activities, the Contractor should ensure that the information satisfies the relevant acceptance criteria listed above and should justify the applicability of the existing program to waste retrieval and waste feed delivery.

\subsection{EVALUATION FINDINGS}

The reviewer will prepare material for an SER, stating whether the Contractor has performed a comprehensive and systematic hazard and accident analysis for waste retrieval and waste feed delivery. The report should include a summary of what was reviewed and why the reviewer finds the material acceptable. For example, the reviewer can document the review as follows:

The hazard and accident analysis chapter has been reviewed against the criteria in Section 3.3 in this Guide and has been found to be acceptable. The Contractor has evaluated the hazards, potential accidents, and the necessary hazard controls associated with waste retrieval and waste feed delivery operations and has defined the safety basis in a manner that permits USQs to be evaluated according to DOE Order 5480.21.

Any exceptions should be noted and stated in a way to provide the Contractor with a clear understanding of the revisions necessary for approval. The reviewer may recommend that the submittal be conditionally approved with provisions for the Contractor to submit additional information within a specified period. 


\subsection{SAFETY STRUCTURES, SYSTEMS, AND COMPONENTS}

\subsection{PURPOSE OF REVIEW}

The purpose of this review is to determine whether the Contractor's TWRS FSAR amendment submittal adequately describes the details of safety-class and safety-significant (jointly referred to as safety SSCs) associated with waste retrieval and waste feed delivery operations.

\subsection{AREAS OF REVIEW}

This chapter of the FSAR describes the functional requirements and performance criteria of the safety-class and safety-significant SSCs that implement the hazard control strategies required to ensure that waste retrieval and waste feed delivery operations are within the radiological dose and toxicological exposure risk guidelines' to the extent practicable during all credible events. This chapter also defines, describes, and categorizes the safety SSCs that "prevent and/or mitigate the consequences of all potential accidents including the bounding design basis accidents."

Safety-class SSCs are defined as "systems, structures, or components, including primary environmental monitors and portions of process systems, whose failure could adversely affect the environment, or safety and health of the public as identified by safety analyses." ${ }^{3}$ For implementing this definition, the phrase "adversely affect" means that the Evaluation Guidelines (Table 3.1) are exceeded. Safety-class SSCs provide the necessary preventive or mitigative functions to keep radioactive and hazardous material exposure to the public below the offsite radiological and toxicological risk guidelines.

Safcty-significant SSCs are components whose preventive or mitigative function is a major contributor to defense-in-depth ${ }^{4}$ and/or worker safety, as determined from hazard analysis but that are not designated safety class. Safety-significant SSC designations based on worker safety

\footnotetext{
'The Evaluation Guidelines are hazardous material dose/exposure values against which the safety analysis is evaluated. The intention is that theoretical individual doses/exposures exceeding these guidelines should not occur at a given location. If the calculated doses exceed the guidelines, then controls are required for risk reduction. Table 3.1 identifies the radiological dose and toxicological exposure guidelines (Evaluation Guidelines) from the TWRS FSAR for waste retrieval and waste feed delivery.

${ }^{2}$ Nuclear Safety Analysis Reports, DOE Order 5480.23, Section 5g, Change 1, March 1994.

${ }^{3}$ Preparation Guide for U.S. Department of Energy Nonreactor Nuclear Facility Safety Analysis Reports, Chapter 4, "Safety Structures, Systems, and Components," DOE-STD-3009-94, July 1994.

"The fundamental principle underlying the safety technology of waste retrieval and waste feed delivery SSCs centers on several layers of protection, including successive barriers preventing the release of radioactive materials to the workplace or the environment. Human aspects of defense-in-depth are considered to protect the integrity of barriers, such as quality assurance, administrative controls, safety reviews, operating limits, personnel qualification and training, and safety programs. Design provisions, including those for normal and for safety SSCs, help 1) prevent undue challenges to the physical barriers' integrity; 2) prevent a barrier from failing if it is challenged; 3) where it exists, prevent consequential damage to multiple barriers in series; and 4) mitigate the consequences of accidents. Defense-in-depth helps ensure that two basic safety functions (controlling the process flow and confining the radioactive material) are preserved and that radioactive materials do not reach the worker, the public, or the environment.
} 
are generally limited to SSCs whose failure is estimated to result in an acute worker fatality or serious injuries to workers. Serious injuries, as used in this definition, refer to medical treatment for immediately life-threatening or permanently disabling injuries (e.g., loss of eye and loss of limb) from other than standard industrial hazards. It specifically excludes potential latent effects (e.g., potential carcinogenic effects of radiological exposure or uptake).

With these definitions of safety-class and safety-significant SSCs in mind, the safety SSCs topics, as identified in DOE Order $5480.23^{5}$ and DOE-STD-3009-94 ${ }^{6}$, for waste retrieval and waste feed delivery should include the following review areas: ${ }^{7}$

1. Codes and Standards - The design codes, standards, regulations, and DOE Orders required to establish the waste retrieval and waste feed delivery safety basis should be identified. (Only safety SSCs requirements that are pertinent to the safety analysis for waste retrieval and waste feed delivery should be listed.)

2. Safety-Class and Safety-Significant SSCs - These SSCs should be described in sufficient detail to provide an understanding of the safety function provided by the SSC and the control strategy, of which the SSC is a part. Summary lists of safety-class and safety-significant SSCs should be provided and should identify the Chapter 3 accident for which the safetyclass designation was made or the Chapter 3 rationale from which the safety-significant determination was made.

3. Preventive or Mitigative Safety Function(s) - These functions, which are provided by the $\mathrm{SSC}$ as determined in the hazard and accident analysis, should be specifically identified.

4. Principles for SSC Performance - The basic principles by which an SSC performs its safety function, including its boundaries and interface points with other SSCs, should be described.

5. Supporting SSCs - Supporting SSCs should be identified. Supporting SSCs are SSCs whose failure would result in the safety SSC losing its ability to perform its required safety function. Supporting SSCs are required for the functioning of safety SSCs, but supporting SSC service may be temporarily interrupted without compromising the safety function of waste retrieval and waste feed delivery SSCs. (The electrical system is an example of a supporting SSC from the approved TWRS FSAR. The electrical system is a supporting SSC for many safety SSCs. However, the safety analysis for the TWRS did not identify any accidents that could be immediately caused by the loss of electrical power to electrically powered safety SSCs. In addition, none of the safety SSCs required continuous electrical power to adequately perform their safety functions; rather, it was concluded that electrical power to electrically powered safety SSCs can be interrupted temporarily without significantly compromising facility safety.)

6. SSC Performance Requirements - The specific requirements (e.g., seismic qualification, flammable gas concentration limits, and operating temperature limits) necessary for the

${ }^{5}$ Nuclear Safety Analysis Reports, DOE Order 5480.23, Change 1, March 1994.

${ }^{6}$ Preparation Guide for U.S. Department of Energy Nonreactor Nuclear Facility Safety Analysis Reports, Chapter 4, "Safety Structures, Systems, and Components," DOE-STD-3009-94, July 1994.

${ }^{7}$ Only areas expected to change as a result of waste retrieval and waste feed delivery need to be addressed. 
safety SSCs to perform their safety functions should be identified. These include pertinent response parameters and the environmental conditions and stresses caused by postulated accidents under which the safety SSCs must operate.

7. Performance Criteria - The performance criteria (e.g., single failure criteria) for safety SSCs to meet their functional requirements should be identified. Performance criteria are necessary to reasonably ensure that the functional requirements of the SSCs will be met and the safety functions satisfied. The ability of the safety SSCs to meet the performance criteria should be evaluated.

8. Accident Analysis Assumptions - The accident analysis assumptions should be identified if they involve safety SSCs and are key to the accident analysis such that, if violated, they would render the analysis invalid. These key assumptions may require a TSR to ensure they remain valid.

Existing supporting documentation should be referenced rather than provided. A brief abstract should be included of the referenced documentation in sufficient detail to provide an understanding of the referenced documentation and its relation to the safety SSCs. On request, complete references can be provided to the regulatory entity.

Many of the safety SSCs identified in Chapter 4 of the current TWRS FSAR ${ }^{8}$ will likely also be required to ensure safe waste retrieval and waste feed delivery operations. For example, the TWRS FSAR identifies the aboveground transfer system as a safety-class system. Because this system will be used for waste retrieval and waste feed delivery, the aboveground transfer system also is expected to be identified as a safety-class system for these activities. In this case, the Contractor may show that the discussion of the aboveground transfer system provided in Chapter 4 of the approved TWRS FSAR is sufficient to encompass the hazard control strategy requirements resulting from the hazard and accident analyses of waste retrieval and waste feed delivery operations. The information provided either in the approved TWRS FSAR or in the additional material submitted for waste retrieval and waste feed delivery operations must address all of the SSC attributes (i.e., numbered items) listed above.

Given the nature of the waste retrieval and waste feed delivery activities, SSCs providing a safety function for specific tanks (e.g., the hydrogen monitoring system for tank 241-SY-101) may likely be directly applicable to other tanks and/or components of waste retrieval and waste feed delivery. In this case, the Contractor should identify the other components that need to be reclassified to safety SSC status and justify the direct applicability of the existing information in the TWRS FSAR to waste retrieval and waste feed delivery operations. If the equipment being reclassified is not identical to that described in the approved TWRS FSAR, the Contractor should provide, at a minimum, the information outlined in the above numbered items.

When reviewing the FSAR amendment submittal, the reviewer should be cognizant of the following SSCs that could potentially be designated as safety-class or safety-significant because of the scope of waste retrieval and waste feed delivery operations:

\footnotetext{
${ }^{8}$ Final Safety Analysis Report for the Tank Waste Remediation System, HNF-SD-WM-SAR-067, Rev. 0, February
} 1999. 
- Master pump shutdown system.

- Waste storage tank, valve pit, pump pit, and transfer line leak detection systems.

- Agitation devices installed in waste storage tanks [e.g., mixer/slurry pumps (both submersible and those with the motor installed external to the tanks), sluicers, and transfer pumps].

- Waste storage tank ventilation systems [blowers, chillers, condensers, demisters, filters (including HEPAs and high efficiency gas adsorbers [HEGAs]), power sources, and monitoring instrumentation].

- Waste flow indication and control/feedback circuitry.

- Chemical addition/dilution systems.

- Double-wall piping (containment and confinement).

- Process control system(s).

If any of the systems listed above are designated as safety SSCs in the approved TWRS FSAR, the Contractor should justify in the FSAR amendment, as appropriate, their continued designation as safety SSCs for waste retrieval and waste feed delivery operations.

\subsection{ACCEPTANCE CRITERIA}

\subsubsection{Acceptability Review}

A one-week acceptability review will be performed to determine whether the safety SSC descriptions contain sufficient information to evaluate them against the regulatory acceptance criteria in Section 4.3 .3 below. Where applicable, the Contractor can demonstrate that information in the TWRS FSAR pertaining to safety SSC descriptions is sufficient to address the control strategies identified in the hazard and accident analyses (Chapter 3 in this Guide) for waste retrieval and waste feed delivery operations. If significant deficiencies are identified in the submittal, the Contractor will be requested to submit additional information before the start of the detailed review of the FSAR amendment.

\subsubsection{Regulatory Requirements}

The review will confirm that the FSAR amendment satisfies the requirements of DOE Order 5480.23, paragraph 8.b.(3)(d), as amplified in Attachment 1 of the Order; paragraphs 4.f.(3)(d)4b and 4.f.(3)(d)4c (Topic 4); paragraph 8.b.(3)(k), as amplified in Attachment 1 of the Order; and paragraph 4.f.(3)(d) $1 \mathrm{n}$ (Topic11). The submittal should also include the information, if applicable, that will partially satisfy the requirements of DOE Order 5480.23, paragraphs 8.b.(3)(b), (f), and (u), as they relate to safety SSCs. 
To facilitate the review, the submittal's format should follow DOE-STD-3009-94, Preparation Guide for U.S. Department of Energy Nonreactor Nuclear Facility Safety Analysis Reports.

Specific design codes, regulations, and DOE Orders that apply to the waste retrieval and waste feed delivery safety-class and safety-significant SSCs include the following:

- 10 CFR 830.120, 1996, "Quality Assurance Requirements," April 5, 1994.

- ASCE 7-95, "American Society of Civil Engineers Minimum Design Loads for Buildings and Other Structures, American Society of Civil Engineers," 1996.

- ASME AG-1, "Code on Nuclear Air and Gas Treatment, American Society of Mechanical Engineers," 1994.

\subsubsection{Regulatory Acceptance Criteria}

The safety SSCs submittal is acceptable if the following criteria are met:"

1. The Contractor identifies the design codes, standards, regulations, and DOE Orders that are required to establish the safety basis for waste retrieval and waste feed delivery activities and that are specific to safety SSCs.

2. The Contractor describes the safety SSCs in sufficient detail to provide an understanding of the SSC's safety function and the control strategy, of which the SSC is a part. The description allows the reviewer to determine that the designated safety SSCs provide the containment, control, monitoring, alarm, and/or other protective functional capability assumed in the hazard and accident safety analysis (Chapter 3 in this Guide).

3. The Contractor provides summary lists of safety-class and safety-significant SSCs. The lists are in tables and identify the accidents (Chapter 3 in this Guide) for which safety-class and safety-significant SSC designations were made. For each SSC the following is described:

a. The safety function (i.e., the reason for designating the SSC as safety-class or safetysignificant, including whether the safety function is preventive or mitigative, as determined in the safety analysis. The safety function is a top-level statement that expresses the objective for the SSC in a given accident scenario.)

b. The functional requirements specifically needed to fulfill the safety function. The functional requirements address the pertinent response parameters or the environmental conditions and stresses caused by postulated accidents under which the safety SSC must operate. Functional requirements include the specific requirements necessary for the safety SSC to perform its safety function (e.g., seismic qualification, flammable gas concentration limits, and operating temperature limits).

\footnotetext{
9 Where applicable, the Contractor may demonstrate that information on safety SSCs, as provided in the approved TWRS FSAR, is essentially unchanged with respect to the hazards for waste retrieval and waste feed delivery and, therefore, no changes are required.
} 
c. The performance criteria (i.e., the specific operational responses and capabilities) necessary to meet the functional requirements.

Figure 4.1 provides an example of the relationship between the hazards and/or accident analysis, safety function, functional requirements, and performance criteria.

4. The Contractor identifies the specific preventative or mitigative safety function(s) provided by the SSC, as determined in the hazard and accident analyses (Chapter 3 in this Guide). The Contractor also summarizes the rationale on which the safety SSC determinations were made.

5. The Contractor describes the basic principles by which an SSC performs its safety function, its boundaries, and its interface points with other systems and equipment.

6. The Contractor identifies support systems to safety SSCs, including proper classification of support systems to preserve the function of the safety SSCs.

7. The Contractor identifies the performance criteria (e.g., single failure criteria) necessary for the safety SSC to meet its functional requirements. The performance criteria reasonably ensure that the SSCs' functional requirements will be met and the safety functions satisfied under all operating conditions.

8. The Contractor evaluates the ability of the safety SSCs to meet their performance criteria.

9. The Contractor identifies accident analysis assumptions for the safety SSCs that require TSR coverage. By carefully examining the accident analyses, the Contractor also identifies values that define the operational limits necessary to ensure that waste retrieval and waste feed delivery operations do not occur outside the bounds of the safety analysis assumptions. This examination will also identify parameters and operating conditions that should be limited to reduce, provide warning of, or mitigate the uncontrolled release of hazardous materials from waste retrieval and waste feed delivery operations.

If the Contractor chooses to provide a rationale for not altering the Chapter 4 discussion in the approved TWRS FSAR, the reviewer should determine that the rationale is adequate and results in reaching the same conclusion. If the Contractor chooses to expand the coverage (e.g., have the designation of hydrogen monitor systems as safety-class systems apply to all double-shell tanks rather than specifically to 241-SY-101), the explanation and rationale for this change should be sufficient to allow the reviewer to reach the same conclusion.

\subsection{EVALUATION FINDINGS}

The reviewer will prepare material for an SER, stating whether the Contractor has provided sufficient information describing the safety-class and safety-significant SSCs associated with waste retrieval and waste feed delivery and whether the information is sufficiently detailed to allow the reviewer to determine that these SSCs will sufficiently reduce risk and function as 


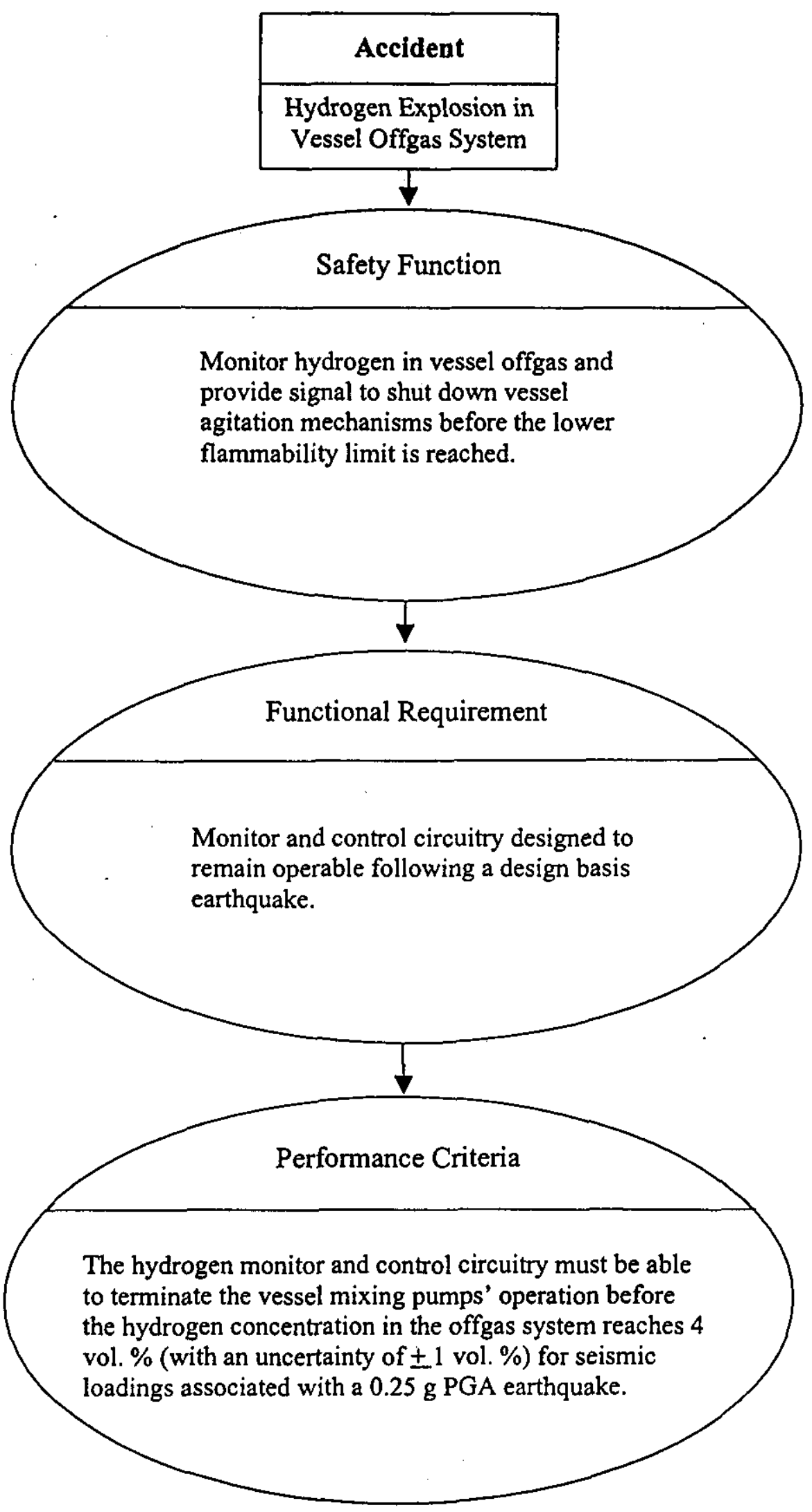

Figure 4.1. Safety Analysis, Safety Function, Functional Requirements, and Performance Criteria Example 
required. The report should include a summary of what was reviewed and why the reviewer finds the material acceptable. For example, the reviewer can document the review as follows:

The safety SSCs chapter has been reviewed against the acceptance criteria in Section 4.3 in this Guide and has been found to be acceptable. The Contractor has updated and adequately summarized the safety-class and safety-significant SSCs associated with waste retrieval and waste feed delivery, and the information will support development of the TSRs.

Any exceptions should be noted and stated in a way to provide the Contractor with a clear understanding of the revisions necessary for approval. The reviewer may recommend that the submittal be conditionally approved with provisions for the Contractor to submit additional information within a specified timeframe. 


\subsection{DERIVATION OF TECHNICAL SAFETY REQUIREMENTS}

\subsection{PURPOSE OF REVIEW}

The purpose of this review is to determine whether the Contractor's TWRS FSAR amendment submittal adequately provides the basis for deriving TSRs, which are required by DOE Order 5480.22, Technical Safety Requirements.'

\subsection{AREAS OF REVIEW}

This chapter of the TWRS FSAR describes the basis for the comprehensive definition of the acceptable waste retrieval and waste feed delivery operating envelope, which addresses all modes of operation for which DOE authorization is sought. While the information in this chapter and the resulting TSRs are key parts of the safety basis for waste retrieval and waste feed delivery operations, neither this chapter nor the TSRs are intended to function as the operating procedures for these operations. This chapter uses the information developed in Chapter 3, "Hazard and Accident Analysis," and in Chapter 4, "Safety SSCs," of the FSAR amendment to derive the TSRs.

The chapter on deriving TSRs consists of summaries and references to pertinent sections of the FSAR that describe the design and administrative features necessary to prevent or mitigate the consequences of accidents. Design and administrative features addressed include ones that 1) provide significant defense-in-depth according to the screening criteria of DOE Order $5480.22,2$ ) provide significant worker safety, 3) protect the environment from large releases, or 4) maintain the consequences of waste retrieval and feed delivery operations below Evaluation Guidelines. ${ }^{2}$ This chapter should contain information in sufficient detail and provide sufficient basis such that TSRs can be derived for any of the following: Limiting Conditions for Operations (LCOs); Surveillance Requirements (SRs); administrative controls for specific control features or to specify programs necessary to perform institutional safety functions; and passive design features. TSRs that are from other projects/facilities and that affect the safety basis for waste retrieval and waste feed delivery should also be identified.

As identified in DOE Order $5480.23^{3}$ and DOE-STD-3009-94 4 , deriving TSRs for waste retrieval and waste feed delivery should include the following review areas:

1. Codes and Standards - The design codes, standards, regulations, and DOE Orders required to establish the safety basis for waste retrieval and waste feed delivery operations should be

\footnotetext{
' Technical Safety Requirements, DOE Order 5480.22, Attachment 1, Section II.2.6, 1992.

${ }^{2}$ Evaluation Guidelines are hazardous material dose/exposure values against which the safety analysis is evaluated. The intention is that theoretical individual doses/exposures exceeding the Evaluation Guidelines should not occur at a given point. The reviewer should refer to Chapter 3 in this Guide for a discussion of the specific Evaluation Guidelines pertinent to the FSAR amendment for waste retrieval and waste feed delivery.

${ }^{3}$ Nuclear Safety Analysis Reports, DOE Order. 5480.23, Change 1, March 1994.

"Preparation Guide for U.S. Department of Energy Nonreactor Nuclear Facility Safety Analysis Reports, Chapter 5, "Derivation of Technical Safety Requirements," DOE-STD-3009-94, July 1994.

${ }^{5}$ Only areas expected to change as a result of waste retrieval and waste feed delivery need to be addressed.
} 
identified. (Only requirements that are for deriving TSRs and that are pertinent to the safety analysis for waste retrieval and waste feed delivery should be listed.)

2. Design and Administrative Features - Design and administrative features should be identified if they provide significant defense-in-depth and significant environmental protection and are significant to worker safety or are needed to ensure that the consequences of waste retrieval and waste feed delivery operations are maintained below the Evaluation Guidelines for all but incredible events.

3. Correlation - The hazard/accident should be correlated with the major features (design and administrative control) that are intended to control that particular hazard/accident.

4. Operating Modes - All operating modes for which authorization is sought should be defined. (In this area, the Contractor is encouraged to develop TSRs for degraded states that would permit limited operations. Examples of such degraded states are discussed below. The TSRs should be developed to allow the maximum extent of degraded operations if such operations are adequately safe, based on the analysis documented in Chapter 3 of the FSAR amendment.)

5. TSR Administrative Controls - Sufficient information should be provided to derive TSR administrative controls for all operating modes or to specify programs necessary to perform institutional safety functions. The derivation and bases for administrative controls for specific control features and for defining staffing requirements should be provided, including minimum staffing requirements for all operating modes that ensure safe operations.

6. Passive Design Features - Passive design features addressed in Chapters 3 or 4 of the FSAR amendment should be identified.

7. Other Facilities - TSRs from other facilities that affect the safety basis for waste retrieval and waste feed delivery should be identified.

Existing supporting documentation should be referenced. Brief references of documentation should be included with enough salient facts to provide an understanding of the referenced documentation and its relation to this chapter. On request, complete references can be provided to the regulatory entity.

A portion of the current RPP authorization basis ${ }^{6}$ provides a derivation of TSR controls for storing tank waste as well as for intertank transfers of waste. Future updates of the RPP authorization basis will address mixer pump operation and sluicing, as well as other activities. Therefore, because these operations will likely be conducted during waste retrieval and waste feed delivery operations, many, if not all, of the TSRs in the current authorization basis are likely also to be applicable to the waste retrieval and waste feed delivery. For example, the authorization basis provides for controls to mitigate spray leaks and other types of accidents resulting from transfers between tanks. Because this operation will be conducted during waste retrieval and waste feed delivery operations, the current controls for waste transfer are likely also

${ }^{6}$ Final Safety Analysis Report for the Tank Waste Remediation System, HNF-SD-WM-SAR-067, Rev. 0, February 1999. 
to apply to waste feed delivery operations. Thus, the Contractor can demonstrate to the reviewer that the discussion on deriving TSRs, as provided in the approved TWRS FSAR, is complete and encompasses the hazard control measures required for waste retrieval and waste feed delivery operations. The information provided either in the approved TWRS FSAR or in the additional material submitted for waste retrieval and waste feed delivery operations must address all of the numbered items listed above.

Because waste retrieval and waste feed delivery operations must meet the TWRS-P Contract ${ }^{7}$ requirements, it may be desirable to perform operations when less than the full complement of equipment is available, as stipulated in the current authorization basis. Therefore, TSR controls for operating under degraded states may need to be derived. Possible degraded states that should be considered by the waste retrieval and waste feed delivery safety analysis include the following:

- Waste retrieval or waste feed delivery operations involving a tank with a degraded or inoperable ventilation system when it has been determined that the particular tank with the compromised ventilation system is producing no flammable gas or quantities so low as to be of no safety concern.

- Waste feed delivery operations with a degraded or inoperable transfer leak detection system in some other RPP waste transfer system, after it has been confirmed that the portion of the leak detection system involved in waste feed delivery is operable.

Hazards and accidents associated with these degraded states and the necessary control strategies for prevention or mitigation should be evaluated and documented in Chapters 3 and 4 of the FSAR amendment. In this chapter, the information in the numbered items above should be provided for the control strategies needed to ensure adequate safety for the degraded operating states.

\subsection{ACCEPTANCE CRITERIA}

\subsubsection{Acceptability Review}

A one-week acceptability review will be performed to determine whether the discussion on deriving TSRs contains sufficient information to evaluate it against the regulatory acceptance criteria in Section 5.3.3 below. Where applicable, the Contractor may demonstrate that the information in the TWRS FSAR pertaining to deriving TSR controls is adequate to address the control strategies identified in the hazard and accident analyses for waste retrieval and waste feed delivery. If significant deficiencies are identified in the submittal, the Contractor will be requested to submit additional information before the start of the detailed review of the FSAR amendment.

\subsubsection{Regulatory Requirements}

The review will confirm that the FSAR amendment satisfies the requirements of DOE Order

7 "Ordering and Contract Order Quantities," Section H.9, DOE Contract DE-RP06-96RL13308, September 1996. 
5480.23, paragraph(s) 8.b.(3)(p), as amplified in Attachment 1, paragraph 4.f.(3)(d)16, of the Order (Topic 16). The submittal should also include information, if applicable, that will partially satisfy the requirements of paragraph(s) 8.b.(3)(b), (f), and (u), as they relate to deriving TSRs.

This chapter provides the technical basis for the TSRs, which are required by DOE Order 5480.22 . $^{8}$ Attachment 1 of DOE Order 5480.23 states that this section of the FSAR "should furnish a logical basis for the comprehensive definition of the acceptable operating envelope for nuclear facilities in compliance with DOE Order 5480.22, Technical Safety Requirements, and the related guidance document. This operating envelope should address all modes of operation ... for which DOE authorization is sought and, as necessary, should accommodate normal operations, maintenance, surveillance... Safety analysis should thoroughly explore the safety acceptability of all modes of operation, set points and operational parameters, combinations of inoperable equipment (emphasis added), staffing and qualification levels of operating crews, and limitations of administrative controls to verify that operation anywhere within the envelope will afford adequate safety provisions. Safety analyses should furnish the information necessary to validate, confirm, derive, or modify the bases for Technical Safety Requirements.""

To facilitate the review, the submittal's format should follow DOE-STD-3009-94, Preparation Guide for U.S. Department of Energy Nonreactor Nuclear Facility Safety Analysis Reports.

Specific regulations and DOE Orders that apply to deriving TSRs for waste retrieval and waste feed delivery include DOE Order 5480.22, Technical Safety Requirements, Change 2, 1996.

\subsubsection{Regulatory Acceptance Criteria}

The submittal on deriving TSRs for waste retrieval and waste feed delivery is acceptable if the following criteria are met: ${ }^{10}$

1. The Contractor identifies the design criteria, standards, regulations, and DOE Orders that are required to establish the safety basis for waste retrieval and waste feed delivery operations and that are specific to deriving TSRs.

2. The Contractor identifies the design and administrative features that provide significant defense-in-depth, environmental protection, and worker safety or that are needed to ensure that the consequences of waste retrieval and waste feed delivery operations are maintained below the Evaluation Guidelines (see Chapter 3 in this Guide) for all but incredible accidents.

3. The Contractor provides a table correlating each waste retrieval and waste feed delivery hazard/accident with the major design and administrative features identified to control that particular hazard/accident. The table also identifies the associated TSR limited conditions of operation, surveillance requirements, administrative controls, and non-TSR design features identified in Chapter 4. Examples include the following:

\footnotetext{
Technical Safety Requirements, DOE Order 5480.22, 1992.

${ }^{9}$ Nuclear Safety Analysis, DOE Order 5480.23, Attachment 1, Section 4.f.(3)(d)16, Change 1, 1994.

${ }^{10}$ Where applicable, the Contractor may demonstrate that the information on facility and process descriptions, as provided in the approved TWRS FSAR, is complete, encompasses waste retrieval and waste feed delivery, and supports the hazard and accident analyses and, therefore, no changes are required.
} 
a. The major design and administrative features are extracted from Chapters 3 and 4 of the FSAR amendment and are those that 1) provide significant defense-in-depth, 2) provide substantial worker safety, 3) provide substantial environmental protection, or 4) are needed to ensure that the consequences of waste retrieval and waste feed delivery operations are maintained within the Evaluation Guidelines for all but incredible events.

b. The specific Evaluation Guidelines (radiological and toxicological risk guidelines) used in the consequence assessment for waste retrieval and waste feed delivery accidents are identified directly or by reference in Chapter 3 of the FSAR amendment.

c. Descriptions of the design and operation features identified in other sections of the FSAR amendment are included by reference.

4. The Contractor identifies and defines all waste retrieval and waste feed delivery operating modes for which authorization is sought, including degraded state operations.

5. The Contractor provides sufficient information to derive Limiting Conditions of Operation or Surveillance Requirements for all defined operating modes, as appropriate.

6. The Contractor provides sufficient information to 1) derive TSR administrative controls for all defined operating modes, or 2) specify programs necessary to perform institutional safety functions. This information should include the following:
a. A commitment to establish, maintain, and implement administrative control TSRs for safety management programs.

b. The derivation and bases for staffing requirements, particularly minimum staffing requirements, to ensure safe operations under all operating modes

7. The Contractor identifies and briefly describes all passive design features addressed in Chapters 3 or 4 of the FSAR amendment for waste retrieval and waste feed delivery. The Contractor may cross-reference to descriptions provided elsewhere in the FSAR amendment or to the existing TWRS FSAR.

8. The Contractor identifies TSRs associated with other facilities or projects that affect the safety basis for waste retrieval and feed delivery.

If the Contractor chooses to use existing TWRS FSAR information on deriving TSRs for waste retrieval and waste feed delivery activities, the Contractor should ensure that the information satisfies the relevant acceptance criteria listed above and should justify the applicability of the existing program to waste retrieval and waste feed delivery.

\subsection{EVALUATION FINDINGS}

The reviewer will prepare material for an SER, stating whether the Contractor has provided sufficient information describing the bases for the TSRs associated with waste retrieval and waste feed delivery and whether the information is sufficiently detailed to allow the reviewer to 
determine that, when implemented, the TSRs will provide sufficient risk reduction. The report should include a summary of what was reviewed and why the reviewer finds the material acceptable. For example, the reviewer can document the review as follows:

The chapter on deriving TSRs has been reviewed against the acceptance criteria in Section 5.3 in this Guide and has been found to be acceptable. The Contractor has adequately presented the bases for the TSRs for waste retrieval and waste feed delivery, and the information has sufficient detail to support the development of the TSRs.

Any exceptions should be noted and stated in a way to provide the Contractor with a clear understanding of the revisions necessary for approval. The reviewer may recommend that the submittal be conditionally approved with provisions for the Contractor to submit additional information within a specified timeframe. 


\subsection{PREVENTION OF INADVERTENT CRITICALITY}

\subsection{PURPOSE OF REVIEW}

The purpose of this review is to determine whether the Contractor's TWRS FSAR amendment submittal adequately presents the criticality hazards and controls that are associated with waste retrieval and waste feed delivery operations and that are required to prevent inadvertent criticality.

\subsection{AREAS OF REVIEW}

This chapter of the FSAR describes the program for preventing inadvertent criticality in waste retrieval and waste feed delivery operations. The chapter should describe the criticality safety and protection program for waste retrieval and waste feed delivery, delineating requirements for criticality control and its implementation. The program must ensure that sufficient controls are in place to reduce the likelihood of inadvertent nuclear criticality as a result of waste retrieval and waste feed delivery operations.

Existing criticality safety analyses that support tank farm operations do not address activities associated with waste retrieval and waste feed delivery. As such, this section of the Guide was prepared based on addressing all elements of a criticality safety assessment program, including criticality controls. However, much of the existing TWRS FSAR criticality safety information is expected to be applicable to waste retrieval and waste feed delivery. Accordingly, existing TWRS FSAR criticality safety information can be included in the amendment by reference, along with adequate justification of the applicability of the information to waste retrieval and waste feed delivery activities.

As identified in DOE Order $5480.23^{1}$ and DOE-STD-3009-94, ${ }^{2}$ the program for preventing inadvertent criticality for waste retrieval and waste feed delivery includes the following review areas: ${ }^{3}$

1. Codes and Standards - The design codes, standards, regulations, and DOE Orders required to establish the safety basis of the waste retrieval and waste feed delivery activities related to criticality should be identified. (Only requirements that are relevant for preventing inadvertent criticality and that are pertinent to the safety analysis for waste retrieval and waste feed delivery should be listed.)

2. Criticality Concerns - This review area should include the following:

a. The fissile material available within waste retrieval and waste feed delivery SSCs should be identified.

${ }^{1}$ Nuclear Safety Analysis Reports, DOE Order 5480.23, Change 1, March 1994.

${ }^{2}$ Preparation Guide for U.S. Department of Energy Nonreactor Nuclear Facility Safety Analysis Reports, Chapter 6, "Prevention of Inadvertent Criticality," DOE-STD-3009-94, July 1994.

${ }^{3}$ Only areas expected to change as a result of waste retrieval and waste feed delivery need to be addressed. 
b. Information should be provided on the location of potential criticality hazards (e.g., description and drawing), the fissile material form (including isotopic content, concentration, and densities), and the maximum quantities involved.

3. Criticality Controls - The information relevant to criticality control during waste retrieval and waste feed delivery should be summarized, including the following:

a. The criticality safety design limits, their bases, and any design criteria used to ensure subcritical configurations under all normal, abnormal, and accident conditions (i.e., to ensure criticality limits are not exceeded).

b. The parameters used for preventing and controlling criticality and the methods for applying and validating these parameters.

c. The application of the double contingency principle in criticality safety.

4. Engineering Controls - The safety design limits on engineered controls, either passive or active, used in the waste retrieval and waste feed delivery design should be summarized, including the following:

a. The bases placed on equipment designs or operations to ensure subcritical conditions under all normal, abnormal, and accident conditions.

b. The use of geometry, spacing, and any other engineered controls (e.g., neutron absorbers, elimination of moderators, storage location limitations, and level detectors).

c. The configuration control program as it relates to configuring criticality-safety-related equipment used to retrieve, store, and transfer the waste.

5. Administrative Controls - The administrative controls used to prevent accidental criticality during waste retrieval and waste feed delivery operations should be summarized, including the following:

a. The administrative controls on nuclear material safety limits such as mass, moderators, neutron absorbers, changes in geometry configurations, and procedures for handling, storing, and transporting fissile materials.

b. The administrative controls for reviewing and approving changes to process or system configurations. (For waste retrieval and waste feed delivery, administrative controls on fissile material concentration and neutron absorber to fissile material ratios are anticipated to form the primary criticality prevention controls.)

6. Application of Double Contingency Principle - The contingency analysis or criticality safety evaluation and the controls used to ensure that at least more than one unlikely, independent, and concurrent change in process conditions would be necessary before a criticality accident is possible should be summarized. The contingency analysis or criticality safety evaluation should identify how the double contingency principle, as defined in DOE 
Order $5480.24,{ }^{4}$ is being met (i.e., control of two independent process parameters or a system of multiple controls on a single parameter).

7. Criticality Protection Program - This review area should include the following:

a. Criticality Safety Program: The criticality safety organization and the criticality protection program for waste retrieval and waste feed delivery are anticipated to be analogous to the existing organization and program for RPP (as outlined in Section 6.5 of the TWRS FSAR). It is expected that either 1) the administrative, management, and training responsibilities for criticality safety of waste retrieval and waste feed delivery will apply to the same organization as described in the existing TWRS FSAR, or 2) a parallel organization will be created for waste retrieval and waste feed delivery with the same functions as described in Section 6.5 of the TWRS FSAR. In either case, the following criticality safety program elements should be addressed:

- The organizational structure that administers the criticality safety program.

- Criticality safety plans and procedures governing operations involving fissile materials.

- Criticality safety training.

- The analytical approach (i.e., methods, codes, and analysis techniques) used to derive operational nuclear criticality limits.

- The criticality safety inspection and audit programs.

- The criticality infraction program for reporting and followup of criticality infractions.

b. Criticality Safety Plans and Procedures: No changes to the existing TWRS FSAR are expected in this area beyond that described in item $7 \mathrm{a}$ above.

c. Criticality Safety Training: In addition to the interface description described in item 7a above, the specific training requirements for personnel associated with waste retrieval and waste feed delivery operations should be summarized.

d. Determination of Operational Nuclear Criticality Limits: No changes to the existing TWRS FSAR are expected in this area beyond that described in item 7a above.

e. Criticality Safety Inspections/Audits: No changes to the existing TWRS FSAR are expected in this area beyond that described in item $7 \mathrm{a}$ above.

f. Criticality Infraction Reporting and Followup: No changes to the existing TWRS FSAR are expected in this area beyond that described in item 7.a above.

8. Criticality Instrumentation - The criticality alarm and detection systems used to mitigate

${ }^{4}$ Criticality Safety, DOE Order 5480.24, Change 0, 1992. 
exposures from a criticality event should be summarized. The summary should include the methods and procedures used to determine the placement of the monitoring equipment and

the selection of the equipment functions and sensitivity (if required).

Existing supporting documentation should be referenced rather than provided. A brief abstract of the referenced documentation should be included to provide an understanding of the referenced documentation and its relation to preventing inadvertent criticality. On request, complete references can be provided to the regulatory entity.

\subsection{ACCEPTANCE CRITERIA}

\subsubsection{Acceptability Review}

A one-week acceptability review will be performed to determine whether the submittal on preventing inadvertent criticality contains sufficient information to evaluate it against the regulatory acceptance criteria in Section 6.3 .3 below. Where applicable, the Contractor may demonstrate that the information pertaining to preventing criticality in the TWRS FSAR is adequate to support the criticality safety basis for waste retrieval and feed delivery operations.

Information required to satisfy the acceptance criteria for preventing inadvertent criticality (Section 6.3.3) should be found in the hazard and accident analysis section of the submittal (Chapter 3 ) or in Chapter 6 in this Guide, where detailed criticality evaluations and controls should be presented. The information should be consistent with criticality analyses and prevention programs described in the approved TWRS FSAR; or if there are inconsistencies, they should be justified. If significant deficiencies are identified in the submittal, the Contractor will be requested to submit additional information before the start of the detailed review of the FSAR amendment.

\subsubsection{Regulatory Requirements}

The review will confirm that the FSAR satisfies the requirements of DOE Order 5480.23, paragraph(s) 8.b.(3)(h), as amplified in Attachment 1, paragraph(s) 4.f.(3)(d)8, of the Order (Topic 8). The submittal should also include information, if applicable, that will partially satisfy the requirements of DOE Order 5480.23, paragraphs 8.b.(3)(e), (f), (h), (k-m), (o), (p), (s) and (u), as they relate to preventing inadvertent criticality.

To facilitate the review, the submittal's format should follow DOE-STD-3009-94, Preparation Guide for U.S. Department of Energy Nonreactor Nuclear Facility Safety Analysis Reports.

Specific standards, regulations, and DOE Orders that apply to waste retrieval and waste feed delivery criticality prevention include the following:

- 10 CFR 71, "Packaging of Radioactive Material for Transport," 1995.

- 49 CFR 171-179, "Transportation," 1995.

- DOE-STD-3007-93, Guidelines For Preparing Criticality Safety Evaluations at Department 
of Energy Non-reactor Nuclear Facilities, 1993.

The following ANSI/ANS standards also apply to waste retrieval and waste feed delivery criticality prevention because they are incorporated by reference into DOE Order 5480.24 (with modifications):

- ANSI/ANS-8.1-1983, "Nuclear Criticality Safety in Operations with Fissionable Materials Outside Reactors," 1983.

- ANSI/ANS-8.3-1986, "Criticality Accident Alarm System," 1986.

- ANSI/ANS-8.7-1975, "Guide for Nuclear Criticality Safety in the Storage of Fissile Materials," 1975.

- ANSI/ANS-8.19-1984, “Administrative Practices for Nuclear Criticality Safety," 1984.

\subsubsection{Regulatory Acceptance Criteria}

The reviewer will determine whether the submittal adequately describes criticality hazards and the controls necessary for preventing criticality in waste retrieval and waste feed delivery operations. Adequacy will be determined based on whether the Contractor has identified the hazards associated with criticality, has analyzed the credible criticality accident scenarios, and has controlled process parameters relevant to criticality such that criticality is prevented during all waste retrieval and waste feed delivery operations.

Existing TWRS FSAR criticality controls could be applicable to the waste retrieval and waste feed delivery operations with little alteration other than modification of the administrative TSRs to identify the waste retrieval and waste feed delivery processes and components subject to criticality control. However, as noted in the following criticality safety evaluations discussions, the submittal should provide, at a minimum, evidence of a rigorous and detailed verification that the waste retrieval and waste feed delivery operations fall within the envelope considered by the existing TWRS FSAR analysis.

Thus, the Contractor has the option of demonstrating to the reviewer that the information on the analyzing criticality hazards and preventing criticality, as described in the approved TWRS FSAR, is adequate to support the evaluation and/or control of inadvertent criticalities for waste retrieval and waste feed delivery. The demonstration must clearly present the basis for concluding that the existing TWRS FSAR information is applicable to waste retrieval and waste feed delivery. If so demonstrated, no other information is required in the FSAR amendment. However, at a minimum, the submittal is expected to discuss the changes in waste composition that are associated with waste retrieval and waste feed delivery and that might affect reactivity of the waste and the applicability of existing criticality safety TSRs to waste retrieval and waste feed delivery operations.

The submittal chapter on preventing inadvertent criticality is acceptable if it supports the hazard 
and accident analysis (Chapter 3 in this Guide) and if the following criteria are met: ${ }^{5}$

1. The Contractor identifies the design codes, standards, regulations, and DOE Orders required to establish the criticality safety basis for waste retrieval and waste feed delivery activities as they relate to criticality safety.

2. The Contractor provides the results of the criticality hazard and accident analysis. The submittal contains criticality hazard and accident analyses in either the hazard and accident analysis (Chapter 3 ) or in the prevention of inadvertent criticality (Chapter 6) portions of the FSAR amendment, or possibly references to supporting Criticality Safety Evaluation Reports. $^{6}$ Whether referenced or incorporated, the criticality hazard and accident analysis for waste retrieval and waste feed delivery includes the following elements:

a. Information is included on the fissile material inventory available in the waste during waste retrieval and waste feed delivery, including the location of potential criticality hazards (e.g., description and drawing), fissile material form (including isotopic content, concentration, and densities), and maximum quantities involved. The information is sufficiently detailed to support the hazard evaluation, accident analysis, and criticality control determination.

[Note: Existing information in the TWRS FSAR is expected to provide a baseline of information on existing fissile isotope contents. However, the submittal should contain supplemental information that accounts for new tank characterization data and worst-case inventories in waste retrieval mixing or holding tanks based on the waste retrieval scenarios within the amendment's scope.]

b. Criticality hazards are identified and evaluated for each point of waste retrieval and waste feed delivery operations where significant quantities of fissile material may accumulate. This qualitative analysis is based on estimates of fissile material inventory, composition, and concentration at the accumulation point (e.g., process tank).

- General examples of variations in process conditions should be considered in identifying criticality hazards associated with waste retrieval and waste feed delivery, including the following:

- Changes in intended shape or dimensions resulting from bulging, corrosion, or bursting of a container or from failures to meet fabrication specifications.

- Possible changes in the mass of fissile material at a location because of operational errors, improper labeling, equipment failure, or failure of analytical techniques.

- Changes in the moderator to fissile material ratio due to 1) inaccuracies in

\footnotetext{
'Altematively, the Contractor may demonstrate that information on preventing inadvertent criticality, as provided in the approved TWRS FSAR, is essentially unchanged with respect to the evaluation and control of inadvertent criticality for waste retrieval and waste feed delivery operations and, therefore, no changes are required.

- Guidelines for Preparing Criticality Safety Evaluations at Department of Energy Non-Reactor Facilities, DOESTD-3007-93, 1993.
} 
instruments or chemical analyses, 2) flooding, spraying, etc., 3) evaporation or displacement of the moderator, 4) precipitation of fissile material from solutions, and 5) dilution of concentrated solutions with additional moderator.

- Changes in the neutron population fraction lost by absorption due to 1) losing solid absorber by corrosion or leaching, 2) losing moderator, 3) redistributing fissile material and absorber material by precipitation of one of the materials from solution, 4) failing to add the intended amount or distribution of absorber material, and 5) miscalculating the correct amounts or concentrations.

- Changes in neutron reflection due to 1 ) adding or changing reflector material (e.g., water or personnel), 2) changing the reflector composition by causing loss of absorber (e.g., from corrosion of an outer casing of absorber), and 3) changing reflection barrier locations.

- Changes in neutron interaction between vessels containing fissile material and reflectors due to 1) introducing additional vessels or reflectors (e.g., personnel) and 2) improperly placing vessels.

- Increasing the density of fissile material.

- Specific examples of process variations relevant to waste retrieval and feed operations should be considered in the submittal, including the following:

- The concentration of fissile material in sludge due to water washing.

- Preferential removal of neutron absorbers from solids containing fissile material due to water washing.

- The concentration of fissile material due to waste dry-out from overheating or evaporation in holding tanks.

- Concentration of fissile material due to chemical dissolution followed by precipitation of fissile material bearing compounds.

- Preferential separation of fissile material compounds from nonfissile solids due to settling, mixing, or pumping activities.

[Note: The existing TWRS FSAR criticality safety basis relies on analysis of hazards that result in high concentrations of fissile material (without relying on tank geometry as a control) and/or hazards that result in low ratios of neutron absorbers to fissile material. If the existing TWRS FSAR hazard analysis is taken as the point of departure, the submittal should identify, at a minimum, any points in the waste retrieval and waste feed delivery process that fall outside the envelope of fissile material concentration or neutron absorber ratios analyzed in the existing TWRS FSAR. For example, equivalent plutonium concentrations up to $0.7 \mathrm{~g} /$ found in the tank characterization database have been cited as an upper limit for fissile material concentrations in the TWRS FSAR. The Contractor should evaluate whether any 
new characterization data are available that may challenge this assumption or whether water washing activities in the waste retrieval or waste feed delivery process may change sludge plutonium concentrations more than wash activities analyzed in Appendix F of the existing TWRS FSAR.]

c. The accident analysis describes all credible accident sequences associated with waste retrieval and waste feed delivery based on the criticality hazards identified in the hazard evaluation. For this analysis, a "credible" event has a frequency greater than $1.0 \mathrm{E}$ 06/year.

d. The criticality safety evaluation demonstrates that the entire process will be subcritical under both normal and credible abnormal conditions and process designs incorporate sufficient factors of safety to require at least two unlikely, independent, and concurrent changes in process conditions before a criticality accident is possible. ${ }^{7}$

e. Based on the results of the hazard and accident analysis for waste retrieval and waste feed delivery (Chapter 3), Chapter 6 of the FSAR amendment contains evaluations of the reactivity for all normal and credible accident conditions for waste retrieval and waste feed delivery. The results of the evaluations show that all scenarios are safely subcritical or that criticality prevention controls (discussed below) are required for waste retrieval and waste feed delivery operations to ensure safely subcritical configurations.

[Note: The existing criticality safety evaluation for the TWRS FSAR may be used as a starting point for evaluating waste retrieval and waste feed delivery hazards. The existing evaluation of reactivity in the tank waste envelopes all hazardous conditions (as discussed above) by analyzing a "conservative waste model (CWM)." The CWM incorporates worst-case criticality parameters for the tank waste (e.g., worst-case absorber ratios, optimal moderation, and infinite geometry) to determine the minimum concentration of fissile material required to achieve criticality. Actual fissile material concentrations in the waste are shown to be safely below the minimum critical concentration in the CWM. The Contractor's submittal may evaluate the reactivity of hazardous conditions by explicitly showing that the existing CWM model and assumptions are valid for waste retrieval and waste feed delivery.

The following hazardous conditions were studied and compared against the CWM in the TWRS FSAR and should be reviewed for the submittal:

- Concentration of fissile material due to chemical dissolution followed by precipitation of fissile material bearing compounds. The TWRS FSAR analyses concluded that dissolution of $\mathrm{Pu}$ compounds is not credible because of the large quantities of reagents that would be required. These conclusions are expected to apply to the chemistry of waste retrieval and waste feed delivery because only water wash will be performed as part of the scope of waste retrieval and waste feed delivery.

- Preferential separation of fissile material compounds from nonfissile solids due to

7 "Guide for Nuclear Criticality Safety in the Storage of Fissile Materials," ANSVANS-8.7-1975.

${ }^{8}$ Criticality Parameters for Tank Waste Evaluation, WHC-SD-SQA-CSA-507, Rev. 0, 1996. 
settling, mixing, or pumping activities. Preferential settling models for plutonium oxide developed for the 241-C 106 sluicing project ${ }^{9}$ indicated that concentration levels of Pu cannot reach the minimum critical concentration value determined by the CWM. However, the analysis noted a large uncertainty in the model result depending on the maximum plutonium-bearing particle size. The particle separation models used data specific to the tanks involved in the 241-C 106 sluicing project. The models and input assumptions should be reviewed and revised, where appropriate, before they are applied to waste retrieval and waste feed delivery activities.

To evaluate the applicability of the CWM to waste retrieval and waste feed delivery, the submittal should determine the worst-case wash factors for waste retrieval and waste feed delivery activities. Best-basis wash factors ${ }^{10}$ for single-shell tank inventories suggest that significant fractions of certain neutron absorbing elements in the waste solids may be removed by waste retrieval and waste feed delivery activities. The upper-bound on the wash factors should be analyzed for the submittal and applied to the spectrum of elements in the waste solids determined to be significant in the CWM. If the waste solids inventories for waste retrieval and waste feed delivery do not fall within the envelope used for the CWM, a new value for the minimum critical concentration of $\mathrm{Pu}$ should be determined for use in the criticality hazard evaluations.]

f. The criticality safety analysis summary should show that simplifications made in modeling the system containing fissile material increase the value of $k_{\text {eff. }}$. This applies to simplification of the waste stream composition by 1) replacing the actual fissile material with a Pu equivalent or 2) replacing the actual moderator/absorber composition with water or some other simplified chemical composition.

3. The Contractor generally discusses the criticality safety design limits, their bases, and any design criteria used to ensure subcritical configurations under all normal, abnormal, and accident conditions (i.e., to ensure criticality limits are not exceeded). The general discussion includes the parameters used for preventing and controlling criticality, the methods for applying and validating these parameters, and the application of the double contingency principle in criticality safety.

4. The Contractor summarizes the safety design limits on engineered controls, either passive or active, and the bases placed on equipment designs or operations to ensure subcritical conditions under all normal, abnormal, and accident conditions. The summary includes the following:

a. The use of geometry, spacing, and any other engineered controls used (e.g., neutron absorbers, elimination of moderators, storage location limitations, and level detectors).

b. A description of the configuration management program as it relates to configuring the equipment used to store, handle, transport, or process fissile material, as required by DOE Order 5480.24, Sections 7.c and 7.e.

9 Criticality Safety Assessment of Tank 241-C 106 Remediation, WHC-SD-320-CSA-001, Rev. 0, July 1996.

${ }^{10}$ Status Report: Pretreatment Chemistry Evaluation-Wash and Leach Factors for Single-Shell Tank Inventory, PNNL-11290, September 1996. 
5. The Contractor summarizes administrative controls used to prevent accidental criticality, including the following:

a. A discussion of the administrative controls on nuclear material safety limits such as mass, moderators, changes in geometry configuration, and procedures for handling, storing, and transporting fissile materials.

b. A discussion of the administrative controls for reviewing and approving changes to the process or system configurations.

The following guidance applies to criterion 4 (engineered criticality controls) and criterion 5 (administrative criticality controls):

c. If, as a result of the criticality evaluations for waste retrieval and waste feed delivery, any credible scenarios are identified with $k_{\text {eff }}>.95$, controls that ensure these scenarios are safely subcritical are developed and discussed.

d. The submittal shows that any credible criticality scenarios satisfy the double contingency principle (taking credit for criticality controls, if necessary).

e. Controls specify "safety limits" for waste retrieval and waste feed delivery operations. "Safety limit" means a limit on a controlled parameter that has sufficient margin for uncertainties, abnormal events, and process variations so that high confidence exists that the system will be subcritical as intended. Margins would normally be included for both estimated and unknown uncertainties (administrative margin) in determining $\mathrm{k}_{\mathrm{eff}}$ and for uncertainties in determining or controlling the actual value of the controlled process parameter. $K_{\text {eff }}$ at the safety limit is always $<1$.

[Note: For the existing TWRS FSAR, controlled parameter safety limits are determined such that they are below the safety limit, $\mathrm{k}_{\mathrm{eff}}<.95$, including adjustments for bias and uncertainty. Uncertainty in the calculated $k_{\text {eff }}$ includes uncertainty in input parameters used in calculating $k_{\text {eff }}$ and uncertainty in the numerical methods used in the calculation. The existing TWRS FSAR requirements on controlled criticality parameter safety limits are expected to apply to the Contractor's amendment to the FSAR for waste retrieval and waste feed delivery.]

f. Where practicable, equipment design that uses passive-engineered controls is relied on rather than administrative controls. The following are techniques for criticality control, listed in the order of preference:

- Passive-engineered controls use fixed design features or devices. No human intervention is required except for maintenance and inspection.

- Active-engineered controls use active hardware to sense parameters and automatically secure the system to a safe condition. No human intervention is required.

- Augmented administrative controls rely on human judgment, training, and actions for 
implementation but use warning devices (visual or audible) that require specific human actions to occur before the process can proceed with the augmented administrative controls.

- Simple administrative controls rely solely on human judgment, training, and actions for implementation.

6. The Contractor summarizes the methods used to ensure that at least more than one unlikely, independent, and concurrent change in process conditions would be necessary before a waste retrieval or waste feed delivery criticality accident is possible (e.g., contingency or criticality safety evaluation). The summary includes the following:

a. The contingency or criticality safety evaluation identifies how the double contingency principle, as defined in DOE Order 5480.24, is being met (e.g., control of two independent process parameters or a system of multiple controls on a single parameter).

b. The submittal demonstrates that, for each credible criticality scenario, the waste retrieval and waste feed delivery design possesses double contingency (required by ANSIANS 8.1, Section 4.2.2, "Double Contingency Principle"). The waste retrieval and waste feed delivery design possesses double contingency if it incorporates sufficient factors of safety to require at least two unlikely, independent, and concurrent changes in process conditions before a criticality accident is possible.

c. The term "independent," as used in double contingency or in control failures and other events in accident sequences, means that the probability of failure of one event is the same regardless of whether the other event has occurred. Therefore, no event is a common cause of both events in question and the occurrence of either does not influence the probability of the other. Independence may not hold for two safety controls when failure of one control causes process or environmental conditions that place stress on the other control. In addition, two administrative safety procedures performed by the same individual, or by a group of individuals in close cooperation, cannot be considered independent.

d. As noted above, protection against criticality is provided by either 1) the control of two independent process parameters or 2) a system of multiple independent controls on a single process parameter. The first method is the preferred approach because of the difficulty in preventing common-mode failure when controlling only one parameter. In all cases, to possess double contingency, no single credible event or failure shall result in a criticality accident.

[Note: The existing TWRS FSAR states that double contingency is satisfied because 1) the analysis of existing tank waste has shown that fissile material concentrations and high neutron absorber ratios prevent the waste from becoming critical under normal operations, including the analyzed washing and transfer operations, and 2) administrative controls are in place to verify that fissile material concentrations and neutron absorber ratios are within the safely subcritical region. The Contractor has the option to make a case that these same contingencies apply to waste retrieval and waste feed delivery. If so, the rationale should be documented in sufficient detail in the FSAR amendment.] 
7. The Contractor describes the interfaces with existing TWRS organizations and the specific waste retrieval and waste feed delivery systems and components that are subject to existing TWRS criticality safety practices in the following areas:

a. The organizational structure that administers the criticality safety program.

b. Criticality safety plans and procedures governing operations involving fissile materials.

c. Criticality safety training.

d. The analytical approach (i.e., methods, codes, and analysis techniques) used to derive operational nuclear criticality limits.

e. The criticality safety inspection and audit programs.

f. The criticality infraction program for reporting and followup of criticality infractions.

8. The Contractor summarizes the specific training requirements for personnel associated with waste retrieval and waste feed delivery operations. The summary includes the training provided on the configuration of waste retrieval and waste feed delivery equipment used to store, handle, or transfer fissile material.

9. The Contractor summarizes the criticality alarm system and detection systems used to mitigate exposures for a criticality event, including the following:

a. The summary includes the methods and procedures used to determine the placement of the monitoring equipment and the selection of the equipment functions and sensitivity, if required.

b. Where criticality alarm systems are required, the following criteria should be satisfied:

- The submittal demonstrates criticality alarm system coverage for all systems and activities (e.g., retrieval, transfer, and storage) that the submittal identifies as credible nuclear criticality hazards.

- In areas requiring criticality alarm coverage, excessive radiation dose rates are reliably detected and audible alarms are signaled for conditions requiring personnel evacuation.

- Emergency plans are maintained where alarm systems are installed.

- The system is uniform throughout for the type of radiation detected, the mode of detection, the alarm signal, the system dependability, and the design criteria.

- An alarm is clearly audible in all areas that must be evacuated.

- Approved procedures are implemented for calibrating instrumentation, testing (individual detectors and the entire system), and documenting the results; and these 
procedures are embedded in the configuration management system.

- The system can detect a nuclear criticality that produces a neutron-plus-gamma absorbed dose of 20 rads in soft tissue at an unshielded distance of 2 meters within one minute (ANSI/ANS-8.7-1975, "Guide for Nuclear Criticality Safety in the Storage of Fissile Materials").

- Formal training is required for personnel to recognize the criticality alarm signal and to evacuate promptly to a safe area.

- The effects of shielding and geometry are considered in demonstrating the adequacy of the alarms to detect a nuclear criticality.

[Note: The existing TWRS FSAR states that criticality alarm systems are not needed because waste stored in the tanks or discharged to tanks during transfers are subject to the administrative controls that are described in criterion 5 above and that ensure that all credible normal and abnormal conditions are safely subcritical. If the submittal applies the same argument to waste retrieval and feed delivery, the continued validity of the argument must be adequately demonstrated in the submittal.]

If the Contractor chooses to use existing TWRS FSAR information on preventing criticality for waste retrieval and waste feed delivery activities, the Contractor should ensure that the information satisfies the relevant acceptance criteria listed above and should justify the applicability of the existing program to waste retrieval and waste feed delivery.

\subsection{EVALUATION FINDINGS}

The reviewer will prepare material for an SER, stating whether the Contractor has provided sufficient information describing criticality hazards related to waste retrieval and waste feed delivery and whether potential criticality accidents are prevented. The report should include a summary of what was reviewed and why the reviewer finds the material acceptable. For example, the reviewer can document the review as follows:

The chapter on preventing inadvertent criticality has been reviewed against the acceptance criteria in Section 6.3.3 in this Guide and has been found to be acceptable. The Contractor has analyzed credible criticality scenarios and shown that, with the criticality controls applied, all scenarios are safely subcritical and satisfy the double contingency principle (or has justified the adequacy of the existing TWRS FSAR information).

Any exceptions should be noted and stated in a way to provide the Contractor with a clear understanding of the revisions necessary for approval. The reviewer may recommend that the submittal be conditionally approved with provisions for the Contractor to submit additional information within a specified timeframe. 


\subsection{RADIATION PROTECTION}

\subsection{PURPOSE OF REVIEW}

The purpose of this review is to determine whether the Contractor's TWRS FSAR amendment submittal adequately describes the radiation protection program and requirements necessary to address the radiological hazards associated with waste retrieval and waste feed delivery.

\subsection{AREAS OF REVIEW}

This chapter of the FSAR describes the radiation protection program for waste retrieval and waste feed delivery. The FSAR amendment for waste retrieval and waste feed delivery is not expected to result in any substantive revisions to this chapter of the FSAR. As such, existing FSAR information on the radiation protection program and organization, as low as reasonably achievable (ALARA) policy and program, radiological protection training, radiation exposure control (including administrative limits, radiological practices, dosimetry, respiratory protection, radiological monitoring, radiological protection instrumentation, radiological protection record keeping, and occupational radiation exposures) may be adequate to address the radiological hazards associated with waste retrieval and waste feed delivery operations. However, a recent amendment to 10 CFR $835^{1}$ is expected to result in editorial revisions to this chapter. The Contractor should justify the applicability of the existing radiation protection program for waste retrieval and waste feed delivery.

As identified in DOE Order $5480.23^{2}$ and DOE-STD-3009-94, ${ }^{3}$ radiation protection applicable to waste retrieval and waste feed delivery should include the following review areas:

1. The design codes, standards, regulations, and DOE Orders required to establish the safety basis of the waste retrieval and waste feed delivery activities should be identified. (Only radiation protection requirements that are pertinent to the safety analysis for waste retrieval and waste feed delivery should be listed.)

2. Changes to the radiation protection program resulting from the 10 CFR 835 amendment should be addressed.

Existing supporting documentation should be referenced. Brief abstracts of referenced documentation should be included with enough salient facts to provide an understanding of the referenced documentation and its relation to this chapter. On request, complete references can be provided to the regulatory entity.

\footnotetext{
'November 4, 1998, Federal Register publication with an effective date of December 4, 1998.

${ }^{2}$ Nuclear Safety Analysis Reports, DOE Order 5480.23, Change 1, March 1994.

${ }^{3}$ Preparation Guide for U.S. Department of Energy Nonreactor Nuclear Facility Safety Analysis Reports, Chapter 7, "Radiation Protection," DOE-STD-3009-94, July 1994.
} 


\subsection{ACCEPTANCE CRITERIA}

\subsubsection{Acceptability Review}

A one-week acceptability review will be performed to determine whether the submittal on radiation protection contains sufficient information to evaluate it against the regulatory acceptance criteria in Section 1.3.3 below. If significant deficiencies are identified in the submittal, the Contractor will be requested to submit additional information before the start of the detailed review of the FSAR amendment.

\subsubsection{Regulatory Requirements}

The review will confirm that the FSAR amendment satisfies the requirements of DOE Order 5480.23, paragraph 8.b.(3)(i), as amplified in Attachment 1, paragraphs 4.f.(3)(d)9 and 4.f.(3)(d)1 1a, of the Order (Topic 9). The amendment should also include or reference information, if applicable, that will partially satisfy the requirements of DOE Order 5480.23 , paragraphs $8 . b .(3)(b),(f)$, and $(u)$, relative to radiation protection.

To facilitate the review, the submittal's format should follow DOE-STD-3009-94, Preparation Guide for U.S. Department of Energy Nonreactor Nuclear Facility Safety Analysis Reports.

Specific regulations and DOE Orders that apply to radiation protection include the following:

- 10 CFR 835, “Occupational Radiation Protection." Final Rule, November 6, 1998.

- 29 CFR 1910, "Occupational Safety and Health Standards," 1998 edition.

- 40 CFR 61, "National Emission Standards for Hazardous Air Pollutants," as amended by 59 FR 36301, July 15, 1994.

- DOE/EH-0256T, Radiological Control Manual, 1994.

- DOE Order 5400.1, General Environmental Protection Program, Change 1, 1990.

- DOE Order 5400.5, Radiation Protection of the Public and the Environment, Change 2, 1993.

- DOE N 5400.9 (as extended), Sealed Radiation Source Accountability, 1991.

- DOE Order 5480.20A, Personnel Selection, Qualification, Training, and Staffing Requirements for DOE Nuclear Facilities, Change O, 1994.

- DOE Order 5480.4, Environmental Protection, Safety, and Health Protection Standards, Change 4, 1993. 


\subsubsection{Regulatory Acceptance Criteria}

The FSAR amendment for radiation protection is acceptable if the following criteria are met:

1. The Contractor identifies the design codes, standards, regulations, and DOE Orders required to establish the safety basis of the waste retrieval and waste feed delivery activities as they relate to radiation protection.

2. The submittal reflects the incorporation of the editorial changes resulting from the 10 CFR 835 amendment.

3. As noted in Section 7.2 in this Guide, existing radiological protection information in the TWRS FSAR does not need to be revised to address the radiological hazards associated with waste retrieval and waste feed delivery operations. The FSAR amendment need only reference the existing FSAR information and summarize justification of its adequacy for ensuring safe waste retrieval and waste feed delivery operations. The justification should be adequate to allow the reviewer to reach the same conclusion.

\subsection{EVALUATION FINDINGS}

The reviewer will prepare material for an SER, stating whether the Contractor has provided a revised radiation protection chapter that reflects the 10 CFR 835 amendment. The report should include a summary of what was reviewed and why the reviewer finds the material acceptable. For example, the reviewer can document the review as follows:

The chapter on radiation protection has been reviewed against the amendment to $10 \mathrm{CFR}$ 835 and has been found to be acceptable. The Contractor has adequately revised the radiation protection program and requirements associated with the amendment to $10 \mathrm{CFR}$ 835 or has justified the adequacy of existing TWRS FSAR information, and the information supports safe waste retrieval and waste feed delivery operations.

Any exceptions should be noted and stated in a way to provide the Contractor with a clear understanding of the revisions necessary for approval. The reviewer may recommend that the submittal be conditionally approved with provisions for the Contractor to submit additional information within a specified timeframe. 


\subsection{HAZARDOUS MATERIAL PROTECTION}

\subsection{PURPOSE OF REVIEW}

The purpose of this review is to determine whether the Contractor's TWRS FSAR amendment submittal adequately describes the hazardous material protection program (other than radiological hazards) associated with waste retrieval and waste feed delivery.

\subsection{AREAS OF REVIEW}

This chapter of the FSAR describes the attributes of the hazardous material protection program necessary for safe waste retrieval and waste feed delivery operations and for worker protection. The hazardous material protection program ensures that waste retrieval and waste feed delivery operations are performed within the occupational health and safety, toxicological, and industrial hygiene requirements for hazardous materials protection. It also defines and describes the programs and procedures necessary to reduce hazardous materials exposures to ALARA and the spread of contamination from hazardous materials, to train employees regarding hazardous materials, to provide respiratory protection, and to implement an occupational medicine program. The information is presented at a level of detail appropriate to summarize the programs based on the type and magnitude of hazards identified in the hazard analysis.

The FSAR amendment for waste retrieval and waste feed delivery is not expected to result in any substantive revisions to this chapter of the FSAR. As such, the existing hazardous material protection program, as described in the TWRS FSAR, would be extended to cover waste retrieval and waste feed delivery. Therefore, the Contractor should focus on justifying the applicability of the existing hazardous material protection program and on identifying and justifying any differences that result from waste retrieval and waste feed delivery operations.

As identified in DOE Order $5480.23^{1}$ and DOE-STD-3009-94, ${ }^{2}$ the hazardous material protection program for waste retrieval and waste feed delivery should include the following review areas: ${ }^{3}$

1. Codes and Standards - The design codes, standards, regulations, and DOE Orders required to establish the safety basis of the waste retrieval and waste feed delivery activities should be identified. (Only hazardous material protection requirements that are pertinent to the safety analysis for waste retrieval and waste feed delivery should be listed.)

2. Hazardous Material Protection and Organization - No changes to the existing TWRS FSAR are expected.

3. ALARA Policy and Program (for hazardous materials) - No changes to the existing TWRS FSAR are expected.

\footnotetext{
'Nuclear Safety Analysis Reports, DOE Order 5480.23, Change 1, March 1994.

${ }^{2}$ Preparation Guide for U.S. Department of Energy Nonreactor Nuclear Facility Safety Analysis Reports, Chapter 8, "Hazardous Material Protection," DOE-STD-3009-94, July 1994.

${ }^{3}$ Only areas expected to change as a result of waste retrieval and waste feed delivery need to be addressed. 
4. Hazardous Material Training - The plans and procedures should be described for general training of 1) waste retrieval and waste feed delivery employees; 2) workers, supervisors, and managers involved in hazardous material activities; and 3) industrial hygiene technicians involved in hazardous material activities.

5. Hazardous Material Exposure Control - Plans and procedures should be described for controlling 1) occupational exposures to hazardous materials, 2) spread of hazardous material contamination, and 3) respiratory protection for waste retrieval and waste feed delivery workers. No changes to the existing TWRS FSAR in the description of the occupational medical program are expected relative to hazardous material protection [including physical examinations, medical evaluations, medical surveillance (including bioassay), and medical record keeping].

6. Hazardous Material Monitoring - The hazardous material sampling and monitoring program that is conducted internal and external to waste retrieval and waste feed delivery operations should be described.

7. Hazardous Material Protection Instrumentation - The plans and procedures governing instrumentation for hazardous material protection for waste retrieval and waste feed delivery should be described.

8. Hazardous Material Protection Record Keeping - No changes to the existing TWRS FSAR are expected.

9. Hazard Communication Program - No changes to the existing TWRS FSAR are expected.

10. Occupational Chemical Exposures - The predicted annual exposure to waste retrieval and waste feed delivery workers from hazardous material sources should be summarized. Measured or estimated (calculated)-or both-worker exposures to the maximum allowable limits should be compared.

Existing supporting documentation should be referenced. Brief references of documentation should be included with enough salient facts to provide an understanding of the referenced documentation and its relation to this chapter. On request, complete references can be provided to the regulatory entity.

\subsection{ACCEPTANCE CRITERIA}

\subsubsection{Acceptability Review}

A one-week acceptability review will be performed to determine whether the hazardous material program descriptions contain sufficient information to evaluate them against the regulatory acceptance criteria in Section 8.3.3 below. Where appropriate, the Contractor may demonstrate that the information in the TWRS FSAR pertaining to hazardous material protection is adequate to support waste retrieval and waste feed delivery operations. If significant deficiencies are identified in the submittal, the Contractor will be requested to submit additional information before the start of the detailed review of the FSAR amendment. 


\subsubsection{Regulatory Requirements}

The regulatory requirements for hazardous material protection are contained in DOE Order 440.1A , Worker Protection Management for DOE Federal and Contractor Employees."

The review will confirm that the FSAR amendment satisfies the requirements of DOE Order 5480.23, paragraph 8.b.(3)(j), as amplified in Attachment 1 of the Order, paragraphs 4.f.(3)(d)10 and 4.f.(3)(d)11a (Topic 10). The submittal should also include information, if applicable, that will partially satisfy the requirements of DOE Order 5480.23 paragraphs $8 . b .(3)(b)$, (f), and (u), as they relate to hazardous material protection.

To facilitate the review, the submittal's format should follow DOE-STD-3009-94, Preparation Guide for U.S. Department of Energy Nonreactor Nuclear Facility Safety Analysis Reports.

Specific regulations and DOE Orders that apply to the waste retrieval and waste feed delivery hazardous material protection and that implement the OSHA regulations identified above include the following:

- DOE O 231.1, Environmental, Safety, and Health Reporting, Change 2, 1996.

- DOE O 440.1A, Worker Protection Management for DOE Federal and Contractor Employees, 1998.

- DOE Order 3790.1B, Federal Employee Occupational Safety and Health Program, 1993.

- DOE Order 5480.4, Environmental Protection, Safety, and Health Protections Standards, Change 4, 1993.

- DOE Order 5480.8A, Contractor Occupational Medical Program, Change 3, 1992.

- DOE Order 5480.9A, Construction Project Safety and Health Management, 1994.

- DOE Order 5484.1, Environmental Protection, Safety, and Health Protection Information Reporting Requirements, 1990.

\subsubsection{Regulatory Acceptance Criteria}

When reviewing the FSAR amendment submittal, the reviewer should be cognizant of the following SSCs that could potentially be introducing new hazardous materials (such as lubricants, sealing fluids, waste treatment chemicals, water treatment chemicals, reagents, inerting or purge gases):

- Agitation devices installed in waste storage tanks [mixer/slurry pumps (both submersible and those with the motor installed external to the tanks), sluicers, and transfer pumps].

\footnotetext{
4 Worker Protection Management for DOE and Federal and Contractor Employees, DOE Order 440.1A, March
} 1998. 
- Waste storage tank ventilation systems [blowers, chillers, condensers, demisters, filters (including HEPAs and HEGAs), power sources, and monitoring instrumentation].

- Chemical addition/dilution systems.

The Contractor's information must demonstrate that a hazardous material protection program is in place to safely manage the waste retrieval and waste feed delivery operations without impacting the health and safety of the workers, the public, and the environment.

The hazardous material protection submittal is acceptable if it is presented at a level of detail to show that waste retrieval and waste feed delivery operations can be conducted safely and that workers are protected and if the following criteria are met:s

1. The Contractor identifies the design codes, standards, regulations, and DOE Orders required to establish the safety basis of the waste retrieval and waste feed delivery activities as they relate to hazardous material protection.

2. The Contractor describes the plans and procedures for general training of 1) waste retrieval and waste feed delivery employees; 2) workers, supervisors, and managers who are involved in hazardous materials protection; and 3) industrial hygiene technicians involved in hazardous materials protection. The plans and procedures describe the frequency of the training and requirements for initial and refresher training. The plans and procedures also meet the regulatory training requirements from the Occupational Safety and Health Administration (OSHA) on hazardous materials operations and training in the DOE Orders listed in Section 8.3.2 in this Guide.

3. The Contractor describes the plans and procedures for 1) controlling the occupational exposure of waste retrieval and waste feed delivery personnel to hazardous materials, 2) controlling the spread of hazardous material contamination due to waste retrieval and waste feed operations, and 3) using respiratory protection. This description includes the following:

a. The process used for identifying and evaluating hazardous material properties (e.g., toxicity, flammability, and reactivity) for waste retrieval and waste feed delivery operations. The summary also describes the industrial hygiene programs (including personnel decontamination procedures), the process used to identify and mitigate new or unknown hazards, the waste retrieval and waste feed delivery hazard analysis process, and hazard elimination and control measures.

b. The waste retrieval and waste feed delivery administrative control levels and exposure limits applied to hazardous materials.

c. The types of respiratory protection equipment and their usage in normal, abnormal, and accident conditions.

\footnotetext{
${ }^{5}$ Where applicable, the Contractor may demonstrate that the information on hazardous material protection, as provided in the approved TWRS FSAR, is complete and encompasses waste retrieval and waste feed delivery and, therefore, no changes are required.
} 
The discussion specifically addresses each chemical of concern for waste retrieval and waste feed delivery operations.

4. The Contractor summarizes the hazardous material monitoring and sampling program conducted internal and external to waste retrieval and waste feed delivery facilities. The summary addresses the following:

a. Overall monitoring to prevent the spread of hazardous materials.

b. Operational monitoring of waste retrieval and waste feed delivery workers.

c. Monitoring and sampling for material released by airborne and other pathways (e.g., water and soil).

d. Programs for the continuing collection of relevant meteorological data.

e. Records and reports generated in the waste retrieval and waste feed delivery monitoring program.

5. The Contractor summarizes the plans and procedures for controlling hazardous material protection instrumentation, including the following:

a. Instruments, whether fixed, portable, or laboratory use, for hazardous material and contamination surveys; sampling; area hazardous material monitoring; and personnel monitoring during normal operations and accidents.

b. Selection and placement criteria for technical equipment and instrumentation, including types of detectors and monitors and their quantity, sensitivity, and range.

c. Hazards for which instrumentation is not available.

6. The Contractor summarizes predicted waste retrieval and waste feed delivery worker annual exposures from hazardous materials (with basis), including the following:

a. Estimation of the projected (calculated) annual exposures from normal waste retrieval and waste feed delivery operations based on expected average and maximum operating conditions, inventories, operating cycles, personnel occupancy factors, etc.

b. The methods and assumptions used in estimating occupational exposures (it is acceptable to estimate hazardous material exposures based on historical data from similar facilities).

c. A comparison of the estimated worker exposures with the maximum allowable limits. This should include a discussion of any discrepancies among the estimated, measured, or allowed values.

If the Contractor chooses to use existing TWRS FSAR information on hazardous material protection for waste retrieval and waste feed delivery activities, the Contractor should ensure that the information satisfies the relevant acceptance criteria listed above and should justify the 
applicability of the existing program to waste retrieval and waste feed delivery.

\subsection{EVALUATION FINDINGS}

The reviewer will prepare material for an SER, stating whether the Contractor has provided sufficient information describing the hazardous material protection program associated with waste retrieval and waste feed delivery and whether the information is sufficiently detailed to determine that waste retrieval and waste feed delivery operations will be conducted safely and workers will be protected. The report should include a summary of what was reviewed and why the reviewer finds the material acceptable. For example, the reviewer can document the review as follows:

The chapter on hazardous material protection has been reviewed against the acceptance criteria in Section 8.3 in this Guide and has been found to be acceptable. The Contractor has updated and adequately summarized the programs, plans, and procedures required for hazardous material protection for waste retrieval and waste feed delivery. Based on the information provided, it is concluded that waste retrieval and waste feed delivery operations involving hazardous materials can be safely conducted and workers are adequately protected.

Any exceptions should be noted and stated in a way to provide the Contractor with a clear understanding of the revisions necessary for approval. The reviewer may recommend that the submittal be conditionally approved with provisions for the Contractor to submit additional information within a specified timeframe. 


\subsection{RADIOACTIVE AND HAZARDOUS WASTE MANAGEMENT}

\subsection{PURPOSE OF REVIEW}

The purpose of this review is to determine whether the Contractor's TWRS FSAR amendment submittal adequately describes the radioactive and hazardous waste management program for waste retrieval and waste feed delivery operations and any impacts on nearby facilities.

\subsection{AREAS OF REVIEW}

This chapter of the FSAR describes the provisions for radioactive and hazardous waste management for waste retrieval and waste feed delivery. As identified in DOE Order 5480.23' and DOE-STD-3009-942, the radioactive and hazardous waste management program for waste retrieval and waste feed delivery should include the following review areas: ${ }^{3}$

1. Codes and Standards - The design codes, standards, regulations, and DOE Orders required to establish the safety basis for waste retrieval and waste feed delivery should be identified. (Only requirements that concern radioactive and hazardous waste management and that are pertinent to the safety analysis for waste retrieval and waste feed delivery should be listed.)

2. Radioactive and Hazardous Waste Management Program and Organization - No changes to the existing TWRS FSAR are expected.

3. Radioactive and Hazardous Waste Streams and Sources - The solid, liquid, and gaseous waste streams and sources associated with waste retrieval and waste feed delivery, including estimated inventories, should be summarized. In addition, the waste handling processes and/or waste treatment systems supporting waste retrieval and waste feed delivery operations should be discussed. Radioactive, hazardous, and mixed waste streams should be addressed.

4. Waste Management Process - No changes to the existing TWRS FSAR are expected.

5. Waste Sources and Characteristics - How and where the waste is generated (i.e., waste streams) and how the waste enters the appropriate waste handling or treatment system should be summarized. For each waste type (i.e., radioactive, mixed, or hazardous), the characteristics, composition, and waste form (i.e., gaseous, liquid, or solid) of the effluent discharges and emission limits should be discussed.

6. Waste Handling or Treatment Systems - No changes to the existing TWRS FSAR are expected.

Existing supporting documentation should be referenced. Brief references of documentation

\footnotetext{
${ }^{1}$ Nuclear Safety Analysis Reports, DOE Order 5480.23, Change 1, March 1994.

${ }^{2}$ Preparation Guide for U.S. Department of Energy Nonreactor Nuclear Facility Safety Analysis Reports, Chapter 9 , "Radioactive and Hazardous Waste Management," DOE-STD-3009-94, July 1994.

${ }^{3}$ Only areas expected to change as a result of waste retrieval and waste feed delivery need to be addressed.
} 
should be included with enough salient facts to provide an understanding of the referenced documentation and its relation to this chapter. On request, complete references can be provided to the regulatory entity.

\subsection{ACCEPTANCE CRITERIA}

\subsubsection{Acceptability Review}

A one-week acceptability review will be performed to determine whether the submittal on radioactive and hazardous waste management contains sufficient information to evaluate it against the regulatory acceptance criteria in Section 9.3 .3 below. Where applicable, the Contractor may demonstrate that information in the TWRS FSAR pertaining to radioactive and hazardous waste management program is directly applicable to waste retrieval and waste feed delivery. If there are any changes to the existing program, the Contractor should identify and justify the changes.

The information in this section is used to ensure that the radioactive and hazardous waste management program adequately addresses the evaluation, treatment, control, and disposal of all radioactive and hazardous constituents in waste streams associated with waste retrieval and waste feed delivery. The waste management program and practices support the safety analyses and protect the assumptions made in the hazards analysis. If significant deficiencies are identified in the submittal, the Contractor will be requested to submit additional information before the start of the detailed review of the FSAR amendment.

\subsubsection{Regulatory Requirements}

The review will confirm that the FSAR satisfies the requirements of DOE 5480.23, paragraph(s) 8.b.(3)(g), as amplified in Attachment 1, paragraph(s) 4.f.(3)(d)Z, of the Order (Topic 7). The submittal should also include information, if applicable, that will partially satisfy the requirements of DOE Order 5480.23, paragraphs 8.b.(3)(b), (f), and (u), as they relate to radioactive and hazardous waste management.

To facilitate the review, the submittal's format should follow DOE-STD-3009-94, Preparation Guide for U.S. Department of Energy Nonreactor Nuclear Facility Safety Analysis Reports.

Specific regulations and DOE Orders that apply to the waste retrieval and waste feed delivery radioactive and hazardous waste management program include the following:

- 40 CFR 61, "National Emissions Standards for Hazardous Air Pollutants," as amended by 59 FR 36301, July 15, 1994.

- 40 CFR 262, "Standards Applicable to Generators of Hazardous Waste," as amended by 58 FR 34370, June 25, 1993.

- 40 CFR 265, "Interim Status Standards for the Treatment, Storage, and Disposal of Hazardous Waste," as amended by 59 FR 48041, September 19, 1994. 
- 40 CFR 268, "EPA Regulations on Land Disposal Restrictions," as amended by 59 FR 48041, September 19, 1994.

- DOE Order 5400.1, General Environmental Protection Program, Change 1, 1990.

- DOE Order 5400.5, Radiation Protection of the Public and the Environment, Change 2, 1993.

- WAC 173-303, "Dangerous Waste Regulations," Washington Administrative Code, 1995.

\subsubsection{Regulatory Acceptance Criteria}

The Contractor's information must demonstrate that a program is in place to safely manage the radioactive and hazardous wastes generated in waste retrieval and waste feed delivery operations without impacting the health and safety of the workers, the public, and the environment.

The radioactive and hazardous waste management submittal is acceptable if the following criteria are met: ${ }^{4}$

1. The Contractor provides the design criteria, standards, regulations, and DOE Orders that are required to establish the safety basis for waste retrieval and waste feed delivery as they relate to radioactive and hazardous waste management.

2. The Contractor describes any changes to the radioactive and hazardous waste management program and organization (i.e., the organizational structure; and the plans, procedures, and training that govern waste management activities) necessary to address waste retrieval and waste feed delivery operations, including the following discussions:

a. The overall philosophy, objectives, and the general process for handling the radioactive and hazardous waste forms associated with waste retrieval and waste feed delivery.

b. The administrative and operational controls important to effectively manage the different waste forms.

c. The waste minimization program applicable to waste retrieval and waste feed delivery.

d. Information in sufficient detail to support the determination of adequate protection of the public, workers, and the environment and the data needs of other FSAR sections.

3. The Contractor summarizes the solid, liquid, and gaseous waste streams, sources, and inventories associated with waste retrieval and waste feed delivery operations, including the following:

a. The chemical forms and characteristics, physical characteristics, and radiological or

\footnotetext{
${ }^{4}$ Where applicable, the Contractor may demonstrate that the information on radioactive and hazardous waste management, as provided in the approved TWRS FSAR, is complete and encompasses waste retrieval and waste feed delivery and, therefore, no changes are required.
} 
toxic/radiological composition, as appropriate.

b. The waste handling processes and/or waste treatment systems supporting waste retrieval and waste feed delivery activities.

c. To the extent that the existing RPP radioactive and hazardous waste management practices are used, a description and justification of the applicability of these practices to waste retrieval and waste feed delivery.

d. Engineering drawings to indicate flow paths and to show the locations of equipment and instrumentation.

e. Presentation of information in sufficient detail to support the determination of adequate protection of the public, workers, and the environment and to support the data needs of other SAR sections.

4. The Contractor summarizes how and where waste associated with waste retrieval and waste feed delivery operations are generated and how the waste enters the appropriate waste handling/treatment system, including the following:

a. The effluent discharges, emission limits, and permitting for each waste type (i.e., radioactive, mixed, or hazardous) discussed by characteristics, composition, and waste form (i.e., gaseous, liquid, or solid).

b. The operating principles, functions, and performance objectives of waste-handling equipment and systems.

If the Contractor chooses to use existing TWRS FSAR information on radioactive and hazardous waste management for waste retrieval and waste feed delivery activities, the Contractor should ensure that the information satisfies the relevant acceptance criteria listed above and should justify the applicability of the existing program to waste retrieval and waste feed delivery.

\subsection{EVALUATION FINDINGS}

The reviewer will prepare material for an SER, stating whether the Contractor has provided sufficient information describing radioactive and hazardous waste management for waste retrieval and waste feed delivery operations and whether the information is adequate to determine that radioactive and hazardous waste can be safely managed. The report should include a summary of what was reviewed and why the reviewer finds the material acceptable. For example, the reviewer can document the review as follows:

The chapter on radioactive and hazardous waste management has been reviewed against the acceptance criteria in Section 9.3 in this Guide and has been found to be acceptable. The Contractor has updated and summarized the information on radioactive and hazardous waste management for waste retrieval and waste feed delivery or has justified the adequacy of existing TWRS FSAR information. The information supports the conclusion that radioactive and hazardous waste from waste retrieval and waste feed 
delivery operations can be safely managed.

Any exceptions should be noted and stated in a way to provide the Contractor with a clear understanding of the revisions necessary for approval. The reviewer may recommend that the submittal be conditionally approved with provisions for the Contractor to submit additional information within a specified timeframe. 


\subsection{INITIAL TESTING, IN-SERVICE SURVEILLANCE, AND MAINTENANCE}

\subsection{PURPOSE OF REVIEW}

The purpose of this review is to determine whether the Contractor's TWRS FSAR amendment submittal adequately describes the initial testing, in-service surveillance, and maintenance programs required to ensure that the safety SSCs for waste retrieval and waste feed delivery meet their performance requirements under normal and accident conditions. Safety SSCs are described in more detail in Chapter 4 of the submittal.

\subsection{AREAS OF REVIEW}

This chapter of the FSAR describes the initial testing, in-service surveillance, and maintenance aspects of waste retrieval and waste feed delivery. The initial testing, in-service surveillance, and maintenance programs are an integral part of ensuring that the safety SSCs will function as intended under all postulated operating and accident conditions.

As identified in DOE Order $5480.23^{\prime}$ and DOE-STD-3009-94, ${ }^{2}$ the initial testing, in-service surveillance, and maintenance topics for waste retrieval and waste feed delivery should include the following review areas: ${ }^{3}$

1. Codes and Standards - The design codes, standards, regulations, and DOE Orders required to establish the safety basis for waste retrieval and waste feed delivery should be identified. (Only requirements that concern initial testing, in-service surveillance, and maintenance and that are pertinent to the safety analysis for waste retrieval and waste feed delivery should be listed. Standards/Requirements Identification Documents may be referenced, as appropriate.)

2. Initial Testing Program - The initial testing program should be summarized, including 1) the initial testing program that ensures operability of a waste retrieval or waste feed delivery system prior to service, and 2) information to ensure that adequate testing activities exist to support waste retrieval and waste feed delivery safety management.

3. In-Service Surveillance Program - The in-service surveillance program.should be summarized, including 1) provisions for testing and calibration, 2) trending of surveillance test results, 3) programmatic review, and 4) training of personnel performing maintenance. No changes to the existing TWRS FSAR discussion of the control and calibration of test equipment are expected.

4. Maintenance Program - The maintenance program supporting safe waste retrieval and waste feed delivery operations should be summarized, including 1) the maintenance

\footnotetext{
' Nuclear Safety Analysis Reports, DOE Order 5480.23, Change 1, March 1994.

${ }^{2}$ Preparation Guide for U.S. Department of Energy Nonreactor Nuclear Facility Safety Analysis Reports, Chapter 10, "Initial Testing, In-Service Surveillance, and Maintenance," DOE-STD-3009-94, July 1994.

${ }^{3}$ Only areas expected to change as a result of waste retrieval and waste feed delivery need to be addressed.
} 
organization, 2) training of maintenance personnel, 3) maintenance facilities and equipment, and 4) post maintenance testing. No changes to the existing TWRS FSAR requirements for the control and calibration of measuring equipment and maintenance history and trending are expected.

The requirements identified above that are not impacted by the hazards introduced by waste retrieval and waste feed delivery operations (i.e., the existing TWRS FSAR information should be adequate) do not need to be addressed in detail within the FSAR amendment or this Guide. However, for these program elements, the FSAR amendment should demonstrate that the inservice surveillance and maintenance programs provided in the approved TWRS FSAR are adequate to ensure that safety SSCs for waste retrieval and waste feed delivery meet their performance requirements under normal and accident conditions. If variations or changes occur to the established programs, these changes should be fully described and justified.

Existing supporting documentation should be referenced. Brief references of documentation should be included with enough salient facts to provide an understanding of the referenced documentation and its relation to this chapter. On request, complete references can be provided to the regulatory entity.

\subsection{ACCEPTANCE CRITERIA}

\subsubsection{Acceptability Review}

A one-week acceptability review will be performed to determine whether the submittal on initial testing, in-service surveillance, and maintenance contains sufficient information to evaluate it against the regulatory acceptance criteria in Section 10.3 .3 below. Where applicable, the Contractor may demonstrate that information in the TWRS FSAR pertaining to initial testing, inservice surveillance, and maintenance is adequate to validate the performance requirements of safety SSCs associated with waste retrieval and waste feed delivery under normal and accident conditions.

The information in this section of the TWRS FSAR is an integral part of the overall assurance that the hazard controls identified in the hazard and accident analyses (Chapter 3 of the submittal) will satisfy their performance requirements under all normal and accident conditions. As such, they help ensure the safety of waste retrieval and waste feed delivery operations. If significant deficiencies are identified in the submittal, the Contractor will be requested to submit additional information before the start of the detailed review of the FSAR amendment.

\subsubsection{Regulatory Requirements}

The review will confirm that the FSAR satisfies the requirements of DOE Order 5480.23, paragraph 8.b.(3)(o), as amplified in Attachment 1, paragraph 4.f.(3)(d)15, of the Order (Topic 15). The submittal should also include information, if applicable, that will partially satisfy the requirements of DOE Order 5480.23 paragraphs $8 . b .(3)(b)$, (f), and (u), as they relate to initial testing, in-service surveillance, and maintenance.

To facilitate the review, the submittal's format should follow DOE-STD-3009-94, Preparation 
Guide for U.S. Department of Energy Nonreactor Nuclear Facility Safety Analysis Reports.

Specific regulations and DOE Orders that apply to initial testing, in-service surveillance, and maintenance for waste retrieval and waste feed delivery include the following:

- DOE O 425.1A, Startup and Restart of Nuclear Facilities, Section 4.d.(5), (8), (10), and (13), "Minimum Core Requirements," and Attachment 1, Section 2.d.(5), (8), (10), and (13), "Minimum Core Requirements," 1998.

- DOE O 430.1A, Life Cycle Asset Management, Attachment 2, "Contractor Requirements Document," 1998.

- DOE Order 4330.4B, Maintenance Management Program, Change 0, 1994.

- DOE Order 5480.19, Conduct of Operations Requirements for DOE Facilities, Chapter VIII, "Control of Equipment and System Status"; Chapter IX, "Lockouts and Tagouts"; and Chapter X, "Independent Verification," Change 1, 1992.

- DOE Order 5480.20A, Personnel Selection, Qualification, and Training Requirements for DOE Nuclear Facilities, Chapter I, "General Requirements," and Chapter IV, "Non-Reactor Nuclear Facility Personnel," Change 0, 1994.

- DOE-76-45/1, Occupancy/Use Readiness Manual, Revision 0, 1992.

\subsubsection{Regulatory Acceptance Criteria}

The initial testing, in-service surveillance, and maintenance submittal is acceptable if it is presented at a level of detail to show that these programs adequately support the hazard and accident analyses (Section 3 in this Guide) and ensure that safety SSCs will meet their performance requirements under all normal and accident conditions and if the following criteria are met: ${ }^{4}$

1. The Contractor identifies design codes, standards, regulations, and DOE Orders required to establish the safety basis for waste retrieval and waste feed delivery as they relate to initial testing, in-service surveillance, and maintenance.

2. The Contractor summarizes the initial testing program that ensures operability of waste retrieval and waste feed delivery SSCs prior to service. The summary shows that adequate testing will be provided to support safe waste retrieval and waste feed delivery operations. In addition, the Contractor provides the plans and provisions for initial and in-service testing, documenting the assessment of the adequacy of the provisions for tests, the scope of the tests, and the frequency and timing of tests.

\footnotetext{
"Where applicable, the Contractor may demonstrate that the information on initial testing, in-service surveillance, and maintenance programs, as described in the approved TWRS FSAR, is essentially unchanged with respect to impacting the hazard and accident analyses for waste retrieval and waste feed delivery and, therefore, no changes are required.
} 
3. The Contractor summarizes the in-service surveillance program for waste retrieval and waste feed delivery, including 1) the provisions for testing and calibration, 2) trending of in-service surveillance test results, 3) programmatic reviews, and 4) training of personnel performing in-service surveillance. These in-service surveillances help ensure the continued availability of safety SSCs for waste retrieval and waste feed delivery.

In addition, the Contractor describes the ways the surveillance test program furnishes realistic validations of the performance of safety functions under accident conditions and catalogs failure modes of safety SSCs that could be detected in planned surveillance tests. The systematic inquiry into whether limitations of the surveillance test program are acceptable or warrant changes is also described.

4. The Contractor summarizes the maintenance program that ensures the continued availability of safety SSCs and safe waste retrieval and waste feed delivery operations, including 1) the maintenance organization, 2) training of maintenance personnel, 3) maintenance facilities and equipment, and 4) post maintenance testing that supports waste retrieval and waste feed delivery. The maintenance program description provides sufficient information to demonstrate compliance with DOE Order 4330.4B. ${ }^{5}$ In addition, limitations imposed on routine maintenance and repair of safety SSCs by waste retrieval or waste feed delivery operations are documented and any compensating actions necessary to prevent limitations of the maintenance program from degrading safety are identified.

If the Contractor chooses to use existing TWRS FSAR information on the initial testing, inservice inspection, or maintenance programs for waste retrieval and waste feed delivery activities, the Contractor should ensure that the information satisfies the relevant acceptance criteria listed above and should justify the applicability of the existing programs to waste retrieval and/or waste feed delivery.

\subsection{EVALUATION FINDINGS}

The reviewer will prepare material for an SER, stating whether the Contractor has provided sufficient information describing the initial testing, in-service surveillance, and maintenance programs for waste retrieval and waste feed delivery and whether the information is sufficiently detailed to confirm support for the hazard and accident analyses, verify assumptions made in the safety analysis, and ensure that safety SSCs will satisfy their performance requirements under all necessary conditions. The report should include a summary of what was reviewed and why the reviewer finds the material acceptable. For example, the reviewer can document the review as follows:

The chapter on initial testing, in-service surveillance, and maintenance has been reviewed against the acceptance criteria in Section 10.3 in this Guide and has been found to be acceptable. The Contractor has adequately described the initial testing, in-service surveillance, and maintenance programs that support safe waste retrieval and waste feed delivery operations and that ensure that safety SSCs will satisfy their performance requirements under all necessary conditions or has justified the adequacy of existing

\footnotetext{
${ }^{3}$ Maintenance Management Program, DOE Order 4330.4B, Change 0, 1994.
} 
TWRS FSAR information. The information supports the hazard and accident analyses for waste retrieval and waste feed delivery and protects assumptions made in the safety analysis.

Any exceptions should be noted and stated in a way to provide the Contractor with a clear understanding of the revisions necessary for approval. The reviewer may recommend that the submittal be conditionally approved with provisions for the Contractor to submit additional information within a specified timeframe. 


\subsection{OPERATIONAL SAFETY}

\subsection{PURPOSE OF REVIEW}

The purpose of this review is to determine whether the Contractor's TWRS FSAR amendment submittal adequately describes the operational safety provisions needed to support waste retrieval and waste feed delivery operations.

\subsection{AREAS OF REVIEW}

This chapter of the FSAR describes the provisions for operational safety. Operational safety topics include the conduct of operations, fire protection, and operational readiness review (ORR) programs. As identified in DOE Order 5480.23' and DOE-STD-3009-94, ${ }^{2}$ the operational safety program for waste retrieval and waste feed delivery includes the following review areas: ${ }^{3}$

1. Codes and Standards - The design codes, standards, regulations, and DOE Orders required to establish the safety basis for waste retrieval and waste feed delivery should be identified. (Only operational safety requirements that are pertinent to the safety analysis for waste retrieval and waste feed delivery should be listed.)

2. Conduct of Operations Program - The following conduct of operations topics should be considered for waste retrieval and waste feed delivery: ${ }^{4} 1$ ) shift routines and operating practices, 2) Control area activities, 3) communications, 4) control of on-shift training, 5) control of equipment and system status, 6) lockouts and tagouts, 7) independent verification, 8) $\log$ keeping, 9) operations turnover, 10) operations aspects of facility chemistry and unique processes, 11) required reading, 12) timely orders to operators, 13) operator aid postings, and 14) equipment and piping labeling.

The conduct of operations program for waste retrieval and waste feed delivery is expected to be largely unchanged from the program described in the existing TWRS FSAR. For conduct of operations topics determined not to require change, the Contractor should provide the rationale for concluding that the existing program is adequate for waste retrieval and waste feed delivery operations.

3. Fire Hazards - This review area should include the following:

a. The magnitude of the fire hazards associated with waste retrieval and waste feed delivery should be summarized in terms of overall combustible and explosive loading in proximity to the hazardous materials being protected.

b. The results of assessments, such as Fire Hazard Analyses (FHAs) and facility

' Nuclear Safety Analysis Reports, DOE Order 5480.23, Change 1, March 1994.

${ }^{2}$ Preparation Guide for U.S. Department of Energy Nonreactor Nuclear Facility Safety Analysis Reports, Chapter 11, "Operational Safety," DOE-STD-3009-94, July 1994.

${ }^{3}$ Only areas expected to change as a result of waste retrieval and waste feed delivery need to be addressed.

${ }^{4}$ Conduct of Operations Requirements for DOE Facilities, DOE Order 5480.19, Change 1, 1992. 
walkdowns, performed for waste retrieval and waste feed delivery to put fire interaction with material into a proper perspective should be summarized.

4. Fire Protection Program and Organization - No changes to the existing TWRS FSAR are expected.

5. Combustible Loading Control - No changes to the existing TWRS FSAR are expected.

6. Fire Fighting Capabilities - The available fire fighting equipment, fire response procedures, basic training and personnel qualifications for fire fighters, and any special precautions taken for fire fighting in radiological or hazardous chemical environments associated with waste retrieval and waste feed delivery should be summarized.

7. Fire Fighting Readiness Assurance - No changes to the existing TWRS FSAR are expected.

8. Operational Readiness Review Program - The operational readiness review program and the expected activities to be used to demonstrate that it is safe to start waste retrieval and waste feed delivery operations should summarize the following:

a. Roles and responsibilities during preparation for the ORR.

b. The assessment plans and criteria for meeting the requirements of DOE Order 425.1.

c. Documentation and reporting requirements for the ORR.

d. Contractor/DOE interactions and responsibilities during the performance of the ORR.

Existing supporting documentation should be referenced. Brief references of documentation should be included with enough salient facts to provide an understanding of the referenced documentation and its relation to this chapter. On request, complete references can be provided to the regulatory entity.

\subsection{ACCEPTANCE CRITERIA}

\subsubsection{Acceptability Review}

A one-week acceptability review will be performed to determine whether the submittal on operational safety contains sufficient information to evaluate it against the regulatory acceptance criteria in Section 11.3.3 below. Where applicable, the Contractor may demonstrate that information in the TWRS FSAR pertaining to operational safety is adequate and encompasses waste retrieval and waste feed delivery.

The information in this section is used to ensure that the FSAR amendment adequately addresses changes to the conduct of operations, fire protection, and operational readiness review program

'Startup and Restart of Nuclear Facilities, DOE Order 425.1, Change 1, 1995. 
elements of the RPP operational safety program related to waste retrieval and waste feed delivery. The operational safety program and practices support the safety analyses and protect the assumptions made in the hazards analysis. If significant deficiencies are identified in the submittal, the Contractor will be requested to submit additional information before the start of the detailed review of the FSAR amendment.

\subsubsection{Regulatory Requirements}

The review will confirm that the FSAR satisfies the requirements of DOE 5480.23, paragraph(s) 8.b.(3)(q), as amplified in Attachment 1, paragraph(s) 4.f.(3)(d)17, of the Order (Topic 17). The submittal should also include information, if applicable, that will partially satisfy the requirements of DOE Order 5480.23 paragraphs 8.b.(3)(b), (f), and (u), as they relate to operational safety.

To facilitate the review, the submittal's format should follow DOE-STD-3009-94, Preparation Guide for U.S. Department of Energy Nonreactor Nuclear Facility Safety Analysis Reports.

Specific regulations and DOE Orders that apply to operational safety programs for waste retrieval and waste feed delivery include the following:

- 29 CFR 1910, “Occupational Safety and Health Standards," 1998 edition.

- 29 CFR 1926, "Safety and Health Regulations for Construction," 1998 edition.

- 49 CFR 172, "Hazardous Materials Table, Special Provisions, Hazardous Material Communications Requirements and Emergency Response Information Requirements," 1998 edition.

- DOE O 425.1A, Startup and Restart of Nuclear Facilities, 1998.

- DOE Order 5480.7A, Fire Protection, 1993.

- DOE Order 5480.19, Conduct of Operations Requirements for DOE Facilities, Change 1, 1992.

- DOE EV-0043, Standard on Fire Protection for Portable Structures, 1979.

- RIID 5480.7, Fire Protection, 1994.

- WAC 173-303, "Dangerous Waste Regulations," Washington Administrative Code, 1995.

\subsubsection{Regulatory Acceptance Criteria}

The Contractor's information must demonstrate that an effective operational safety program is in place to safely manage waste retrieval and waste feed delivery operations without impacting the health and safety of the workers, the public, and the environment. 
The operational safety submittal is acceptable if it contains sufficient information to show that the assumptions made in the hazards analysis (Chapter 3 ) are protected and if the following criteria are met: ${ }^{6}$

1. The Contractor identifies the regulations and DOE Orders required to establish the safety basis for waste retrieval and waste feed delivery as they relate to operational and fire safety.

2. The Contractor summarizes the conduct of operations program that contributes to the overall operational safety of waste retrieval and waste feed delivery. The summary addresses 1) shift routines and operating practices, 2) control area activities, 3) communications, 4) control of on-shift training, 5) control of equipment and system status, 6) lockouts and tagouts, 7) independent verification, 8) log keeping, 9) operations turnover, 10) operations aspects of facility chemistry and unique processes, 11) required reading, 12) timely orders to operators, 13) operator aid postings, and 14) equipment and piping labeling. The summary is sufficiently detailed to allow reviewers to determine that any assumptions made in the hazards analysis are protected. If portions of the existing RPP conduct of operations program are credited as directly applicable to waste retrieval and waste feed delivery operations, the Contractor provides adequate justification to allow the reviewer to reach the same conclusion.

3. The Contractor summarizes the magnitude of fire hazards associated with waste retrieval and waste feed delivery in terms of overall combustible and explosive loading in proximity to the hazardous materials being protected. The summary is consistent with the FHA for waste retrieval and waste feed delivery and provides sufficient information to validate any assumptions made in the hazard and accident analysis.

4. The Contractor summarizes the results of assessments, such as FHAs and facility walkdowns, performed for waste retrieval and waste feed delivery to evaluate the potential for fire interaction with hazardous materials. The summary provides sufficient information to validate any assumptions made in the safety analysis.

5. The Contractor summarizes the available fire fighting equipment, fire response procedures, basic training and personnel qualifications for fire fighters, and any special precautions taken for fire fighting in radiological or hazardous chemical environments associated with waste retrieval and waste feed delivery. The summary is consistent with the FHA for waste retrieval and waste feed delivery and provides sufficient information to validate any assumptions made in the safety analysis.

6. The Contractor summarizes the operational readiness review program and the expected activities for demonstrating that it is safe to start waste retrieval and waste feed delivery operations, including the following:

a. The roles and responsibilities during preparation for conducting the ORR for waste retrieval and waste feed delivery.

\footnotetext{
${ }^{6}$ Where applicable, the Contractor may demonstrate that the information on operational safety, as provided in the approved TWRS FSAR, is complete and encompasses waste retrieval and waste feed delivery and, therefore, no changes are required.
} 
b. Identification of the assessment plans and criteria to be prepared to meet the requirements of DOE Order 425.1.

c. Documentation and reporting requirements for the results of operational readiness assessment activities.

d. The Contractor/DOE interactions and responsibilities during the preparation, performance, and documentation of the assessment to determine the readiness to start waste retrieval and waste feed delivery operations.

The intent is for the Contractor to describe the operational readiness review process in sufficient detail to demonstrate that the waste retrieval and waste feed delivery process can be safely started and operated within the approved authorization basis (TWRS FSAR).

If the Contractor chooses to use existing TWRS FSAR information on operational safety for waste retrieval and waste feed delivery activities, the Contractor should ensure that the information satisfies the relevant acceptance criteria listed above and should justify the applicability of the existing program information to waste retrieval and waste feed delivery.

\subsection{EVALUATION FINDINGS}

The reviewer will prepare material for an SER, stating whether the Contractor has provided sufficient information describing the operational safety program and practices for waste retrieval and waste feed delivery and whether the information is sufficiently detailed to determine that the hazard and accident analysis assumptions are valid. The report should include a summary of what was reviewed and why the reviewer finds the material acceptable. For example, the reviewer can document the review as follows:

The operational safety chapter has been reviewed against the acceptance criteria in Section 11.3 in this Guide and has been found to be acceptable. The Contractor has provided sufficient information on the conduct of operations, fire protection, and operational readiness review programs to show that waste retrieval and waste feed delivery operations can be safely performed. The use and adequacy of existing TWRS FSAR operational safety information are adequately justified. The operational safety information is consistent with the FHA and validates the assumptions made in the safety analysis for waste retrieval and waste feed delivery.

Any exceptions should be noted and stated in a way to provide the Contractor with a clear understanding of the revisions necessary for approval. The reviewer may recommend that the submittal be conditionally approved with provisions for the Contractor to submit additional information within a specified time frame. 


\subsection{PROCEDURES AND TRAINING}

\subsection{PURPOSE OF REVIEW}

The purpose of this review is to determine whether the Contractor's TWRS FSAR amendment submittal adequately describes the procedures and training needed to support waste retrieval and waste feed delivery.

\subsection{AREAS OF REVIEW}

This chapter of the FSAR describes the processes by which the technical content of the procedures and training programs related to waste retrieval and waste feed delivery are developed, verified, and validated. These processes are intended to ensure that waste retrieval and waste feed delivery operations are performed by personnel who are well-qualified and competent to carry out their job responsibilities using well-written procedures and training elements kept current using feedback and continuous improvement.

As identified in DOE Order 5480.23 ' and DOE-STD-3009-94, ${ }^{2}$ procedures and training for waste retrieval and waste feed delivery operations should include the following review areas: ${ }^{3}$

1. Codes and Standards - The design codes, standards, regulations, and DOE Orders required to establish the safety basis for waste retrieval and waste feed delivery should be identified. (Only procedures and training requirements that are pertinent to the safety analysis for waste retrieval and waste feed delivery should be listed.)

2. Procedure Program - The procedures program necessary to ensure safe waste retrieval and waste feed delivery operations should be discussed. If the procedure program in the existing TWRS FSAR is relied on for the waste retrieval and waste feed delivery operations, the applicability to these activities should be discussed and justified.

3. Development of Procedures - The process by which the form and technical content of procedures for waste retrieval and waste feed delivery are developed, verified, and validated for normal, abnormal, and emergency operations, and for surveillance testing and maintenance should be summarized. The technical content of the procedures should include the accident analyses performed for waste retrieval and waste feed delivery (Chapter 3 ).

4. Maintenance of Procedures - No changes to the existing TWRS FSAR are expected.

5. Training Program - The training program necessary to ensure safe waste retrieval and waste feed delivery operations should be summarized. If the training program in the existing TWRS FSAR is relied on for the waste retrieval and waste feed delivery operations, the

\footnotetext{
${ }^{1}$ Nuclear Safety Analysis Reports, DOE Order 5480.23, Change 1, March 1994.

${ }^{2}$ Preparation Guide for U.S. Department of Energy Nonreactor Nuclear Facility Safety Analysis Reports, Chapter 12, "Procedures and Training," DOE-STD-3009-94, July 1994.

${ }^{3}$ Only areas expected to change as a result of waste retrieval and waste feed preparation need to be addressed.
} 
applicability to these activities should be discussed along with any changes to the program discussed in the current FSAR.

6. Development of Training - The process by which the technical content of training specific to waste retrieval and waste feed delivery is developed, verified, and validated should be summarized. The program's technical content should include the hazard and accident analyses performed for waste retrieval and waste feed delivery (Chapter 3 in this Guide).

7. Maintenance of Training - No changes to the existing TWRS FSAR are expected.

8. Modification of Training Materials - No changes to the existing TWRS FSAR are expected.

Existing supporting documentation should be referenced. Brief references of documentation should be included with enough salient facts to provide an understanding of the referenced documentation and its relation to this chapter. On request, complete references can be provided to the regulatory entity.

\subsection{ACCEPTANCE CRITERIA}

\subsubsection{Acceptability Review}

A one-week acceptability review will be performed to determine whether the submittal on procedures and training contains sufficient information to evaluate it against the regulatory acceptance criteria in Section 12.3 .3 below. Where applicable, the Contractor may demonstrate that information in the TWRS FSAR pertaining to procedures and training encompasses waste retrieval and waste feed delivery. The information in this section is used to demonstrate that the Contractor has procedures and training programs that support safe waste retrieval and waste feed delivery operations. If significant deficiencies are identified in the submittal, the Contractor will be requested to submit additional information before the start of the detailed review of the FSAR amendment.

\subsubsection{Regulatory Requirements}

The review will confirm that the FSAR satisfies the requirements of DOE Order 5480.23, paragraph 8.b.(3)(m), as amplified in Attachment 1, paragraph 4.f.(3)(d)13, of the Order (Topic 13), and paragraph 8.b.(3)(k), as amplified in Attachment 1, paragraph 4.f.(3)(d)11k, of the Order (Topic 11). The submittal should also include the information, if applicable, that will partially satisfy the requirements of DOE Order 5480.23, paragraphs 8.b.(3)(b), (f), and (u), as they relate to procedures and training.

To facilitate the review, the submittal's format should follow DOE-STD-3009-94, Preparation Guide for U.S. Department of Energy Nonreactor Nuclear Facility Safety Analysis Reports.

Specific regulations and DOE Orders that apply to procedures and training include the following:

- DOE Order 4330.4B, Maintenance Management Program, Change 0, 1994. 
- DOE Order 5480.19, Conduct of Operations Requirements for DOE Facilities, Change 1, 1992.

- DOE Order 5480.20A, Personnel Selection, Qualification, Training, and Staffing Requirements at DOE Reactor and Non-Reactor Facilities, Change 0, 1994.

\subsubsection{Regulatory Acceptance Criteria}

The Contractor's information must demonstrate that the procedures and training programs are in place to safely manage the waste retrieval and waste feed delivery operations without impacting the health and safety of the workers, the public, and the environment. The procedures and training submittal is acceptable if the following criteria are met: ${ }^{4}$

1. The Contractor identifies the design criteria, standards, regulations, and DOE Orders that are required to establish the safety basis for waste retrieval and waste feed delivery as they relate to procedures and training.

2. The Contractor summarizes the procedures program necessary to support safe waste retrieval and waste feed delivery. If the procedure program in the existing TWRS FSAR is used, the Contractor discusses and justifies the applicability of the procedures program to waste retrieval and waste feed delivery.

3. The Contractor summarizes the process for deriving the technical content of procedures for waste retrieval and waste feed delivery operations from the accident analyses. The summary addresses developing, verifying, and validating normal, abnormal, and emergency operation procedures, as well as those for surveillance and maintenance. If the process for deriving the technical content of procedures in the existing TWRS FSAR is used, the Contractor discusses and justifies the applicability of the procedures program to waste retrieval and waste feed delivery.

4. The Contractor summarizes the training program necessary to ensure safe waste retrieval and waste feed delivery operations. If the training program in the existing TWRS FSAR is used, the Contractor discusses and justifies the applicability of the training program to waste retrieval and waste feed delivery.

5. The Contractor summarizes the process for deriving the technical content of training related to waste retrieval and waste feed delivery operations from the accident analyses. The summary addresses how the training is developed, verified, and validated, as well as training methods and qualification requirements for activities, such as the following:

- Conduct of normal, abnormal, and emergency operations.

- On-shift and classroom training.

- Criticality safety training.

- Radiation and hazardous material protection training.

\footnotetext{
${ }^{4}$ Where applicable, the Contractor may demonstrate that the information on procedures and training, as provided in the approved TWRS FSAR, is complete and encompasses waste retrieval and waste feed delivery and, therefore, no changes are required.
} 
- Surveillance testing and maintenance training.

- Fire protection training.

- Quality assurance training.

- Emergency preparedness training.

[Note: The above activities are examples of what should be covered; other activities may be included. If training on these activities is discussed in other sections of the FSAR, the Contractor should cross-reference the other sections rather than repeat the material here. If these activities are covered in the existing TWRS FSAR, the Contractor should address the item by stating why the information in the existing FSAR is applicable to the waste retrieval and waste feed delivery activities.]

If the Contractor chooses to use existing TWRS FSAR information on procedures and training for waste retrieval and waste feed delivery activities, the Contractor should ensure that the information satisfies the relevant acceptance criteria listed above and should justify the applicability of the existing program to waste retrieval and waste feed delivery.

\subsection{EVALUATION FINDINGS}

The reviewer will prepare material for an SER, stating whether the Contractor has provided the information necessary to assess the adequacy of the procedures and training programs to ensure safe waste retrieval and waste feed delivery operations. The report should include a summary of what was reviewed and why the reviewer finds the material acceptable. For example, the reviewer can document the review as follows:

The procedures and training chapter has been reviewed against the acceptance criteria in Section 12.3 in this Guide and has been found to be acceptable. The Contractor has adequately described the processes by which the technical content of the procedures and training programs are developed, verified, and validated for waste retrieval and waste feed delivery operations or has justified the adequacy of the existing FSAR information on procedures and training. When the processes are followed, reasonable assurance exists that waste retrieval and waste feed delivery operations will be performed by personnel who are well qualified and competent to carry out their assigned responsibilities using well-written procedures.

Any exceptions should be noted and stated in a way to provide the Contractor with a clear understanding of the revisions necessary for approval. The reviewer may recommend to the approval authority that the submittal be conditionally approved with provisions for the Contractor to submit additional information within a specified timeframe. 


\subsection{HUMAN FACTORS}

\subsection{PURPOSE OF REVIEW}

The purpose of this review is to determine whether the Contractor's TWRS FSAR amendment submittal adequately demonstrates that human factors are considered in waste retrieval and waste feed delivery where humans are relied on for preventive and mitigative actions during abnormal and emergency operations.

\subsection{AREAS OF REVIEW}

This chapter of the FSAR describes the provisions for considering human factors in ensuring safety for waste retrieval and waste feed delivery. Attachment 1 of DOE Order 5480.23' states that human factors safety refers to 1 ) allocating control functions to personnel versus automatic devices; 2) staffing and qualifying operating crews; 3 ) personnel training; 4) preparing, validing, and using written procedures to guide operations, surveillance, and maintenance; and 5) designing the human-machine interface to build on strengths and protect against the susceptibility to human error in operating crews. Human factors consist of the following:

- Human factors engineering that focuses on designing facilities, systems, equipment, and tools so they are sensitive to the capabilities, limitations, and needs of humans.

- Human reliability analysis that quantifies the contribution of human error to the facility risk.

This chapter focuses exclusively on human factors engineering, its importance to safety of facilities for waste retrieval and waste feed delivery, and the design of these facilities to optimize human performance. The chapter should demonstrate that human factors are considered in waste retrieval and waste feed delivery operations where humans are relied on for preventative actions (e.g., surveillance and maintenance activities during normal operations) and for operator mitigative actions during abnormal and emergency operations. In this respect, the humanmachine interface is an integral part of facility safety. The emphasis is on the human-machine interfaces required for ensuring the safety function of safety SSCs (described in Chapter 4 of the FSAR amendment submittal) and on the provisions made for optimizing the design of those human-machine interfaces to enhance reliable human performance.

As identified in DOE Order $5480.23^{2}$ and DOE-STD-3009-94, ${ }^{3}$ human factors for waste retrieval and waste feed delivery should include the following review areas: ${ }^{4}$

1. Codes and Standards - The design codes, standards, regulations, and DOE Orders required to establish the safety basis for waste retrieval and waste feed delivery should be identified.

\footnotetext{
' Nuclear Safety Analysis Reports, DOE Order 5480.23, Attachment 1, paragraph 3.c.(1)(b), Change 1, 1994.

${ }^{2}$ Nuclear Safety Analysis Reports, DOE Order 5480.23, Change 1, March 1994.

${ }^{3}$ Preparation Guide for U.S. Department of Energy Nonreactor Nuclear Facility Safety Analysis Reports, Chapter 13, "Human Factors," DOE-STD-3009-94, July 1994.

${ }^{4}$ Only areas expected to change as a result of waste retrieval and waste feed delivery need to be addressed.
} 
(Only human factor requirements that are pertinent to the safety analysis for waste retrieval and waste feed delivery should be listed.)

2. Human Factors Process - This area should address the following:

a. The process for systematically evaluating the importance of human factors in the design, maintenance, and safe operation of waste retrieval and waste feed delivery SSCs should be summarized.

b. The process features ensuring that the importance of human-machine interfaces is considered in waste retrieval and waste feed delivery safety should be identified.

3. Identification of Human-Machine Interfaces - This area should address the following:

a. The safety SSCs requiring human-machine interfaces to function and the required human-machine interfaces that are identified in conjunction with the results of the hazard and accident analysis (Chapter 3 of the submittal) should be summarized.

b. The human-machine interfaces necessary for the surveillance and maintenance of safety SSCs during normal operations and the human-machine interfaces required for ensuring the safety function during normal, abnormal, and emergency operations should be identified.

c. Required human actions should be described so that it is clear what waste retrieval and waste feed delivery personnel are expected to do and the importance of the actions to the safety of SSCs and waste retrieval and waste feed delivery operations.

4. Optimization of Human-Machine Interfaces - This area should address the following:

a. The systematic inquiry into optimizing human-machine interfaces with safety SSCs to enhance the human performance for waste retrieval and waste feed delivery operations should be summarized.

b. Furnished instrumentation, provisions for communication, and operational aids to support timely, reliable performance for safety functions should be described.

c. The layout and design of controls and instrumentation, and provision for labeling that apply the principles of ergonomics and human engineering should be described.

d. The work environments, including physical access, need for protective clothing or breathing apparatus, noise levels, temperature, humidity, distractions, and other factors bearing on physical comfort, alertness, fitness, etc., should be identified.

e. Staffing considerations (e.g., minimum staffing levels, allocation of control functions, overtime restrictions, waste retrieval and waste feed delivery status tumover between shifts, procedures, and training) should be provided.

Existing supporting documentation should be referenced. Brief references of documentation 
should be included with enough salient facts to provide an understanding of the referenced documentation and its relation to this chapter. On request, complete references can be provided to the regulatory entity.

\subsection{ACCEPTANCE CRITERIA}

\subsubsection{Acceptability Review}

A one-week acceptability review will be performed to determine whether the description of human factors in the FSAR amendment submittal contains sufficient information to evaluate it against the regulatory acceptance criteria in Section 13.3.3 below. Where applicable, the Contractor may demonstrate that existing information on human factors in the approved TWRS FSAR is adequate and encompasses the human factors considerations for safety SSCs and operations for waste retrieval and waste feed delivery. If significant deficiencies are identified in the submittal, the Contractor will be requested to submit additional information before the start of the detailed review of the FSAR amendment.

\subsubsection{Regulatory Requirements}

The review will confirm that the FSAR satisfies the requirements of DOE Order 5480.23, paragraph 8.b.(3)(n), as amplified in Attachment 1, paragraph 4.f.(3)(d)14, of the Order (Topic 14). The FSAR amendment submittal should also include information, if applicable, that will partially satisfy the requirements of DOE Order 5480.23, paragraphs 8.b.(3)(b), (f), and (u), as they relate to human factors engineering.

To facilitate the review, the submittal's format should follow DOE-STD-3009-94, Preparation Guide for U.S. Department of Energy Nonreactor Nuclear Facility Safety Analysis Reports.

Specific regulations and DOE Orders that apply to human factors for waste retrieval and waste feed delivery include the following:

- 10 CFR 830, "Nuclear Safety Management," 1994.

- DOE O 232.1A, Occurrence Reporting and Processing of Operations Information, 1997.

- DOE Order 5480.19, Conduct of Operations Requirements for DOE Facilities, Change 1, 1990.

- DOE Order 5480.20A, Personnel Selection, Qualification, Training, and Staffing Requirements for DOE Nuclear Facilities, 1994.

\subsubsection{Regulatory Acceptance Criteria}

It should be noted that the SER for the TWRS FSAR found considerable shortcomings in

\footnotetext{
${ }^{3}$ Safety Evaluation Report for the Tank Waste Remediation System (TWRS) Final Safety Analysis Report (FSAR) and Technical Safety Requirements, TWRS-RT-SER-003, January 28, 1999.
} 
implementing a human factors program and directed the Contractor to incorporate human factors safety analysis into all FSAR analyses. Because of this shortcoming, considerable detail on acceptability criteria for human factors is provided in this section for application to waste retrieval and waste feed delivery operations.

The human factors submittal is acceptable if it adequately demonstrates that human factors were considered in designing waste retrieval and waste feed delivery SSCs where humans are relied on for preventive actions during normal operations and for mitigative actions during abnormal and emergency operations and if the following criteria are met: ${ }^{6}$

1. The Contractor provides the design codes, standards, regulations, and DOE Orders that are required to establish the safety basis for waste retrieval and waste feed delivery as they relate to human factors.

2. The Contractor summarizes the process used to systematically evaluate the importance of human factors in waste retrieval and waste feed delivery safety, including the following:

a. Discussion of the process used to ensure that human factors are appropriately considered and included in the functional requirements and technical criteria specified for designing, fabricating, installing, maintaining, modifying, and operating safety SSCs. For example, if a systems requirements analysis was performed as part of the design process for waste retrieval and waste feed delivery, the Contractor also describes the process for including human factors engineering considerations in the analysis. The Contractor also describes how human factors engineering was integrated into system development and at what points in the design process (e.g., planning, requirements analysis, system design, and system test and evaluation).

b. Selection of appropriate human factors engineering requirements. Specifications of human factors engineering requirements within the functional requirements include constraints on (or allocation of capabilities to) personnel and to personnel-equipment interactions.

c. Preference given to using automatic controls if performing a function 1) involves danger to the operator, 2) requires exceptional skill, or 3) requires tedious or repetitive work. (A function is considered to be in the exceptional skill category if, within the allotted time, the number of operator actions required or the absence of key information prevents corrective actions from being taken.)

d. Human performance was appropriately factored into developing the written procedures for operating and maintaining waste retrieval and waste feed delivery SSCs.

e. Operators are not obliged to perform complicated mental operations to determine the margin of the limit values or the deviation of process parameters from set values.

3. The Contractor summarizes the safety SSCs (from Chapter 4 of the submittal) requiring

\footnotetext{
${ }^{6}$ Where applicable, the Contractor can demonstrate that information on human factors provided in the approved TWRS FSAR is adequate and encompasses the SSCs and operations for waste retrieval and waste feed delivery and, therefore, no changes are required.
} 
human-machine interfaces to function and the required human-machine interfaces necessary to ensure safety during normal, abnormal and emergency operations, including the following:

a. The human-machine interfaces necessary for the surveillance and maintenance of safety SSCs during normal operations are identified in conjunction with results of the hazard and accident analysis documented in Chapter 3 of the FSAR amendment.

b. The inquiry into the safety significance of reliable, correct, and effective human-machine interactions, including the surveillance and maintenance of safety SSCs during normal, abnormal, and emergency operations, is systematically conducted and adequately documented.

c. Appropriate human factors analyses were performed for systems important to safety to ensure that risks to the public, personnel, and safety SSCs are acceptably reduced.

d. Vital activity tasks that the operator must perform to satisfactorily complete a safety function are systematically analyzed.

e. Effects of human error in task performance are evaluated, particularly for critical tasks and for those requiring concentrated operator attention.

f. The human actions required are identified such that the reviewer can understand what the operators are expected to do (e.g., close isolation valves) and the safety significance of their actions (e.g., ensure confinement and actuate a protective system response). For example, the electrical and/or valving controls for the Contractor's waste feed delivery system and those for the vitrification plant receiving tanks may not be interlocked. The potential for human errors causing accidents involving mistransfers or spills of waste may require very careful coordination between the Contractor's and vitrification plant operators.

4. The Contractor summarizes the systematic inquiry into optimizing the design of the humanmachine interface for SSCs for which reliable, effective human performance by the operating crew is important to safety. This should include using checklists to document the systematic inquiry and appropriately considering administrative controls and operating procedures.

5. The Contractor summarizes the instrumentation, communication systems, and operational aids that support the timely, reliable performance of human operations of safety significant SSCs, including the following:

a. A rationale or philosophy of alarm system design is formulated and described.

b. Warning systems are designed to provide sufficient time to respond appropriately to the problem.

c. The number of alarms is limited so that the operator's attention is not diverted from the more important alarms.

d. Clearing of alarm conditions requires a positive response from assigned personnel. 
e. Where computer displays are provided as human-machine interfaces, information that operators need for handling alarms is not distributed among several pages of the display; a special page should be provided to link the information needed to respond to multiple alarms.

f. The communications system allows operators to transmit and receive information accurately and conveniently with minimum distraction from their other tasks. For example, communications among the members of a crew may take place via radio or telephone, often in a noisy environment. Errors may occur from poor understanding among personnel. Therefore, reviewers should evaluate whether the submittal documents the capability of communications equipment for maintaining high quality transmission of dialog between crew wherever they are.

6. The Contractor summarizes the layout and design of controls and instrumentation and provides labeling that apply the principles of ergonomics and human engineering, including the following:

a. The layout and design of controls and instrumentation are consistent with the reliable performance of human activities of particular importance to the safety of waste retrieval and waste feed delivery.

b. The arrangement of controls on a panel promotes efficient use of task-related components and rapid location of any given component.

c. Components are grouped on the basis of specific criteria appropriate for the required $\operatorname{task}(\mathrm{s})$.

d. Component arrangement conventions are considered, particularly when mimic displays are not provided.

e. When several components related by flow direction (e.g., motor-operated valve, pump) are placed in sequence, the direction of the sequence of the controls (e.g., left-to-right) is consistent for each similar situation.

f. Mirror image arrangements of components are avoided.

g. The labeling of controls and instrumentation that apply the principles of ergonomics and human factors engineering is consistent with the reliable performance of human activities particularly important to the safety of waste retrieval and waste feed delivery. For example, if computer displays are provided as human-machine interfaces, function keys have the same functions on different display pages.

h. Controls are selected considering the uses of coding methods, including location, size, shape, and color.

i. Label designs are consistent.

j. Abbreviations and acronyms for control labels are avoided. 
k. Where a common control center is provided for waste retrieval and pumping from a series or sequence of tanks, controls are appropriately modified, relabeled, and reprogrammed to assist operator performance.

1. Workstations are designed to provide useful information (e.g., information on actual operating conditions with respect to limit values).

m. The arrangement of displays on a panel promotes maximum operator awareness of plant conditions. Displays promote easy association of related controls and displays or other related components. Displays are placed above, and relatively close to, the related control.

7. The Contractor summarizes the work environment factors that could degrade the reliability of operations personnel in performing tasks, including surveillance, maintenance, and operations that are particularly important to safety. The work environment factors to be considered include physical access, the need for protective clothing or breathing apparatus, noise levels, temperature, humidity, distractions, and other factors bearing on physical comfort, alertness, and fitness.

8. The Contractor summarizes staffing considerations, including minimum staffing levels, allocation of control functions, overtime restrictions, waste retrieval and waste feed delivery status turnover between shifts, procedures, and training, including the following:

a. The ability of personnel performing waste retrieval or waste feed delivery activities to accomplish their responsibilities in potential accident environments is considered as part of the systematic inquiry.

b. Where mitigating controls require human response actions, the availability of a human to respond and the likelihood that a human could respond within a specified time are evaluated.

c. In developing operator requirements, task conditions associated with high work load features, concurrent emergency conditions, and tasks that must be performed concurrently and to a high degree of accuracy in short time periods are adequately considered.

If the Contractor chooses to use existing TWRS FSAR information on human factors for waste retrieval and waste feed delivery activities, the Contractor should ensure that the information satisfies the relevant acceptance criteria listed above and should justify the applicability of the existing program to waste retrieval and waste feed delivery.

\subsection{EVALUATION FINDINGS}

The reviewer will prepare material for the SER, stating whether the Contractor has provided sufficient information describing the role of human factors in ensuring the performance of safety SSCs associated with waste retrieval and waste feed delivery. The report should include a summary statement of what was reviewed and why the reviewer finds the submittal acceptable. For example, the reviewer can document the review as follows: 
The human factors chapter has been reviewed against the acceptance criteria in Section 13.3 in this Guide and has been found to be acceptable. The Contractor has demonstrated that human factors were considered in designing waste retrieval and waste feed delivery SSCs where humans are relied on for preventive actions during normal operations and for mitigative actions during abnormal and emergency operations. The Contractor has evaluated the human factor aspects necessary to ensure the performance of safety SSCs associated with waste retrieval and waste feed delivery and has adequately identified and described the human-machine interfaces. The Contractor has considered those aspects of the human-machine interfaces for safety SSCs necessary to enhance human performance in waste retrieval and waste feed delivery.

Any exceptions should be noted and stated in a way that provides the Contractor with a clear understanding of the revisions necessary for approval. The reviewer may recommend that the FSAR amendment be conditionally approved with provisions for the Contractor to submit additional information within a specified timeframe. 


\subsection{QUALITY ASSURANCE}

\subsection{PURPOSE OF REVIEW}

The purpose of this review is to determine whether the Contractor's TWRS FSAR amendment submittal adequately describes the essential features of the quality assurance program needed to support waste retrieval and waste feed delivery operations.

\subsection{AREAS OF REVIEW}

This chapter of the FSAR amendment describes the quality assurance program as applied to waste retrieval and waste feed delivery. As identified in DOE Order 5480.23' and DOE-STD$3009-94,{ }^{2}$ the quality assurance program for waste retrieval and waste feed delivery includes the following review areas: ${ }^{3}$

1. Codes and Standards - The design codes, standards, regulations, and DOE Orders required to establish the safety basis for waste retrieval and waste feed delivery should be identified. (Only quality assurance requirements that are pertinent to the safety analysis for waste retrieval and waste feed delivery should be listed.)

2. Quality Assurance Program and Organization - The quality assurance program plan should be updated to include waste retrieval and waste feed delivery. This update should include the areas of quality improvement, documents and records, and quality assurance performance (e.g., work processes, design, procurement, inspection and testing for acceptance, and independent assessment).

3. Quality Improvement - No changes to the existing TWRS FSAR are expected.

4. Documents and Records - No changes to the existing TWRS FSAR are expected.

5. Quality Assurance Performance - No changes to the existing TWRS FSAR are expected.

The waste retrieval and waste feed delivery activities are expected to use much of the existing quality assurance program (e.g., items $2-5$ above). If this is the case, the Contractor should provide the rationale for using the existing program and discuss any changes to them.

Existing supporting documentation should be referenced. Brief references of documentation should be included with enough salient facts to provide an understanding of the referenced documentation and its relation to this chapter. On request, complete references can be provided to the regulatory entity.

\footnotetext{
'Nuclear Safety Analysis Reports, DOE Order 5480.23, Change 1, March 1994.

${ }^{2}$ Preparation Guide for U.S. Department of Energy Nonreactor Nuclear Facility Safety Analysis Reports, Chapter 14, "Quality Assurance," DOE-STD-3009-94, July 1994.

${ }^{3}$ Only areas expected to change as a result of waste retrieval and waste feed preparation need to be addressed.
} 


\subsection{ACCEPTANCE CRITERIA}

\subsubsection{Acceptability Review}

A one-week acceptability review will be performed to determine whether the submittal on quality assurance contains sufficient information to review it against the acceptance criteria in Section 14.3 .3 below. Where applicable, the Contractor may demonstrate that the information in the TWRS FSAR pertaining to quality assurance is adequate and encompasses waste retrieval and waste feed delivery.

The information in this section is used to demonstrate that the Contractor has a quality assurance program in place for waste retrieval and waste feed delivery that provides clear evidence of a programmatic commitment to the safety basis. If significant deficiencies are identified in the submittal, the Contractor will be requested to submit additional information before further review of the FSAR amendment.

\subsubsection{Regulatory Requirements}

The review will confirm that the FSAR satisfies the requirements of DOE Order 5480.23, paragraph 8.b.(3)(r), as amplified in Attachment 1, paragraph 4.f.(3)(d)18, of the Order (Topic 18). The amendment should also include information, if applicable, that will partially satisfy the requirements of DOE Order 5480.23, paragraphs 8.b.(3)(b), (f), and (u), as they relate to quality assurance.

To facilitate the review, the submittal's format should follow DOE-STD-3009-94, Preparation Guide for U.S. Department of Energy Nonreactor Nuclear Facility Safety Analysis Reports.

Specific regulations and DOE Orders that apply to quality assurance for waste retrieval and waste feed delivery include 10 CFR 830.120, "Quality Assurance Requirements," April 5, 1994.

\subsubsection{Regulatory Acceptance Criteria}

The quality assurance submittal is acceptable if it clearly demonstrates the Contractor's commitment to maintaining the safety basis and if the following criteria are met: ${ }^{4}$

1. The Contractor provides the design criteria, standards, regulations, and DOE Orders that are required to establish the safety basis for waste retrieval and waste feed delivery as they relate to quality assurance.

2. The Contractor updates the quality assurance program plan to include waste retrieval and waste feed delivery, including the areas of quality improvement, documents and records, and quality assurance performance (e.g., work processes, design, procurement, inspection and testing for acceptance, and independent assessment).

\footnotetext{
${ }^{4}$ Where applicable, the Contractor can demonstrate that the information on quality assurance, as provided in the approved TWRS FSAR, is complete and encompasses waste retrieval and waste feed delivery and, therefore, no changes are required.
} 
If the Contractor chooses to use existing TWRS FSAR information on quality assurance for waste retrieval and waste feed delivery activities, the Contractor should ensure that the information satisfies the relevant acceptance criteria listed above and should justify the applicability of the existing program to waste retrieval and waste feed delivery.

\subsection{EVALUATION FINDINGS}

The reviewer will prepare material for an SER, stating whether the Contractor has provided an adequate quality assurance summary. The report should include a summary of what was reviewed and why the reviewer finds the material acceptable. For example, the reviewer can document the review as follows:

The quality assurance chapter has been reviewed against the acceptance criteria in Section 14.3 in this Guide and has been found to be acceptable. The Contractor has demonstrated a commitment to a quality assurance program for waste retrieval and waste feed delivery that provides clear evidence of a programmatic commitment to the safety basis.

Any exceptions should be noted and stated in a way to provide the Contractor with a clear understanding of the revisions necessary for approval. The reviewer may recommend that the submittal be conditionally approved with provisions for the Contractor to submit additional information within a specified timeframe. 


\subsection{EMERGENCY PREPAREDNESS PROGRAM}

\subsection{PURPOSE OF REVIEW}

The purpose of this review is to determine whether the Contractor's TWRS FSAR amendment submittal adequately describes the changes in the emergency preparedness program (EPP) resulting from hazards associated with waste retrieval and waste feed delivery operations.

\subsection{AREAS OF REVIEW}

This chapter of the FSAR describes the emergency preparedness program for waste retrieval and waste feed delivery. The FSAR amendment is not expected to result in any substantive revisions to this chapter of the TWRS FSAR. As such, existing FSAR information on the scope of emergency preparedness and emergency preparedness planning (including the emergency response organization, assessment actions, notification, emergency facilities and equipment, protective actions, training and exercises, and recovery and reentry) may be adequate to address emergency preparedness concerns of waste retrieval and waste feed delivery operations. If the established EPP is used for waste retrieval and waste feed delivery, the Contractor should justify its use. However, a revision to the Hanford site emergency response plan, Hanford Emergency Response Plan, ' was released October 1, 1999. This revision is expected to result in editorial revisions to this chapter.

As identified in DOE Order $5480.23^{2}$ and DOE-STD-3009-94, ${ }^{3}$ the emergency preparedness program for waste retrieval and waste feed delivery should include the following review areas: ${ }^{4}$

1. Codes and Standards - The design codes, standards, regulations, and DOE Orders required to establish the safety basis of the waste retrieval and waste feed delivery activities should be identified. (Only requirements for emergency preparedness that are pertinent to the safety analysis for waste retrieval and waste feed delivery should be listed.)

2. EPP Changes - Changes to the EPP resulting from revision of the Hanford Emergency Response Plan should be adequately incorporated.

Existing supporting documentation should be referenced. Brief references of documentation should be included with enough salient facts to provide an understanding of the referenced documentation and its relation to this chapter. On request, complete references can be provided to the regulatory entity.

\footnotetext{
' DOE/RL-94-02, Rev. 2, October 1999.

${ }^{2}$ Nuclear Safety Analysis Reports, DOE Order 5480.23, Change 1, March 1994.

${ }^{3}$ Preparation Guide for U.S. Department of Energy Nonreactor Nuclear Facility Safety Analysis Reports, Chapter 15, "Emergency Preparedness Program," DOE-STD-3009-94, July 1994.

${ }^{4}$ Only areas expected to change as a result of waste retrieval and waste feed delivery need to be addressed.
} 


\subsection{ACCEPTANCE CRITERIA}

\subsubsection{Acceptability Review}

A one-week acceptability review will be performed to determine whether the submittal on emergency preparedness contains sufficient information to evaluate it against the regulatory acceptance criteria in Section 1.3.3 below. If significant deficiencies are identified in the submittal, the Contractor will be requested to submit additional information before the start of the detailed review of the FSAR amendment.

\subsubsection{Regulatory Requirements}

The review will confirm that the FSAR amendment satisfies the requirements of DOE Order 5480.23, paragraph 8.b.(3)(s), as amplified in Attachment 1, paragraph 4.f.(3)(d)19, of the Order (Topic 19). The amendment should also include or reference information, if applicable, that will partially satisfy the requirements of DOE Order 5480.23, paragraphs 8.b.(3)(b), (f), and (u), as they relate to the emergency preparedness program.

To facilitate the review, the submittal's format should follow DOE-STD-3009-94, Preparation Guide for U.S. Department of Energy Nonreactor Nuclear Facility Safety Analysis Reports.

Specific regulations and DOE Orders that apply to the emergency preparedness program include the following:

- 10 CFR 835, “Occupational Radiation Protection,” Final Rule, November 6, 1998.

- 29 CFR 1910, "Occupational Safety and Health Standards," 1998 edition.

- 40 CFR 265, "Interim Status Standards for Owners and Operators of Hazardous Waste Treatment, Storage, and Disposal Facilities," 1998 edition.

- 40 CFR 302, "Designation Reportable Quantities, and Notification," 1998 edition.

- 40 CFR 355, "Emergency Planning and Notification; EPA/Superfund, Emergency Planning, and Community Right-To-Know Programs," 1998 edition.

- DOE O 232.1, Occurrence Reporting and Processing of Operations Information, Change 1, 1995.

- DOE O 440.1A, Worker Protection Management for DOE and Federal Contractor Employees, 1998.

- DOE Order 5500.1B, Emergency Management System, Change 1, 1992.

- DOE Order 5500.2B, Emergency Categories, Classes, and Notification and Reporting Requirements, Change 1, 1992. 
- WAC 173-303, "Dangerous Waste Regulations," 1995.

- WAC 296-62, “Occupational Health Standards - Safety Standards for Carcinogens,” 1995.

\subsubsection{Regulatory Acceptance Criteria}

The FSAR amendment for the emergency preparedness program is acceptable if the following criteria are met:

1. The Contractor identifies the design codes, standards, regulations, and DOE Orders required to establish the safety basis of the waste retrieval and waste feed delivery activities as they relate to the emergency preparedness program.

2. The Contractor incorporates the changes resulting from revision to the Hanford Emergency Response Plan. As noted in Section 15.2 in this Guide, the existing emergency preparedness information in the TWRS FSAR may not have to be revised to address waste retrieval and waste feed delivery operations. The FSAR amendment need only reference the existing FSAR information and summarize its adequacy for the scope of waste retrieval and waste feed delivery operations.

If the Contractor chooses to use existing TWRS FSAR information on emergency preparedness for waste retrieval and waste feed delivery activities, the Contractor should ensure that the information satisfies the relevant acceptance criteria listed above and should justify the applicability of the existing program to waste retrieval and waste feed delivery.

\subsection{EVALUATION FINDINGS}

The reviewer will prepare material for an SER, stating whether the Contractor has provided a revised emergency preparedness program description that reflects the revisions to the Hanford Emergency Response Plan and adequately justifies applying the established EPP to waste retrieval and waste feed delivery. The report should include a summary of what was reviewed and why the reviewer finds the material acceptable. For example, the reviewer can document the review as follows:

The emergency preparedness program chapter has been reviewed against the revised Hanford Emergency Response Plan and has been found to be acceptable. The Contractor has adequately revised the emergency preparedness program associated with the revision to the Hanford Emergency Response Plan or has justified the adequacy of existing TWRS FSAR information; and the information will support safe waste retrieval and waste feed delivery operations.

Any exceptions should be noted and stated in a way to provide the Contractor with a clear understanding of the revisions necessary for approval. The reviewer may recommend that the submittal be conditionally approved with provisions for the Contractor to submit additional information within a specified timeframe. 


\subsection{PROVISIONS FOR DECONTAMINATION AND DECOMMISSIONING}

\subsection{PURPOSE OF REVIEW}

The purpose of this review is to determine whether the Contractor's TWRS FSAR amendment submittal adequately describes the provisions that facilitate future decontamination and decommissioning (D\&D) of the waste retrieval and waste feed delivery SSCs. The review also covers the conceptual D\&D plan as applied to waste retrieval and waste feed delivery.

\subsection{AREAS OF REVIEW}

This chapter of the FSAR describes provisions that facilitate future D\&D of the waste retrieval and waste feed delivery SSCs and the conceptual D\&D plan. As identified in DOE Order $5480.23^{1}$ and DOE-STD-3009-94, ${ }^{2}$ the provisions for D\&D for waste retrieval and waste feed delivery should include the following review areas: ${ }^{3}$

1. Codes and Standards - The design codes, standards, regulations, and DOE Order used in developing the $D \& D$ program for waste retrieval and waste feed delivery should be identified. (Only D\&D requirements that are pertinent to the safety analysis for waste retrieval and waste feed delivery should be listed.)

2. Design Features - Design features incorporated into waste retrieval and waste feed delivery SSCs to facilitate future D\&D should be described.

3. Operational Considerations - Operational considerations for waste retrieval and waste feed delivery to facilitate future $D \& D$ should be described.

4. Conceptual D\&D Plan - The conceptual D\&D plan for waste retrieval and waste feed delivery activities should be described.

Existing supporting documentation should be referenced. Brief references of documentation should be included with enough salient facts to provide an understanding of the referenced documentation and its relation to this chapter. On request, complete references can be provided to the regulatory entity.

\footnotetext{
${ }^{1}$ Nuclear Safety Analysis Reports, DOE Order 5480.23, Change 1, March 1994.

${ }^{2}$ Preparation Guide for U.S. Department of Energy Nonreactor Nuclear Facility Safety Analysis Reports, Chapter 16, "Provisions for Decontamination and Decommissioning," DOE-STD-3009-94, July 1994.

${ }^{3}$ Only areas expected to change as a result of waste retrieval and waste feed delivery need to be addressed.
} 


\subsection{ACCEPTANCE CRITERIA}

\subsubsection{Acceptability Review}

A one-week acceptability review will be performed to determine whether the submittal on provisions for D\&D and the conceptual D\&D plan contains sufficient information to evaluate it against the regulatory acceptance criteria in Section 16.3 .3 below. Where applicable, the Contractor may demonstrate that information in the TWRS FSAR and the conceptual D\&D plan encompasses the D\&D considerations for waste retrieval and waste feed delivery. If significant deficiencies are identified in the submittal, the Contractor will be requested to submit additional information before the start of the detailed review of the FSAR amendment.

\subsubsection{Regulatory Requirements}

The review will confirm that the FSAR satisfies the requirements of DOE Order 5480.23 , paragraph 8.b.(3)(t), as amplified in Attachment 1, paragraph 4.f.(3)(d)20, of the Order (Topic 20). The submittal should also include information, if applicable, that will partially satisfy the requirements of DOE Order 5480.23, paragraphs 8.b.(3)(b), (f), and (u), as they relate to provisions for D\&D.

To facilitate the review, the submittal's format should follow DOE-STD-3009-94, Preparation Guide for U.S. Department of Energy Nonreactor Nuclear Facility Safety Analysis Reports.

Specific regulations and DOE Orders that apply to D\&D include the following:

- DOE Order 5400.5, Radiation Protection of the Public and the Environment, Change 2, 1993.

- "Regulations for Implementing Procedural Provisions of the National Environmental Policy Act," Permit WA7890009067, Rev. 2, Ecology, 1995.

- WAC 173-303, "Dangerous Waste Regulations," Washington Administrative Code, 1995.

\subsubsection{Regulatory Acceptance Criterìa}

The description of provisions for D\&D is acceptable if the following criteria are met: ${ }^{4}$

1. The Contractor identifies the design codes, standards, regulations, and DOE Orders used in developing the D\&D program for waste retrieval and waste feed delivery.

2. The Contractor describes the design features incorporated into the waste retrieval and waste feed delivery SSCs that facilitate future D\&D. The description includes both engineering design features (e.g., materials of construction used in equipment and ability to flush equipment) and administrative features used to minimize the spread of contamination and the

\footnotetext{
${ }^{4}$ Where applicable, the Contractor may demonstrate that information on provisions for $D \& D$, as provided in the approved TWRS FSAR, is complete and encompasses waste retrieval and waste feed delivery and, therefore, no changes are required.
} 
generation of waste. Features described include those that reduce radiation exposure to the workers and the public during and following D\&D activities. The description clearly conveys the Contractor's approach to planning to ensure that design or modification activities minimize the potential for spreading contamination.

3. The Contractor describes operational considerations proposed to facilitate future D\&D of waste retrieval and waste feed delivery SSCs. The description clearly conveys the Contractor's approach to planning to ensure that operational activities minimize the potential for spreading contamination.

4. The Contractor describes changes to the conceptual D\&D plan in the TWRS FSAR to include waste retrieval and waste feed delivery SSCs.

If the Contractor chooses to use existing TWRS FSAR information pertaining to the provisions for $D \& D$ for waste retrieval and waste feed delivery activities, the Contractor should ensure that the information satisfies the relevant acceptance criteria listed above and should justify the applicability of the existing program to waste retrieval and waste feed delivery.

\subsection{EVALUATION FINDINGS}

The reviewer will prepare material for an SER, stating whether the Contractor has adequately described the provisions for D\&D of waste retrieval and waste feed delivery SSCs. The report should include a summary of what was reviewed and why the reviewer finds the material acceptable. For example, the reviewer can document the review as follows:

The chapter on provisions for D\&D has been reviewed against the acceptance criteria in Section 16.3 in this Guide and has been found to be acceptable. The Contractor has described the design features incorporated to facilitate future D\&D of the waste retrieval and waste feed delivery SSCs, has described the proposed operational considerations that will facilitate future D\&D, and has demonstrated how waste retrieval and waste feed delivery are included in the conceptual D\&D plan.

Any exceptions should be noted and stated in a way to provide the Contractor with a clear understanding of the revisions necessary for approval. The reviewer may recommend that the submittal be conditionally approved with provisions for the Contractor to submit additional information within a specified timeframe. 


\subsection{MANAGEMENT, ORGANIZATION, AND INSTITUTIONAL SAFETY PROVISIONS}

\subsection{PURPOSE OF REVIEW}

The purpose of this review is to determine whether the Contractor's TWRS FSAR amendment submittal adequately describes the management, organization, and institutional safety provisions needed to support waste retrieval and waste feed delivery.

\subsection{AREAS OF REVIEW}

This chapter of the FSAR describes the management, organization, and institutional safety provisions needed to support safe waste retrieval and waste feed delivery operations. The chapter also describes the requirements used to develop the safety management programs and presents sufficient information on the safety management policies and programs to demonstrate that waste retrieval and waste feed delivery operations are embedded in a safety-conscious environment. The chapter should also describe the responsibilities of and relationships between the line operating organization and the nonoperating organizations having a safety function.

As identified in DOE Order 5480.23 ${ }^{1}$ and DOE-STD-3009-94, ${ }^{2}$ the management, organization, and institutional safety provisions for waste retrieval and waste feed delivery should include the following review areas: $:^{3}$

1. Codes and Standards - The design codes, standards, regulations, and DOE Orders required to establish the safety basis of the waste retrieval and waste feed delivery activities should be identified. (Only requirements that are related to management, organization, and institutional safety provisions and that are pertinent to the safety analysis for waste retrieval and waste feed delivery should be listed.)

2. Organizational Considerations - The organizational structure, responsibilities, and interfaces for waste retrieval and waste feed delivery activities should be discussed. In particular, the manner in which the organization responsible for waste retrieval and waste feed delivery activities interfaces and interacts with the existing organization should be discussed. The discussion should identify and describe the position and the attendant qualifications for the position involved in the interface.

3. Safety Management - Safety management policies and programs should be discussed as they apply to 1) safety review and performance assessment, 2) configuration and document control, and 3 ) the occurrence reporting programs.

4. Safety Culture - No changes to the existing TWRS FSAR are expected.

\footnotetext{
${ }^{\prime}$ Nuclear Safety Analysis Reports, DOE Order 5480.23, Change 1, March 1994.

2 Preparation Guide for U.S. Department of Energy Nonreactor Nuclear Facility Safety Analysis Reports, Chapter 17, "Management, Organization, and Institutional Safety Provisions," DOE-STD-3009-94, July 1994.

${ }^{3}$ Only areas expected to change as a result of waste retrieval and waste feed delivery need to be addressed.
} 
Existing supporting documentation is to be referenced. Brief references of documentation should be included with enough salient facts to provide an understanding of the referenced documentation and its relation to this chapter. On request, complete references can be provided to the regulatory entity.

\subsection{ACCEPTANCE CRITERIA}

\subsubsection{Acceptability Review}

A one-week acceptability review will be performed to determine whether the submittal on management, organization, and institutional safety provisions contains sufficient information to evaluate it against the regulatory acceptance criteria in Section 17.3.3 below. Where applicable, the Contractor may demonstrate that information in the TWRS FSAR pertaining to management, organization, and institutional safety provisions is complete and adequate to support waste retrieval and waste feed delivery operations.

The information in this section is used to ensure that the organization and the related support organizations responsible for safe waste retrieval and waste feed delivery operations are in place and have the necessary authority to perform their tasks. If significant deficiencies are identified in the submittal, the Contractor will be requested to submit additional information before the start of the detailed review of the FSAR amendment.

\subsubsection{Regulatory Requirements}

The review will confirm that the FSAR satisfies the requirements of DOE Order 5480.23, paragraph 8.b.(3)(1), as amplified in Attachment 1, paragraph 4.f.(3)(d)12, of the Order (Topic 12). The submittal should also include information, if applicable, that will partially satisfy the requirements of DOE Order 5480.23, paragraphs 8.b.(3)(b), (f), and (u), as they relate to management, organization, and institutional safety provisions.

To facilitate the review, the submittal's format should follow DOE-STD-3009-94, Preparation Guide for U.S. Department of Energy Nonreactor Nuclear Facility Safety Analysis Reports.

Specific regulations and DOE Orders that apply to management, organization, and institutional safety provisions include the following:

- 10 CFR 830, "Nuclear Safety Management," 1994.

- DOE O 210.1, Performance Indicator and Analysis of Operations Information, 1996.

- DOE O 231.1, Environmental, Safety, and Health Reporting, Change 2, 1996.

- DOE O 232.1A, Occurrence Reporting and Processing of Operations Information, Change $1,1997$.

- DOE Order 5480.19, Conduct of Operations Requirements for DOE Facilities, Change 1, 1990. 
- DOE Order 5480.20A, Personnel Selection, Qualification and Training Requirements for DOE Nuclear Facilities, Change 0, 1994.

- DOE Order 5480.21, Unreviewed Safety Questions, Change 0, 1991.

- DOE Order 5480.22, Technical Safety Requirements, Change 2, 1996.

\subsubsection{Regulatory Acceptance Criteria}

The Contractor's submittal on management, organization, and institutional safety is acceptable if the following criteria are met: ${ }^{4}$

1. The Contractor identifies the design codes, standards, regulations, and DOE Orders required to establish the safety basis of the waste retrieval and waste feed delivery activities as they relate to management, organization, and institutional safety provisions.

2. The Contractor describes the overall organizational structure for waste retrieval and waste feed delivery, including the interfaces of management of other RPP operating organizations as well as management outside the operating organization. In addition, the Contractor identifies and explains any changes to the organization described in Chapter 17 of the TWRS FSAR.

3. The Contractor summarizes the organization's responsibilities and authorities, its interfaces with organizations discussed either in this chapter or in other sections in this Guide, and the general safety programs and issues related to waste retrieval and waste feed delivery. This summary includes areas such as the following:
a. Technical and engineering support, maintenance, and modifications.
b. Safety issue discovery, communication, management, and resolution.
c. Independent safety review, audit, and compliance determination.
d. Safety analysis services, including USQ evaluation.
e. Support services such as utilities and other offsite support.

4. The Contractor provides the bases for staffing levels and describes the knowledge, skills, and abilities of personnel performing waste retrieval or waste feed delivery activities and in the organizations directly supporting these activities.

5. The Contractor describes the programs and procedures used to ensure independent oversight, safety reviews, USQ determination, and appraisal of the safety performance of organizations involved in safely conducting waste retrieval and waste feed delivery operations (including

\footnotetext{
${ }^{4}$ Where applicable, the Contractor may demonstrate that information on the management, organization, and institutional provisions, as provided in the approved TWRS FSAR, is essentially unchanged with respect to safe waste retrieval and waste feed delivery operations and, therefore, no changes are required.
} 
such organizations or activities as industrial safety, fire inspections, and hazardous material control), with particular attention to any changes to the pertinent information in the TWRS FSAR. The programs and provisions for monitoring the safety performance of waste retrieval and waste feed delivery operations are also described, with particular emphasis on changes to existing programs that have been described in the TWRS FSAR.

6. The Contractor describes the programs for controlling modifications associated with waste retrieval and waste feed delivery, as well as the programs for controlling all documentation serving a related safety function (e.g., as-built drawings, operating procedures, and training manuals), with particular emphasis on any changes in the established programs and the reason for the changes.

7. The Contractor describes the provisions for investigating abnormal events and reporting procedures to DOE, selecting and analyzing information for occurrence reports, evaluating operational experience and trends, developing feedback and corrective actions, and communicating lessons learned as they relate to waste retrieval and waste feed delivery operations, with particular emphasis on any changes in the established programs and the reason for the changes.

If the Contractor chooses to use existing TWRS FSAR information on management, organization, and institutional safety provisions for waste retrieval and waste feed delivery activities, the Contractor should ensure that the information satisfies the relevant acceptance criteria listed above and should justify the applicability of the existing program to waste retrieval and waste feed delivery. The Contractor should describe and justify any variance to the existing programs and procedures.

\subsection{EVALUATION FINDINGS}

The reviewer will prepare material for an SER, stating whether the Contractor has provided the information describing the management, organization, and institutional safety provisions needed for safe waste retrieval and waste feed delivery operations. The report should include a summary of what was reviewed and why the reviewer finds the material acceptable. For example, the reviewer can document the review as follows:

The chapter on management, organization, and institutional safety provisions for safe waste retrieval and waste feed delivery operations has been reviewed against the acceptance criteria in Section 17.3 in this Guide and has been found to be acceptable. The Contractor has adequately described the organizational structure, responsibilities, and interfaces of the organizations responsible for safe waste retrieval and waste feed delivery operations or has justified the adequacy of the existing information in the TWRS FSAR. The Contractor has also adequately described the safety management programs and policies for waste retrieval and waste feed delivery or has discussed any changes to established programs and the rationale for the changes. If these programs are carried out, reasonable assurance exists that waste retrieval and waste feed delivery activities can be safely managed.

Any exceptions should be noted and stated in a way to provide the Contractor with a clear 
understanding of the revisions necessary for approval. The reviewer may recommend that the submittal be conditionally approved with provisions for the Contractor to submit additional information within a specified timeframe. 


\section{DISTRIBUTION SHEET}

\begin{tabular}{|c|c|c|c|c|c|}
\hline \multirow{2}{*}{$\begin{array}{l}\text { To } \\
\text { R.T. French }\end{array}$} & \multirow{2}{*}{\multicolumn{3}{|c|}{$\begin{array}{l}\text { From } \\
\text { R.W. Griffith }\end{array}$}} & \multicolumn{2}{|c|}{ Page 1 of 1} \\
\hline & & & & \multicolumn{2}{|c|}{ Date $10 / 12 / 99$} \\
\hline \multirow{2}{*}{\multicolumn{4}{|c|}{$\begin{array}{l}\text { Project Title/Work Order } \\
\text { office of River Protection }\end{array}$}} & \multirow{2}{*}{\multicolumn{2}{|c|}{$\begin{array}{ll}\text { EDT No. } N / A \\
\text { ECN No. N/A }\end{array}$}} \\
\hline & & & & & \\
\hline Name & $\begin{array}{c}\text { MSI } \\
N\end{array}$ & $\begin{array}{c}\text { Text } \\
\text { With } \\
\text { All } \\
\text { Attac } \\
\text { h. }\end{array}$ & $\begin{array}{l}\text { Text } \\
\text { Only }\end{array}$ & $\begin{array}{c}\text { Attach. } \\
\text { / } \\
\text { Append } \\
\text { ix } \\
\text { Only }\end{array}$ & $\begin{array}{c}\text { EDT/E } \\
\text { CN } \\
\text { Only }\end{array}$ \\
\hline CENTRAL FILES & B1-07 & $x$ & & & \\
\hline DPC & H6-08 & $x$ & & & \\
\hline DOE READING ROOM & H2-53 & $x$ & & & \\
\hline HANFORD TECH. LIB. & $P 8-55$ & $x$ & & & \\
\hline
\end{tabular}


TECHNICAL SUPPORT DIVISION [TSD]

DISTRIBUTION SHEET

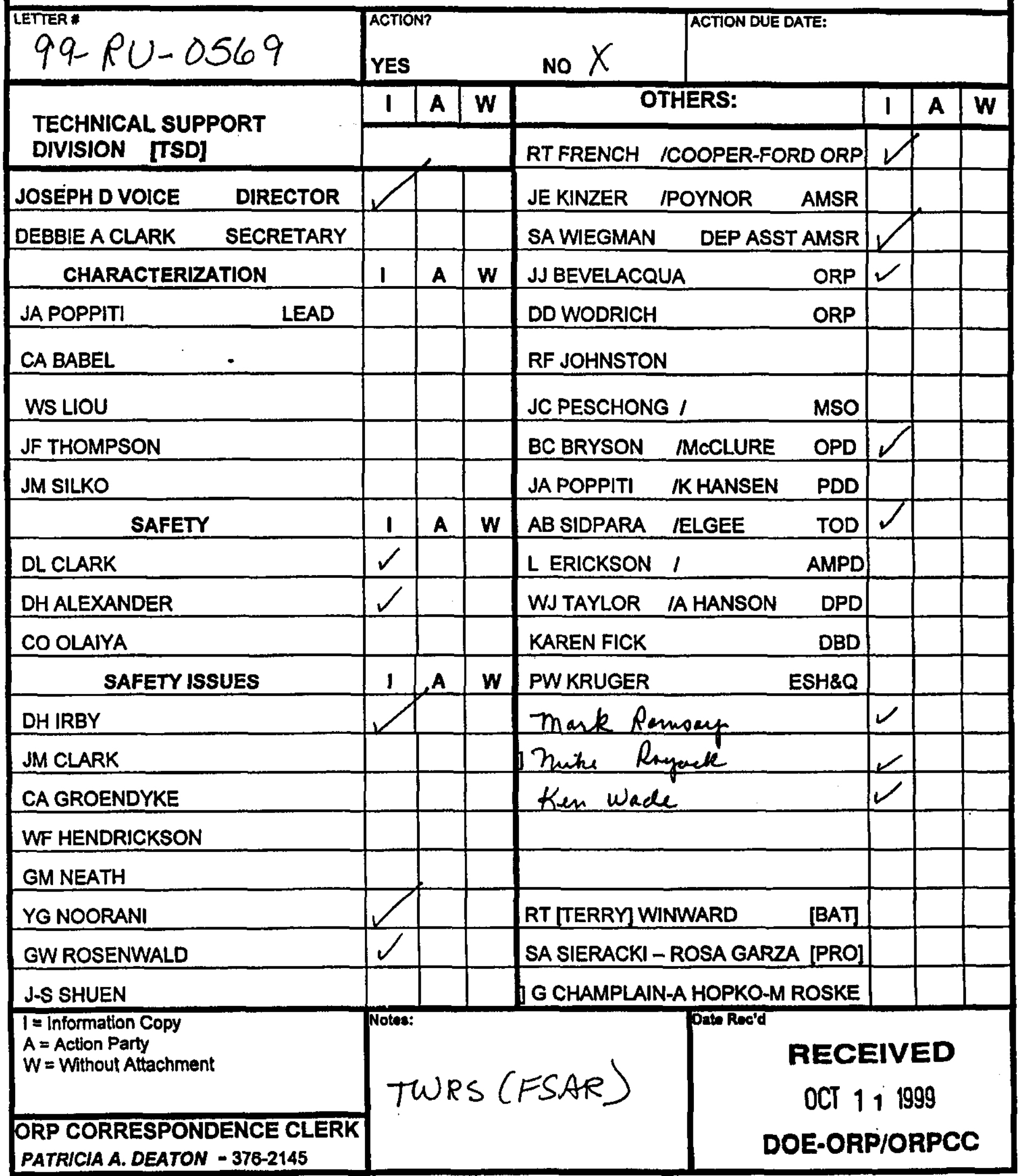

